\title{
CALAGEM E GESSAGEM NA ESPECIAÇÃO IÔNICA DA SOLUÇÃO DE UM LATOSSOLO SOB SISTEMA DE PLANTIO DIRETO
}

\section{FERNANDO CÉSAR BACHIEGA ZAMBROSI}

Engenheiro Agrônomo

\begin{abstract}
Dissertação apresentada à Escola Superior de Agricultura "Luiz de Queiroz", Universidade de São Paulo, para obtenção do título de Mestre em Agronomia, Área de Concentração: Solos e Nutrição de Plantas.
\end{abstract}

P I R A C I C A B A

Estado de São Paulo - Brasil

Dezembro - 2004 


\title{
CALAGEM E GESSAGEM NA ESPECIAÇÃO IÔNICA DA SOLUÇÃO DE UM LATOSSOLO SOB SISTEMA DE PLANTIO DIRETO
}

\section{FERNANDO CÉSAR BACHIEGA ZAMBROSI}

Engenheiro Agrônomo

Orientador: Prof. Dr. LUÍS REYNALDO FERRACIÚ ALLEONI

\begin{abstract}
Dissertação apresentada à Escola Superior de Agricultura “Luiz de Queiroz”, Universidade de São Paulo, para obtenção do título de Mestre em Agronomia, Área de Concentração: Solos e Nutrição de Plantas.
\end{abstract}

P I R A C I C A B A

Estado de São Paulo - Brasil

Dezembro - 2004 
Dados I nt er naci onais de Cat al ogação na Publi cação ( CI P) DI VI SÃO DE BI BLI OTECA E DOCUMENTAÇÃO - ESALQI USP

Zambrosi, Fernando César Bachiega

Calagem e gessagem na especiação iônica da solução de um latossolo sob sistema de plantio direto / Fernando César Bachiega Zambrosi. - - Piracicaba, 2004.

$111 \mathrm{p}$.

Dissertação (Mestrado) - - Escola Superior de Agricultura Luiz de Queiroz, 2004. Bibliografia.

1. Adubação 2. Calagem 3. Especiação química 4. Fertilidade do solo 5. Gessagem 6. Latossolo 7. Plantio direto 8. Química do solo I. Título

CDD 631.821 
Aos meus irmãos Flávio, Fabricio e minhas avós Idalina e Léa,

pelo incentivo, carinho, apoio e por tudo que significam para mim.

OFEREÇO

Aos meus queridos pais Raimundo e Vera,

pelo exemplo, apoio, carinho, amor e esforço incansável

para que eu completasse mais esta etapa, pois sem vocês, nada teria conseguido. 


\section{AGRADECIMENTOS}

Ao Prof. Dr. Luís Reynaldo Ferraciú Alleoni pela orientação, amizade, paciência e apoio para a realização desse trabalho e pela oportunidade concedida desde a minha graduação;

Ao professor Dr. Eduardo Fávero Caires pelo apoio e disponibilização da área para a realização deste trabalho;

Aos professores Luis Ignácio Prochnow, Carlos Alexandre Costa Crusciol e Pablo Vidal-Torrado pelas importantes sugestões;

À Coordenação do Programa de pós-graduação em Solos e Nutrição de Plantas pela oportunidade concedida;

Aos funcionários do departamento de Solos e Nutrição de Plantas pela colaboração e amizade, em especial aos técnicos Luis Silva e Lurdes pelo auxílio nas determinações laboratoriais, e a secretária Nancy pela atenção;

Aos amigos do curso de pós-graduação pela convivência, aprendizado e amizade criada ao longo desses anos;

Aos amigos de análise em laboratório Tiago,Valdomiro, Miriam, Martha Gonzáles, Camila, Cindy, Heloísa, Gilmar, Marta, Roberta pela amizade, convívio e paciência, e aos graduandos Rafael e Cíntia pela amizade e boa vontade em ajudar; 
Aos companheiros e grandes amigos Marcio Roberto Soares e Eros Artur Bohac pela amizade, convivência, aprendizado e importantes sugestões que contribuíram para a realização desse trabalho;

Ao grande amigo e companheiro Michel Alexandro Cambri pela idéia inicial deste trabalho, amizade, e incentivos para a conclusão desta dissertação;

Aos amigos de república Rudão, Xiko e Veia pela valiosa amizade e agradável convivência;

À grandiosa ESALQ na figura de seus professores pela minha formação profissional; e à Casa do Estudante Universitário (CEU) pelo acolhimento durante o meu período de graduação;

Ao grupo de oração universitário (GOU “Frutos”) na figura de todas as pessoas que por lá passaram pelos bons momentos compartilhados;

Ao Centro Nacional de Pesquisa e Desenvolvimento (CNPq) pela concessão de bolsa de estudos;

Enfim, a todos que de maneira indireta ou direta contribuíram para o cumprimento de mais essa etapa, meu muito obrigado. 


\section{SUMÁRIO}

Página

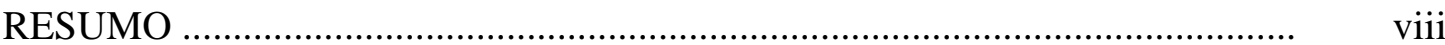

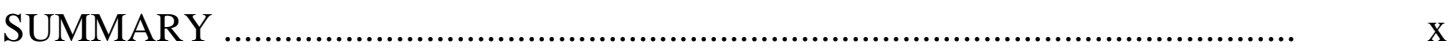

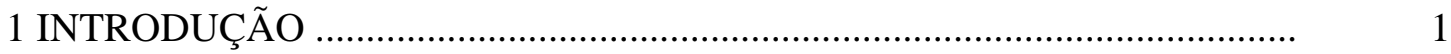

2 REVISÃO DE LITERATURA …...............................................................

2.1 Sistema de plantio direto........................................................................... 3

2.2 Correção da acidez do solo no sistema de plantio direto...................................

2.3 Solução do solo ........................................................................................

2.4 Especiação iônica e atividade química dos íons em solução............................ 11

2.5 Dinâmica do alumínio ligado à fase sólida do solo.......................................... 12

3 MATERIAL E MÉTODOS ...................................................................... 15

3.1 Área Experimental................................................................................ 15

3.2 Análise química do solo ................................................................................. 17

3.3 Fracionamento do alumínio no solo.............................................................. 18

3.4 Extração e análise da solução do solo............................................................. 18

3.5 Especiação iônica da solução do solo........................................................... 20

3.6 Análise dos resultados .................................................................................. $\quad 20$

4 RESULTADOS E DISCUSSÃO ..................................................................... 21

4.1 Solução do solo sob sistema de plantio direto ................................................ 21

4.1.1 pH da solução do solo ................................................................................ 21

4.1.2 Carbono orgânico dissolvido................................................................... 23

4.1.3 Força iônica da solução do solo .............................................................. 25 
4.1.4 Cátions na solução do solo .................................................................. 26

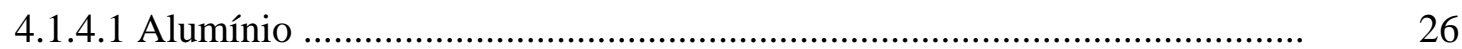

4.1.4.2 Cálcio, magnésio e potássio ................................................................. $\quad 30$

4.1.4.3 Micronutrientes catiônicos ...................................................................... 42

4.1.5 Ânions na solução do solo ....................................................................

4.2 Especiação iônica da solução do solo.......................................................... 49

4.2.1 Distribuição das espécies de alumínio ......................................................... 49

4.2.2 Distribuição das espécies de cálcio .......................................................... 56

4.2.3 Distribuição das espécies de magnésio ....................................................... 57

4.2.4 Distribuição das espécies de potássio ......................................................... 64

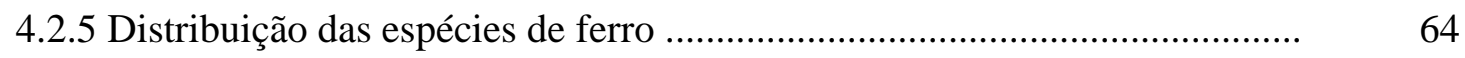

4.2.6 Distribuição das espécies de manganês ........................................................ 71

4.2.7. Distribuição das espécies de fósforo ………............................................... 75

4.2.8. Distribuição das espécies de S-sulfato ........................................................ $\quad 79$

4.2.9 Distribuição das espécies de N-nitrato ......................................................... $\quad 79$

4.2.10 Distribuição das espécies de cloreto ....................................................... $\quad 79$

4.3 Fracionamento do alumínio na fase sólida do solo e efeito dos tratamentos .. $\quad 89$

5 CONCLUSÕES _................................................................................... 9

REFERÊNCIAS BIBLIOGRÁFICAS …....................................................... 99 


\title{
CALAGEM E GESSAGEM NA ESPECIAÇÃO IÔNICA DA SOLUÇÃO DE UM LATOSSOLO SOB SISTEMA DE PLANTIO DIRETO
}

\author{
Autor: FERNANDO CÉSAR BACHIEGA ZAMBROSI \\ Orientador: Prof. Dr. LUÍS REYNALDO FERRACCIÚ ALLEONI
}

\section{RESUMO}

O Sistema de Plantio Direto (SPD) apresenta destacado papel na produção agrícola brasileira, ocupando extensas áreas, sob as mais variadas condições de solo, clima e técnicas de manejo do sistema produtivo. Em relação ao sistema convencional de cultivo, ocasiona profundas alterações físicas, biológicas e químicas no solo. O estudo da solução do solo e de sua variação perante as práticas de cultivo são de suma importância para o manejo da fertilidade do solo e da nutrição de plantas. Estudouse o efeito de formas de aplicação de calcário $\left(4,5 \mathrm{t} \mathrm{ha}^{-1}\right.$ - incorporado ou aplicado em superfície, numa só aplicação ou parcelado em três anos) e de doses de gesso (3; 6 e 9 t $\mathrm{ha}^{-1}$ ) na fase de implantação do SPD em área de pastagem nativa, na composição e na especiação iônica da solução do solo (extrato aquoso 1:1), até a profundidade de 0,8 m. Utilizaram-se amostras de um experimento de campo instalado em 1998 sobre um Latossolo Vermelho distrófico textura argilosa, em Ponta Grossa/PR. As amostras foram coletadas nas profundidades de $0-0,05 ; 0,05-0,1 ; 0,1-0,2 ; 0,2-0,4 ; 0,4-0,6$ e $0,6-0,8 \mathrm{~m}$ no mês de maio de 2003, após a colheita da cultura da soja. A calagem, tanto superficial como incorporada, promoveu aumento do $\mathrm{pH}$ da solução do solo até $0,2 \mathrm{~m}$, mas não 
afetou os teores de carbono orgânico dissolvido (COD) e os valores de força iônica. A calagem, exceto na camada de 0-0,05 m com a forma incorporada de aplicação, incrementou os teores de $\mathrm{Ca}$ e $\mathrm{Mg}$ até 0,2 e 0,6 m, respectivamente, mas somente o $\mathrm{Mg}$ teve acréscimo de sua atividade. O gesso promoveu incremento da concentração de $\mathrm{SO}_{4}{ }^{-2}$, assim como da concentração e atividade do Ca em solução, ao longo de todas as profundidades amostradas. Houve efeito negativo do gesso em relação ao $\mathrm{Mg}$, promovendo tanto lixiviação, como redução da atividade deste nutriente. Os teores dos demais ânions analisados $\left(\mathrm{Cl}^{-}, \mathrm{F}^{-}, \mathrm{NO}_{3}^{-}, \mathrm{PO}_{4}^{-3}\right)$ e de $\mathrm{Al}$ em solução não foram afetados pelos tratamentos. Os ânions orgânicos e o $\mathrm{F}^{-}$foram os principais agentes complexantes do $\mathrm{Al}$ em solução, sendo que a forma livre $\mathrm{Al}^{+3}$ foi de baixa ocorrência e baixa atividade, sem sofrer efeito dos tratamentos. $\mathrm{Na}$ fase sólida do solo, o Al esteve predominantemente complexado pela MO. Para $\mathrm{Ca}$ e $\mathrm{Mg}$, os principais ligantes em solução foram os ânions orgânicos, no entanto, em muito maior proporção para o Ca. Para o $\mathrm{P}\left(\mathrm{PO}_{4}^{-3}, \mathrm{HPO}_{4}^{-2}, \mathrm{H}_{2} \mathrm{PO}_{4}{ }^{-}\right)$, o principal par iônico foi com o $\mathrm{Al}$, enquanto para o $\mathrm{SO}_{4}{ }^{-2}$, foi com $\mathrm{Ca}$ e $\mathrm{Mg}$ principalmente. $\mathrm{O} \mathrm{Fe}$, por sua vez, teve sua especiação dividida entre as formas hidroxiladas e ligada ao $\mathrm{COD}$. Os elementos $\mathrm{Mn}, \mathrm{K}, \mathrm{N}^{-\mathrm{NO}_{3}}{ }^{-}$e $\mathrm{Cl}$ não formaram pares iônicos com outros elementos em proporções significativas na solução do solo, ao longo de todas as profundidades. 


\title{
LIME AND GYPSUM AS AFFECTING THE SOIL SOLUTION IONIC SPECIATION OF AN OXISOL UNDER NO-TILLAGE
}

\author{
Author: FERNANDO CÉSAR BACHIEGA ZAMBROSI \\ Adviser: Prof. Dr. LUÍS REYNALDO FERRACCIÚ ALLEONI
}

\section{SUMMARY}

No-tillage systems (NTS) play a very important role in Brazilian agriculture. NTS are widespread through extensive areas with different climates, soil types and under different management production systems. NTS deeply alter the biological, physical and chemical properties of the soils, as compared to conventional tillage. Soil solution studies, evaluating nutrient concentration changes under management practices, are very important in soil fertility, plant nutrition and management. The effect of liming and three methods of application (one application of $4.5 \mathrm{t} \mathrm{ha}^{-1}$ incorporated, one application of $4.5 \mathrm{t} \mathrm{ha}^{-1}$ surface applied, and, $1.5 \mathrm{t} \mathrm{ha}^{-1}$ applied in each of three years) on the composition and ionic speciation of soil solution, during the implantation of NTS in a native pasture area until $0.8 \mathrm{~m}$ depth was studied. The effect of gypsum rate $\left(3 ; 6\right.$ and $\left.9 \mathrm{t} \mathrm{ha}^{-1}\right)$ was also studied under the same conditions. Soil samples were extracted from a field experiment installed in1998 in Ponta Grossa/PR. The selected soil was classified as a dystrophic clayey Rhodic Hapludox. After the harvesting of soybeans in May of 2003, the samples were collected at the following depths: $0-0.05 ; 0.05-0.1 ; 0.1-0.2 ; 0.2-0.4 ; 0.4-0.6$ and $0.6-0.8 \mathrm{~m}$. Liming 
increased the $\mathrm{pH}$ of soil solution, but did not affect dissolved organic carbon (DOC) contents and ionic strength values. It was observed that $\mathrm{pH}$ was increased up to a depth of $0.2 \mathrm{~m}$. Liming increased calcium and magnesium concentrations up to $0.2 \mathrm{~m}$ and 0.6 $\mathrm{m}$ depth, respectively, except for first layer with incorporate lime. However, only $\mathrm{Mg}$ showed an increase in activity. Gypsum application increased the $\mathrm{SO}_{4}{ }^{-2}$ e and $\mathrm{Ca}$ concentration, and $\mathrm{Ca}$ activity through the studied profile. A negative effect of gypsum was the leaching of $\mathrm{Mg}$ and a reduction in its activity. The concentration of anions $\left(\mathrm{Cl}^{-}\right.$, $\mathrm{F}^{-}, \mathrm{NO}_{3}^{-}, \mathrm{PO}_{4}^{-3}$ ) and $\mathrm{Al}$ were neither affected by gypsum or by lime. The main $\mathrm{Al}$ complexing agents in solution were organic anions and $\mathrm{F}^{-}$. A low free $\mathrm{Al}^{+3}$ concentration and activity was detected, with no differences management treatments. The $\mathrm{Al}$ in the solid phase was mainly complexed by organic matter. The $\mathrm{Ca}$ and $\mathrm{Mg}$ were complexed by organic anions, and the effect was more pronounced for Ca. The $\mathrm{P}\left(\mathrm{PO}_{4}{ }^{-3}, \mathrm{HPO}_{4}{ }^{-3}\right.$, $\mathrm{H}_{2} \mathrm{PO}_{4}^{-3}$ ) was main complexed for $\mathrm{Al}$, while the $\mathrm{SO}_{4}{ }^{-2}$ was with $\mathrm{Ca}$ and $\mathrm{Mg}$ mainly. $\mathrm{Fe}$ was the form $\mathrm{Fe}-\mathrm{OH}$ and $\mathrm{Fe}-\mathrm{DOC}$. The elements $\mathrm{Mn}, \mathrm{K}, \mathrm{N}-\mathrm{NO}_{3}{ }^{-}$and $\mathrm{Cl}$ formed insignificant quantities ionic pairs in soil solution in whole layers. 


\section{INTRODUÇÃO}

Atualmente, o sistema de plantio direto (SPD) ocupa extensa área utilizada para a produção agrícola brasileira, estando sob as mais variadas condições edafoclimáticas, de espécies cultivadas, tipo e nível de manejo e até mesmo de condições sócio-econômicas. Pesquisas envolvendo esse sistema de cultivo se intensificaram nos últimos tempos, envolvendo entre outros aspectos, a correção/manejo da acidez do solo.

O SPD caracteriza-se por profundas alterações no sistema, gerando a necessidade de desenvolvimento de manejo mais adequado com a nova dinâmica encontrada. As pesquisas relacionadas ao manejo da acidez nesse sistema são, em sua maioria, estudos de alterações dos atributos químicos do solo em função de formas, doses do corretivo e respostas das culturas. O principal enfoque destes trabalhos tem sido as formas trocáveis (disponíveis) dos nutrientes no solo.

Os estudos envolvendo a solução do solo são de menor freqüência, talvez pelas dificuldades encontradas, desde a sua extração até a variação temporal das concentrações dos nutrientes dissolvidos. No entanto, é esta fase do solo a responsável direta pela nutrição das plantas e onde ocorre a maioria das reações químicas no solo. Desta maneira, o seu estudo é de fundamental importância para maiores esclarecimentos quanto ao melhor manejo da fertilidade do solo em SPD.

No SPD é muito comum a ausência ou a baixa resposta das culturas à aplicação de calcário e/ou gesso. Muitas explicações são dadas para tal ocorrência, como a menor atividade do Al na solução do solo, complexação do elemento com a MO, relação adequada de cátions básicos e elementos tóxicos, entre outras. Contudo, esses 
mecanismos não são ainda muito bem esclarecidos e um melhor entendimento pode ser obtido com estudo da solução.

Somente a determinação da concentração total de um elemento em solução não é a maneira mais adequada para predizer a disponibilidade ou toxicidade às plantas, pois não há distinção entre o potencial de absorção ou de provocar danos que as diferentes espécies apresentam. Desta maneira, para melhor compreensão do comportamento dos nutrientes, tem-se a especiação iônica como importante ferramenta. Os estudos que envolvem especiação da solução em condições de campo para solos cultivados com SPD, associados à aplicação conjunta de calcário e gesso são ainda escassos.

O objetivo deste trabalho foi de avaliar o efeito de formas de aplicação de calcário e doses gesso na etapa de introdução do SPD em área cultivada com pastagem nativa, na composição e na especiação iônica da solução de um Latossolo Vermelho distrófico textura argilosa até a profundidade de $0,8 \mathrm{~m}$, após cinco anos de cultivo em SPD.

As hipóteses testadas foram:

- Aplicação de calcário e gesso eleva a concentração e atividade de Ca e/ou Mg e reduzirá a atividade do $\mathrm{Al}$ na solução do solo;

- Na especiação iônica há grande participação dos ânions orgânicos na complexação de cátions na solução do solo, principalmente em relação ao $\mathrm{Al}$;

- A especiação iônica dos elementos se altera com a calagem e/ou gessagem. 


\section{REVISÃO DE LITERATURA}

\subsection{Sistema de plantio direto}

Um dos maiores avanços no processo produtivo da agricultura brasileira foi a introdução do sistema de plantio direto (SPD) no sul do Brasil, a partir da década de 70 (Lopes et al., 2004). No SPD a semeadura é feita diretamente sobre resíduos de uma cultura anterior, morta com a utilização de produtos químicos ou por meios mecânicos (Muzilli, 1985). O SPD caracteriza-se pelo não revolvimento do solo e pela conseqüente manutenção dos restos culturais sobre a superfície (Pottker, 2000).

O SPD pode ser dividido em duas fases: fase de implantação e fase estabilizada ou estabelecida do sistema. A fase de implantação compreende o período inicial, quando ainda não se descriminam as alterações nas propriedades químicas, físicas e biológicas do solo. Esse período compreende aos primeiros quatro a cinco anos, após o início do sistema, variando de acordo com o manejo, solo e clima (Salet, 1994). Após a fase de implantação, o SPD apresenta alterações nas propriedades químicas, físicas e biológicas em relação ao sistema convencional (Salet, 1994). O SPD altera várias propriedades do solo, quando comparado ao sistema convencional, devendo afetar profundamente a produção das culturas (Ismail et al., 1994).

O SPD é marcado por certas mudanças em relação ao sistema convencional de preparo, como rápida redução do $\mathrm{pH}$ das camadas superficiais, principalmente com intensa aplicação de fertilizantes nitrogenados, maior acúmulo de matéria orgânica (MO) no solo, redução do processo erosivo, manutenção da estrutura do solo e alteração na dinâmica de nutrientes, como maior acúmulo de fósforo nas camadas superficiais (Muzilli, 1983). 
Do ponto de vista físico, em geral, solos no SPD sofrem compactação devido ao tráfego de máquinas e implementos em sua superfície e uma consolidação natural, apresentando maior densidade na camada superior, principalmente em solos argilosos, além de proporcionar maior tamanho de agregados estáveis em água que o preparo convencional do solo, possivelmente devido à não destruição mecânica dos agregados pelos implementos de preparo do solo e à proteção conferida pela palha (Elts et al., 1989).

O conhecimento das alterações ocorridas no SPD em condições específicas de solo e clima é muito importante no entendimento da potencialidade do sistema de manejo em relação à produtividade das culturas e na adoção de práticas para contornar possíveis limitações advindas de sua utilização (Bayer \& Mielniczuk, 1997).

Devido ao grande número de benefícios encontrados, a adoção do SPD atende as condições de solo e clima de grande parte das áreas agrícolas brasileiras, devendo ter sua adoção valorizada e incentivada.

\subsection{Correção da acidez no sistema de plantio direto}

A acidez é generalizada em solos agrícolas brasileiros (Franchini et al., 2001), sendo em muitos casos um dos principais fatores limitantes à produção agrícola. A acidificação do solo é um processo natural, resultado da lixiviação de cátions básicos solúveis $(\mathrm{Ca}, \mathrm{Mg}, \mathrm{K})$, seguida pela sua substituição por cátions ácidos $(\mathrm{H}$ e $\mathrm{Al})$ no complexo de troca catiônica, processo acelerado pela adição de certos fertilizantes nitrogenados (Ziglio et., 1999).

A deficiência de $\mathrm{Ca}$ e a toxidez por $\mathrm{Al}$ são as principais limitações químicas para o crescimento radicular, cujas conseqüências se manifestam pelo estresse nutricional e hídrico nas plantas (Ritchey et al., 1980). O aprofundamento do sistema radicular confere às plantas maior resistência a períodos de baixa precipitação pluvial e possibilita maior absorção de nutrientes, pela exploração de maior volume de solo (Ernani, 1993). 
A calagem é a prática mais utilizada para o controle da acidez do solo devido ao seu efeito no aumento do $\mathrm{pH}$ e de cátions básicos, e na diminuição do $\mathrm{Al}$ trocável. No entanto, o calcário aplicado superficialmente apresenta mobilidade lenta, diminuindo sua eficiência na correção da acidez subsuperficial (Ziglio et al., 1999), sendo o efeito da calagem restrito ao local de aplicação (Gonzáles-Erico et al., 1979). Os valores de $\mathrm{pH}$ alteram-se pouco em profundidade, devido à baixa solubilidade dos corretivos agrícolas de acidez e à alta reatividade de seus ânions com os ácidos presentes na camada de solo em que o calcário é aplicado (Ernani et al., 2001).

A correção do subsolo ácido pode ser feita por meio da calagem profunda. Contudo, essa prática necessita de revolvimento do solo, razão porque não é de interesse em áreas já estabelecidas com sistema de cultivo que não envolve o preparo convencional. Além disso, a calagem profunda exige máquinas potentes e equipamentos caros, o que torna a prática onerosa. Outra alternativa seria por meio da aplicação superficial do gesso agrícola, que parece ser a mais viável por não exigir o revolvimento do solo (Caires et al., 1998). Essas técnicas apresentam como principal objetivo incrementar o cálcio na zona de crescimento das raízes e reduzir a saturação por alumínio. Isso não ocorre de maneira sensível com a utilização de calcário, pela falta de um ânion acompanhante estável para o $\mathrm{Ca}^{+2}$, já que o $\mathrm{CO}_{3}{ }^{-2}$ se decompõe em condições de acidez (Dal Bó et al., 1986). O gesso $\left(\mathrm{CaSO}_{4} \cdot 2 \mathrm{H}_{2} \mathrm{O}\right)$ parece ser adequado para esse fim, por questões de disponibilidade e porque sua movimentação não é excessivamente rápida (Ritchey et al., 1980). Assim, a utilização de gesso pode favorecer o aprofundamento do sistema radicular no solo, devido a diminuição da toxicidade do $\mathrm{Al}$ pela formação do par iônico $\mathrm{Al}\left(\mathrm{SO}_{4}\right)^{+}$(Pavan et al., 1987) e do enriquecimento com $\mathrm{Ca}$ na subsuperfície.

A eficiência da aplicação superficial de calcário no SPD, particularmente na correção da acidez do subsolo, é controvertida, com resultados demonstrando nenhum movimento além do seu local de aplicação até movimento com correção do subsolo (Caires et al., 2000). A viabilidade de correção da acidez no sistema de plantio direto sem a necessidade de revolvimento do solo para a incorporação do corretivo tem sido estudada e comprovada sob as mais diferentes condições de sistema de produção. 
Santos et al. (1995) verificaram que, após três anos de cultivo, em um Latossolo Vermelho-Escuro argiloso, não houve diferença de $\mathrm{pH}$ entre a aplicação de calcário superficialmente e incorporado a 0,2 m. Foram encontrados maiores teores de $\mathrm{Ca}+\mathrm{Mg}$ e menores de Al trocável nas camadas de 0-0,05 m e 0,05-0,1 m no SPD em relação ao SPC.

Caires et al. (2000) testaram quatro doses de calcário Latossolo Vermelho-Escuro distrófico textura média, observaram que ação da calagem nos aumentos de $\mathrm{pH}, \mathrm{Ca}+\mathrm{Mg}$ trocáveis e saturação por bases e na redução da acidez potencial $(\mathrm{H}+\mathrm{Al})$, ocorreu até os $0,1 \mathrm{~m}$ de profundidade, isto aos 12 meses após a calagem. A movimentação do corretivo pode chegar até profundidades maiores, de uma forma lenta e gradual como 0,4 m (Oliveira \& Pavan, 1996), em 32 meses após a aplicação, e 0,6-0,8 m ao 40 meses após a aplicação.

Um conjunto de mecanismos envolve a movimentação de corretivos da acidez aplicados superficialmente no solo em SPD. A movimentação física ocorre por meio de canais formados por raízes mortas e que são mantidos intactos em razão da ausência de preparo (Oliveira \& Pavan, 1994). A redução da acidez do subsolo pode ocorrer por meio da liberação de hidroxilas pelas plantas ao absorverem os nitratos que foram lixiviados com Ca e Mg (Caires et al., 1999) denominada de absorção alcalina (Raij et al., 1988), promovendo desta maneira a elevação do pH do solo.

Um aspecto muito importante a ser considerado é o papel dos resíduos orgânicos na movimentação de cátions ao longo do perfil do solo, principalmente no SPD onde se acumulam em maior quantidade. Em geral, ocorre a formação de complexos hidrossolúveis de $\mathrm{Ca}$, resultantes de um estádio avançado de decomposição do material orgânico (Franchini et al 1999; Miyazawa et al., 1996). Nessa complexação há alteração da carga do cátion, facilitando sua descida ao longo do perfil e, na camada subsuperficial, o $\mathrm{Ca}$ e o $\mathrm{Mg}$ dos complexos são deslocados pelo $\mathrm{Al}$ trocável, devido à maior estabilidade do complexo Al-orgânico em relação ao $\mathrm{Ca}$ ou $\mathrm{Mg}$-orgânico, diminuindo a acidez trocável.

No sistema de plantio direto ocorrem alterações nas condições químicas, físicas e biológicas do solo, que influenciam a dinâmica do sistema, promovendo uma 
resposta diferenciada à calagem superficial (Ciotta et al., 2004). O efeito negativo da acidez do solo e da toxidez por Al na produção agrícola não tem sido observado na maior parte dos solos sob SPD (Cambri, 2004).

A menor resposta das culturas à calagem no sistema de plantio direto, pode estar relacionada com o menor efeito tóxico do alumínio, decorrente da formação de complexos orgânicos solúveis nos restos de plantas (Myazawa et al., 1996), ou com o fato de os teores de cálcio, magnésio e potássio apresentarem disponibilidade suficiente no perfil do solo para manter uma relação adequada como o alumínio (Caires et al., 1998). Alleoni et al. (2003) não observaram efeito da aplicação de calcário em um Latossolo Vermelho em Tibagi, PR, sob SPD na produtividade de milho e soja, com dose para elevar a V\% a 70. Em um Latossolo Vermelho distrófico de Ponta GrossaPR, Caires et al. (1999) não encontraram efeito da aplicação de calcário em SPD, na produção de milho, trigo e soja, em condições de acidez ( $\mathrm{pH} 4,5$; V\% de 32 e m\% de $18)$.

Quanto à aplicação de gesso, a reposta encontrada também tem sido baixa, sendo variável entre as culturas. Caires et al. (1999) observaram somente resposta do milho à aplicação superficial de gesso de gesso no SPD, com aumento da produção segundo ajuste quadrático, enquanto soja e trigo não apresentaram resposta. A resposta do milho foi explicada tanto pelo fornecimento do enxofre pelo gesso, quanto pela redução da saturação por alumínio e aumento dos teores de cálcio trocável no perfil do solo e aumento da relação $\mathrm{Ca} / \mathrm{Mg}$.

$\mathrm{Na}$ cultura da soja, a maioria dos trabalhos tem mostrado ausência de resposta ao gesso aplicado, enquanto o trigo apresenta resposta variável, desde ausência até incrementos de $50 \%$ na produtividade (Caires et al. 1999). Não é possível ainda, prever com segurança no SPD já estabilizado ou na fase de implantação, a eficiência da calagem ou gessagem superficial na correção subsuperficial da acidez e a reposta das culturas a estas práticas, devido à complexidade de condições climáticas, práticas de manejo, culturas utilizadas, tipo de solo, doses e qualidade dos corretivos.

Para a definição de doses a recomendar devem-se, inicialmente, esclarecer as questões da química e da dinâmica do Al (Anghinoni \& Salet, 2000). 
Dentro desse conjunto de alterações no ambiente de produção com a adoção do SPD, ocasionando um comportamento diferenciado dos cultivos, são necessários estudos que possam ajudar explicar essas modificações e assim contribuir para o desenvolvimento de recomendações futuras.

\subsection{Solução do solo}

A solução do solo representa o local predominante de ocorrência das reações químicas no solo e o meio natural crescimento das plantas, além abrigar as frações químicas dos elementos imediatamente disponíveis no ambiente (Wolt, 1994). Sendo assim, o conhecimento da composição química da solução é de grande importância (Ciotta, 2004), tanto para estudos de manejo ambiental, como da fertilidade do solo e da nutrição de plantas.

A composição e a força iônica da solução do solo são importantes para a maioria dos aspectos da química do solo, sendo a composição, boa indicadora da biodisponibilidade dos nutrientes. Porém, a análise da solução do solo tem sido empregada somente em trabalhos de pesquisa e não para análise de rotina do solo, porque sua extração em condições de umidade do solo no campo apresenta grandes dificuldades metodológicas Gillman \& Bell (1977). O procedimento tradicional para a obtenção da solução envolve o deslocamento da solução a partir de uma coluna com solo úmido. Este procedimento requer grande quantidade de amostra de solo, consome muito tempo e demanda considerável experiência no acondicionamento das colunas Gillman \& Bell (1977).

Devido às dificuldades de obtenção da solução do solo, diversas relações entre solução e extrato de solo têm sido utilizadas. Isto está sendo possível mediante observação de boa relação entre força iônica da solução condutividade elétrica do extrato de solo, permitindo a predição de quantidades relativas de cátions na solução, parâmetros importantes nos estudos de nutrição de plantas (Gillman \& Bell, 1977).

A escolha do método de extração da solução do solo a ser utilizado é muito importante, devido principalmente, às possíveis diferenças causadas pelos 
métodos na composição da solução (Dahlgren, 1993). Independentemente do método empregado, a extração da solução do solo é lenta, porque somente um pouco de amostra pode ser extraída ao mesmo tempo. Isto pode levar a problemas, porque a composição da solução deve mudar substancialmente durante o período de armazenamento antes de ser obtida (Quian \& Wolt, 1990). Para obtenção de resultados que se aproximem da verdadeira composição da solução do solo, a mesma deve ser extraída imediatamente após a amostragem (Edmeades et al., 1985) ou ser coletada diretamente no campo, por exemplo, com o uso de lisímetros. No geral, a força iônica da solução do solo aumenta durante o período de armazenamento ou incubação do solo. Entre os cátions, os maiores aumentos nas concentrações são normalmente observados para $\mathrm{Ca}$ e $\mathrm{Mg}$ (Curtin \& Smillie, 1983).

A solução do solo apresenta uma dinâmica muito grande (Figura 1), e os elementos que se encontram dissolvidos são afetados pelas cinéticas de várias reações, como o equilíbrio entre ácido e base, complexação iônica, precipitação e dissolução de sólidos, oxidação, redução e troca iônicas (Chaves et al., 1991). Na região tropical, devido à intensa intemperização dos minerais do solo, a solução do solo apresenta baixa concentração de nutrientes (Stark \& Jordan, 1978), confirmando a necessidade de introdução via adubações, aplicação de corretivos para manutenção de nível de fertilidade adequado.

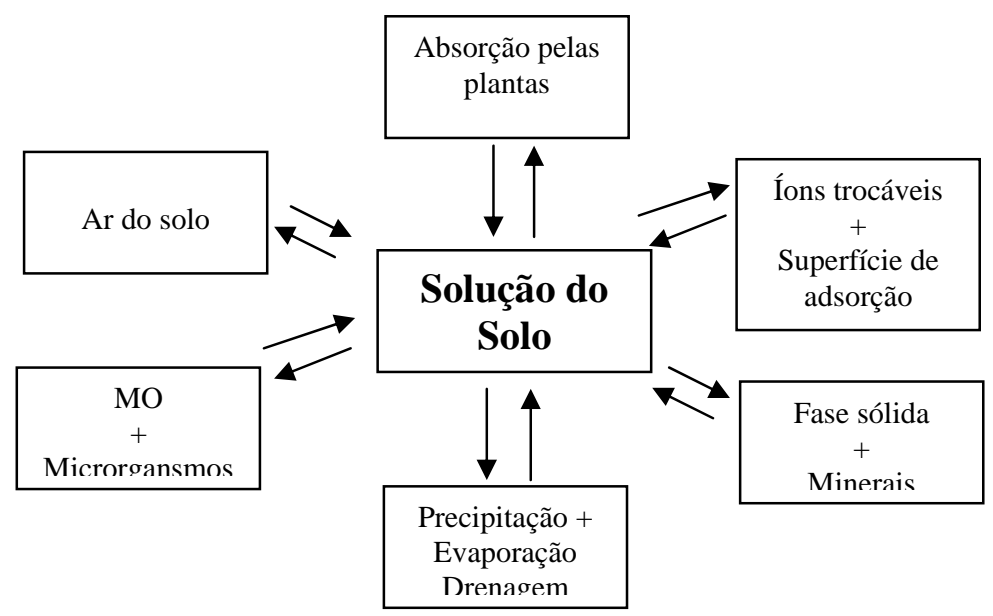

Figura 1 - Dinâmica dos equilíbrios que ocorrem na solução do solo. Fonte: Lindsay (1979) 
A concentração da maioria dos cátions $(\mathrm{Ca}, \mathrm{Mg}, \mathrm{K}$ e $\mathrm{Na})$ na solução do solo é determinada pelo equilíbrio com os cátions trocáveis (Nemeth et al., 1970). Calagem em solos ácidos é provavelmente a prática agrícola com o maior potencial para alterar a composição do complexo de troca e conseqüentemente da solução do solo. Graças ao rápido equilíbrio entre as fases (sólida e líquida) do solo, os efeitos da calagem e/ou gessagem manifestam-se rapidamente sobre a dinâmica de íons em solução (Amaral, 1998).

O problema da medida de concentração ou atividade de íons, nutrientes ou quaisquer substâncias na solução do solo tem sido abordado há muito tempo por pesquisadores interessados em ciência do solo. Mesmo assim, nenhuma solução plenamente satisfatória foi até hoje apresentada, talvez devido à própria complexidade do sistema solo-solução. O método mais comumente utilizado consta da agitação de certa quantidade de solo com uma solução extratora, em dada proporção e por determinado tempo. Várias críticas podem ser impostas a este procedimento, a principal dela por envolver a completa destruição do arranjo natural do sistema poroso solosolução do solo (Reichardt et al., 1977).

A solução aquosa contida no espaço poroso do solo é um sistema dinâmico aberto, cuja composição é uma conseqüência das inúmeras reações que podem ocorrer simultaneamente entre as três fases que constituem o solo (líquida, sólida e gasosa), as quais variam tanto com o tempo, quanto com o espaço. Um sistema tão complexo assim é de difícil reconstituição em qualquer experimentação de laboratório, mas, sendo assim, muitos estudos podem ser feitos com aplicação de princípios químicos (Berton, 1989).

Apesar das grandes dificuldades de trabalho com solução do solo, variabilidade de métodos de obtenção, dependência das condições edafoclimáticas, o estudo da solução com detalhamento em nível de especiação iônica contribui para elucidação de dúvidas na química do solo, principalmente para sistema de cultivo como o SPD, no qual, profundas alterações ocorrem no sistema. 


\subsection{Especiação Iônica e atividade química dos íons em solução}

A especiação química refere-se à forma como uma molécula ou íon encontra-se na solução do solo. A distribuição de um elemento químico em suas possíveis formas pode ser descrita com a utilização de constantes de equilíbrio (Lindsay, 1979). No sistema solo, a maioria dos íons pode estar presente na forma livre ou interagir com outros íons ou moléculas, formando pares iônicos. A solução do solo pode conter de 100 a 200 complexos solúveis diferentes. Geralmente, os cátions metálicos livres e complexados com sulfato são mais importantes em solos ácidos, enquanto os complexos com carbonato e borato destacam-se em solos alcalinos (Sposito, 1994).

A biodisponibilidade e o potencial tóxico dos elementos no ambiente dependem de sua especiação na solução do solo (Cancès et al., 2003). As interações que ocorrem entre os íons e moléculas fazem com que ocorra diminuição do potencial químico do íon no estado padrão. A medida desse desvio do potencial químico é denominada atividade. A atividade, na essência, é uma quantidade sem dimensão; por convenção, a atividade de qualquer íon no estado padrão é igual a 1. Portanto, quanto o maior o número e mais intensa a interação dos íons em solução, mais reduzida será sua atividade.

A atividade de um determinado íon $\left(a_{i}\right)$ é obtida pelo produto da concentração deste íon $\left(c_{i}\right)$ pelo coeficiente de atividade $\left(y_{i}\right)$ :

$$
a i=c i * y i
$$

O coeficiente de atividade pode ser estimado por meio de equações como a de Debye-Huckel, baseada em leis eletrostáticas e de termodinâmica.

$$
\log y_{i}=-A Z_{i}^{2} \mu^{1 / 2}
$$

em que: $\mathrm{A}=0,509$ para água a $25^{\circ} \mathrm{C} ; \mathrm{Zi}=$ valência do íon; $\mu=$ força iônica da solução (Lindsay, 1979).

Pode-se prever a formação e a estabilidade de um complexo na solução do solo pela aplicação dos princípios de ácidos e bases, duros e moles de Lewis (HSAB). Um ácido de Lewis (cátion metálico com um orbital eletrônico vazio ao iniciar a reação) 
é considerado duro quando tem um tamanho relativamente pequeno, alta eletronegatividade, alto estado de oxidação, baixa polaridade e quando os elétrons mais externos apresentam relativa dificuldade de serem excitados para estados de energia mais elevados. Um ácido mole apresenta o inverso destas características. Uma base dura se caracteriza por possuir alta eletronegatividade, baixa polaridade, difícil oxidação e não possuir orbitais eletrônicos de baixa energia vazios. A regra para formação de complexos, com base neste princípio, é que as bases duras preferem se unir a ácidos duros e formar complexos de esfera externa, e as bases moles a ácidos moles, formando complexos de esfera interna (Sposito, 1981).

$\mathrm{Na}$ solução do solo há grande número de interação entre nutrientes, elementos fitotóxicos e ânions inorgânicos e orgânicos. Estes últimos assumem papel de maior importância em sistema que favorecem o acúmulo de MO no solo, como solos florestais e SPD. Essas interações afetam a disponibilidade e a mobilidade, principalmente dos elementos catiônicos na solução do solo.

\subsection{Dinâmica do alumínio ligado à fase sólida do solo}

O alumínio é um dos elementos mais abundantes no solo, compreendendo aproximadamente $7,1 \%$ em peso da crosta terrestre. Durante o intemperismo, o Al é liberado dos minerais primários e precipitado como minerais secundários, sendo mais comuns os aluminosilicatos. Nos solos, como a perda de sílica é muito mais intensa, o alumínio, acaba se acumulando e precipitando como óxidos e hidróxidos, além de tornar-se como um importante íon trocável (Lindsay, 1979). Em solos ácidos, o Al existe em diferentes formas (Shigemitsu, 1975). Na fase sólida, aliado à predominância nos minerais aluminossilicatados e demais minerais de argila, o Al é encontrado ainda como íon trocável, adsorvido ou precipitado, componente de compostos hidroxilados complexos e associações organo minerais (Soom, 1993).

O cultivo do solo altera a relação entre as formas de alumínio do solo. Geralmente, ação antrópica diminui os teores de MO do solo pelo desbalanço entre ganhos e perdas, principalmente, pelo aumento nas taxas de decomposição (Kaminsk \& 
Rheinheirmer, 2000). No entanto, em solos cultivados com SPD, normalmente ocorre ao invés de queda, aumento dos teores de MO.

Em solos manejados sob sistema de plantio direto, o acúmulo de matéria orgânica e as interações entre os compostos orgânicos solúveis e os minerais do solo geram condições para a complexação do $\mathrm{Al}$, deixando-o numa forma não tóxica as plantas. A distribuição das formas trocável e complexada com a matéria orgânica pode ser determinada mediante o uso de diferentes extratores.

$\mathrm{O}$ teor de $\mathrm{Al}$ trocável do solo é extraído com $\mathrm{KCl} 1 \mathrm{~mol} \mathrm{~L}^{-1}$, que corresponde a fração de $\mathrm{Al}$ adsorvida pelos mecanismos de complexação de esfera externa (Vence et al., 1995). Para extração do Al ligado à MO do solo, é empregada a solução de $\mathrm{CuCl}_{2} 0,5 \mathrm{~mol} \mathrm{~L}^{-1}$, que apresenta um poder maior de extração de $\mathrm{Al}$ maior que a solução de $\mathrm{KCl} 1 \mathrm{~mol} \mathrm{~L}^{-1}$ (Mendonça e Rowell, 1994), obtendo-se assim o Al dos complexos de esfera interna da MO (Cambri \& Alleoni, 2003). $\mathrm{O} \mathrm{CuCl}_{2}$ é considerado como um extrator de alumínio complexado pela $\mathrm{MO}$ em complexos de baixa à média estabilidade (complexos de esfera interna) (Urrutia, 1995)

Para sais não tamponados, a eficiência na extração é acompanhada pela valência; desta maneira, o poder de extração do Al ligado à matéria orgânica é dado pela seguinte ordem: $\mathrm{La}^{+3}>\mathrm{Ca}^{+2}>\mathrm{K}^{+}$. O cobre é uma exceção a esta regra, resultado de sua estrutura iônica e tendência de formar complexos de esfera interna com a matéria orgânica deslocando o $\mathrm{Al}$ (Hargrove \& Thomas, 1984). $\mathrm{O} \mathrm{CuCl}_{2}$, devido a sua afinidade pelos mesmos ligantes do $\mathrm{Al}$ e pela acidez da solução ( $\mathrm{pH}$ 3,3), favorece a despomilerização dos polímeros Al-OH. Contudo, tem o incoveniente de ser capaz de extrair polímeros hidróxi-alumínicos dos espaços interlaminares dos filossilicatos 2:1 (Urrutia, 1995).

Toda forma de $\mathrm{Al}$ capaz de doar prótons em $\mathrm{pH}$ menor do que 7,0 é denominado de $\mathrm{Al}$ reativo e extração com $\mathrm{CuCl}_{2}$ dá uma rápida e simples estimativa do pool de Al potencialmente reativo em solos fortemente ácidos (Shigemitsu, 1975). O alto poder complexante dos íons $\mathrm{Cu}^{+2}$ e a condição de acidez de sua solução ( $\mathrm{pH} 3,3$ ) permiti ao extrato a liberação de formas potencialmente ativas de Al originado de 
complexos associados com a matéria orgânica, bem como os polímeros de hidróxidos de Al e o Al amorfo mais solúvel da fase inorgânica do solo.

$\mathrm{O}$ fato de o $\mathrm{CuCl}_{2} 1 \mathrm{~mol} \mathrm{~L}^{-1}$ extrair duas vezes ou mais $\mathrm{Al}$ do que o $\mathrm{KCl}$ $1 \mathrm{~mol} \mathrm{~L}^{-1}$ na superfície de solos ácidos suporta uma prévia decisão de que a redução da saturação de $\mathrm{Al}$ a zero requer que as taxas calcário determinada para $\mathrm{Al}$ extraído em $\mathrm{KCl}$ seja multiplicado por um fator de 2 a 3, evidenciando que $\mathrm{Al}$ extraído com $\mathrm{CuCl}_{2}$ $1 \mathrm{~mol} \mathrm{~L}{ }^{-1}$ é provavelmente um dos constituintes mais importantes em controlar o poder tampão de solos ácidos de pH 4 a 6 (Juo \& Kamprath, 1979). A interação entre Al e MO é uma das reações que mais influenciam as propriedades, organização e evolução dos solos ácidos, participando em processos como a redução da toxicidade por Al (Hue et al., 1986), na amortização do pH e nos equilíbrios sólido-dissolução, além de contribuir com a acidez potencial (Urrutia, 1995).

Formas trocáveis e não trocáveis têm sido referidas como alumínio reativo, incluindo além do $\mathrm{Al}$ solúvel e do efetivamente trocável, os polímeros hidroxialumínio inorgânicos positivamente carregados, adsorvidos aos colóides ou situados nas entrecamas de vermiculita e montimorilonita, os íons $\mathrm{Al}^{+3}$ e íons hidróxialumínio associado com a matéria orgânica, em formas de complexos orgânicos, e as formas mais solúveis de $\mathrm{Al}(\mathrm{OH})_{3}$ (Juo Kamprath, 1979). No entanto, não existe uma linha divisória clara entre a fração trocável e não trocável, sendo essas formas normalmente diferenciadas em função do método empregado na determinação (Pionke \& Corey, 1967). No SPD, as formas não trocáveis de Al passam a ter uma fundamental participação no comportamento deste cátion no solo, daí a importância do conhecimento destas distintas formas de $\mathrm{Al}$. 


\section{MATERIAL E MÉTODOS}

\section{1 Área experimental}

Foram utilizadas amostras de um experimento de campo instalado no ano de 1998 num Latossolo Vermelho distrófico textura argilosa, localizado no município de Ponta Grossa/PR $\left(25^{\circ} 05^{\prime} 58^{\prime}\right.$ S e $\left.59^{\circ} 09^{\prime} 30^{\prime \prime} \mathrm{W}\right)$. As características física e química do solo antes da instalação do experimento estão apresentadas nas tabelas 1 e 2 , sendo os resultados obtidos segundo metodologia da Embrapa (1997).

Antes da instalação do experimento, o solo estava cultivado com pastagem nativa da região. O delineamento experimental foi em blocos ao acaso com parcelas subdivididas, com três repetições. Nas parcelas, foram aplicados quatro tratamentos de calcário dolomítico com $89 \%$ de PRNT, definidos de acordo com a necessidade de calagem para elevação da saturação por bases do solo a $70 \%$, na camada de 0-0,2 m: testemunha (sem calcário); 4,5 $\mathrm{t} \mathrm{ha}^{-1}$ incorporado (a 0,2 $\mathrm{m}$ ); 4,5 $\mathrm{t} \mathrm{ha}^{-1}$ na superfície e três aplicações de $1,5 \mathrm{t} \mathrm{ha}^{-1}$ anualmente na superfície. Nas subparcelas, foram aplicadas três doses de gesso em superfície: 3, 6 e 9 t ha ${ }^{-1}$, além da testemunha. 
Tabela 1. Resultado da análise química em diferentes profundidades, antes da instalação do experimento

\begin{tabular}{|c|c|c|c|c|c|c|c|c|c|c|}
\hline Prof. & $\begin{array}{c}\mathrm{pH} \text { em } \\
\mathrm{CaCl}_{2} 0,01 \\
\mathrm{~mol}^{-1}\end{array}$ & $\mathrm{H}+\mathrm{Al}$ & $\mathrm{Al}^{3+}$ & $\mathrm{Ca}^{2+}$ & $\mathrm{Mg}^{2+}$ & $\mathrm{K}^{+}$ & $\begin{array}{c}\mathrm{P} \\
\text { (Mehlich-1) }\end{array}$ & $\mathrm{C}$ & V & $\mathrm{m}$ \\
\hline $\mathrm{m}$ & & ----. & $---m$ & $\overline{\mathrm{l}_{\mathrm{c}} \mathrm{dm}^{-}}$ & $-\cdots$ & --- & $\mathrm{mg} \mathrm{dm}^{-3}$ & $\mathrm{~g} \mathrm{dm}^{-3}$ & ---- & --- \\
\hline $0-0,2$ & 4,6 & 77,6 & 3 & 25 & 20 & 3,6 & 0,3 & 31 & 38 & 6 \\
\hline $0,2-0,4$ & 4,2 & 97,0 & 8 & 7 & 8 & 2,2 & 0,1 & 21 & 15 & 32 \\
\hline $0,4-0,6$ & 4,2 & 83,6 & 8 & 4 & 8 & 1,5 & 0,1 & 14 & 14 & 37 \\
\hline $0,6-0,8$ & 4,2 & 72,0 & 8 & 4 & 4 & 1,2 & 0,1 & 10 & 11 & 46 \\
\hline
\end{tabular}

Tabela 2. Resultado da análise granulométrica em diferentes profundidades, antes da instalação do experimento

\begin{tabular}{cccc}
\hline Profundidade & Areia & Silte & Argila \\
\hline $\mathrm{m}$ & $---\mathrm{-o}$ & 130 & 580 \\
$0-0,2$ & 290 & 100 & 600 \\
$0,2-0,4$ & 300 & 100 & 620 \\
$0,4-0,6$ & 280 & 89 & 640 \\
$0,6-0,8$ & 271 & &
\end{tabular}

As formas de aplicação do calcário foram escolhidas, com objetivo de verificar a necessidade de parcelamento da dose aplicada superficialmente, e sua viabilidade em relação à forma incorporada na correção da acidez do solo, devido às dúvidas quanto à eficiência da calagem superficial no estabelecimento do SPD. A maior dose de gesso foi definida de acordo com a equivalência em cálcio da dose de aplicada calcário, e as demais para constituir o modelo de regressão.

As aplicações de calcário dolomítico e de gesso agrícola foram realizadas em julho e em outubro de 1998, respectivamente. O calcário, no tratamento com incorporação, foi aplicado em duas etapas. A primeira constou de aplicação manual de metade da dose, antes da aração com arado de discos, a $0,2 \mathrm{~m}$ de profundidade. $\mathrm{Na}$ segunda etapa, foi aplicado o restante do calcário, manualmente, após a aração e imediatamente antes da gradagem com grade niveladora. No tratamento com 
parcelamento anual de calcário na superfície, a segunda aplicação foi em maio de 1999 e a terceira em maio de 2000. A área de cada parcela e subparcela foram $224 \mathrm{~m}^{2}$ e $56 \mathrm{~m}^{2}$, respectivamente.

Amostras de terra foram coletadas, logo após a colheita da soja, em maio de 2003, retirando-se, por meio de trado, doze subamostras por subparcela para compor uma amostra composta nas camadas de 0-0,05, 0,05-0,1, 0,1-0,2 m, e cinco subamostras para as camadas de 0,2-0,4, 0,4-0,6 0,6-0,8 $\mathrm{m}$ de profundidade.

Após a coleta, as amostras foram imediatamente secas ao ar (TFSA), com o objetivo de minimizar possíveis alterações que viessem a ocorrer, como intensificação do processo de mineralização da MO. Após a etapa de secagem, as amostras foram destorroadas, passadas em peneira de malha de $2 \mathrm{~mm}$ de diâmetro e acondicionadas em recipientes plásticos para posterior realização das análises. Do armazenamento até a obtenção da solução do solo correspondeu a um período aproximado de 12 meses. Desde a instalação do experimento até a coleta solo foram conduzidas as seguintes culturas: soja (1998/99), cevada (inverno/1999), soja (1999/00), trigo (inverno/2000), soja (2000/01), milho (2001/02) e soja (2002/03).

\subsection{Analises químicas do solo}

As análises foram realizadas segundo os métodos descritos em Raij et al. (2001):

- Carbono orgânico: obtido pela oxidação da matéria orgânica do solo com solução de dicromato de potássio $0,167 \mathrm{~mol} \mathrm{~L}^{-1}$ em presença de ácido sulfúrico e titulação do excesso de dicromato com sulfato ferroso amoniacal $0,4 \mathrm{~mol} \mathrm{~L} \mathrm{~L}^{-1}$.

- $\quad$ pH em $\mathrm{CaCl}_{2}$ 0,01 mol L $\mathrm{L}^{-1}$ : proporção solo:solução de 1:2,5 realizando a medida do $\mathrm{pH}$ em eletrodo de vidro. 


\subsection{Fracionamento do Al no solo}

As extrações de $\mathrm{Al}$ com $\mathrm{KCl} 1 \mathrm{~mol} \mathrm{~L} \mathrm{~L}^{-1}$ e $\mathrm{CuCl}_{2} 0,5 \mathrm{~mol} \mathrm{~L} \mathrm{~L}^{-1}$, correspondem ao Al trocável e Al complexado pela matéria orgânica (complexos de esfera interna), respectivamente. As extrações foram realizadas mediante agitação de $2 \mathrm{~g}$ da amostra com $20 \mathrm{ml}$ de cada solução extratora por uma hora, centrifugando-se em seguida a suspensão a $1500 \mathrm{rpm}$, durante 30 minutos. $\mathrm{O} \mathrm{Al}$ obtido na extração com $\mathrm{KCl}$ foi posteriormente titulado com $\mathrm{NaOH} 0,025 \mathrm{~mol} \mathrm{~L}^{-1}$, enquanto o $\mathrm{Al}$ extraído em $\mathrm{CuCl}_{2}$ foi determinado no ICP-OES.

A quantificação do Al extraído pelos dois extratores ocorreu de maneira diferenciada por questões de dificuldades metodológicas. A extração com $\mathrm{KCl}$ conferia a amostra uma elevada concentração salina, o que dificultava as leituras de ICP-OES, obrigando a diluição das amostras. Mas os teores trocáveis eram baixos, e por isso, com as elevadas diluições, muitos resultados ficavam abaixo do limite de detecção do aparelho.

Com a diferença entre os teores de $\mathrm{Al}$ extraído entre o cloreto de cobre e de potássio $\left(\mathrm{Al}_{\mathrm{CuCl}}-\mathrm{Al}_{\mathrm{KCl}}\right)$ foi obtido o $\mathrm{Al}$ complexado pela $\mathrm{MO}$ do solo. Essa subtração é necessária, porque o $\mathrm{CuCl}_{2} 0,5 \mathrm{~mol} \mathrm{~L}^{-1}$ extrai também a forma trocável, além das complexadas pela MO.

Apesar dos baixos teores trocáveis de Al encontrados no solo, o fracionamento do $\mathrm{Al}$ na forma trocável e complexada com a MO, foi realizada com o objetivo de melhor compreensão da dinâmica deste cátion no SPD, e a relação de suas formas com os teores e sua atividade na solução do solo.

\subsection{Extração e análise da solução do solo}

Para extração da solução do solo foi empregado o método do extrato aquoso (Wolt, 1994), utilizando uma relação solo:água 1:1. Foram tomados $20 \mathrm{~g}$ de terra em tubo de centrífuga de $50 \mathrm{~mL}$, aos quais foram adicionados $20 \mathrm{~g}$ de água ultrapurificada. Posteriormente os tubos foram colocados em mesa agitadora horizontal, 
agitando-se por 15 minutos a $150 \mathrm{rpm}$, permanecendo posteriormente em descanso por $1 \mathrm{~h}$. Transcorrido esse período, a solução foi agitada novamente por mais 5 minutos (Wolt, 1994) e centrifugada durante 30 minutos a $1500 \mathrm{rpm}$. Foram realizadas três extrações separadamente para obtenção dos extratos de cátions, ânions e carbono orgânico dissolvido (COD).

Para obtenção do extrato para leitura de cátions, a solução foi passada em membrana de celulose de $0,45 \mu \mathrm{m}$. A solução foi acidificada com uma gota de ácido nítrico concentrado e conservada em geladeira até a realização da leitura. Em outra extração, a solução foi passada em membrana de celulose de $0,22 \mu \mathrm{m}$ para posterior determinação dos ânions. O extrato para leitura de COD foi obtido após a passagem do extrato em filtro de microfibra de vidro $\mathrm{GF} / \mathrm{F}$ de $0,7 \mu \mathrm{m}$, previamente calcinado a $500^{\circ} \mathrm{C}$ por seis horas e depois acondicionados em frascos submetidos ao mesmo processo de calcinação. Utilizou-se também nesta última extração cerca de $0,1 \mathrm{~mL}$ de solução de $\mathrm{HgCl}_{2} 30 \mathrm{mmol} \mathrm{L}^{-1}$ para evitar o ataque de microrganismos ao COD das amostras.

Todas as filtragens para obtenção dos extratos foram realizadas com auxílio de suporte para filtros de $13 \mathrm{~mm}$ de diâmetro para a fração cátions e ânions e de $25 \mathrm{~mm}$ para o COD. Esses suportes eram conectados em seringas plásticas de $60 \mathrm{ml}$, nas quais eram colocados os extratos obtidos após centrifugação e filtrados mediante pressão por força manual. Nas soluções, imediatamente após a centrifugação, foram determinados $\mathrm{pH}$ e condutividade elétrica (CE) (também pode ser utilizada para o cálculo da força iônica da solução do solo). Os teores de cátions $(\mathrm{Ca}, \mathrm{Mg}, \mathrm{K}, \mathrm{Na}, \mathrm{Al}, \mathrm{Cu}$, $\mathrm{Fe}, \mathrm{Mn}$ e $\mathrm{Zn})$ foram determinados no ICP-OES, enquanto os teores de ânions $\left(\mathrm{NO}_{3}{ }^{-}\right.$, $\mathrm{SO}_{4}^{-2}, \mathrm{PO}_{4}^{-3}, \mathrm{Cl}^{-}$e F ), determinados por cromatografia iônica, e o COD no analisador de carbono Shimadzu 5000 A.

A força iônica (I) da solução do solo foi calculada segundo a equação a seguir (Sposito, 1989):

$$
I=1 / 2 \sum_{i=1}^{n} C i \cdot(Z i)^{2}
$$

em que: $C i$ a concentração $\left(m o l L^{-1}\right)$ de cada íon da solução e $Z i$ sua carga. 


\subsection{Especiação iônica da solução do solo}

A especiação iônica da solução do solo foi realizada a partir das concentrações dos cátions e dos ânions inorgânicos e orgânicos, força iônica calculada e o pH medido da solução, com auxílio do programa computacional Visual MINTEQ (Gustafsson, 2004). Com a especiação, estimou-se a distribuição das espécies livres e complexadas, obtendo-se a distribuição porcentual, concentração e atividades de cada espécie na solução do solo. As espécies ligadas aos ânions orgânicos foram estimadas com base no teor de COD pelo modelo "Gaussian DOM" (Grim et al., 1991).

Para análise da influência da calagem (formas de aplicação) na especiação dos elementos na solução do solo, foram tomadas as parcelas que receberam somente a aplicação de calcário (testemunhas de gesso). Para verificação de efeito isolado das doses de gesso na especiação, foi tomado o tratamento testemunha de calcário. Quanto ao efeito combinado de calagem e gessagem, considerou-se o tratamento de 4,5 t ha ${ }^{-1}$ de calcário em superfície em combinação com as doses de gesso. Esses tratamentos foram escolhidos por isolar o efeito da aplicação exclusiva de calcário, gesso, bem como a aplicação combinada dos mesmos. Além disso, representam o que pode ser empregado no manejo da acidez em áreas sob SPD.

\subsection{Análise dos resultados}

Realizou-se a análise de variância seguindo o modelo em parcelas subdivididas. Na ausência de interação significativa de calcário x gesso nas variáveis, os efeitos da calagem foram comparados pelo teste de Tukey, e do gesso por meio da análise de regressão. No caso de interação significativa, realizou-se análise de regressão em função de doses de gesso para cada tratamento de calcário. Também foram realizadas análises de correlação simples entre a concentração e a atividade de formas químicas dos íons em solução com alguns atributos químicos do solo e da solução. 


\section{RESULTADOS E DISCUSSÃO}

\subsection{Solução do solo sob sistema de plantio direto}

\subsection{1 pH da solução do solo}

Em todas as camadas não houve interação significativa entre calagem e gessagem nos valores de $\mathrm{pH}$ da solução do solo. A calagem promoveu a elevação do $\mathrm{pH}$ da solução do solo até $0,2 \mathrm{~m}$ (Tabela 3). Apenas na camada de 0,05-0,1 m o aumento do pH não dependeu da forma pela qual o corretivo foi aplicado. A incorporação mecânica do corretivo permitiu a obtenção do maior valor de $\mathrm{pH}$ na camada de 0,1-0,2 m, enquanto na camada mais superficial, o valor foi menor do que quando o calcário foi aplicado superficialmente, devido à menor concentração superficial do calcário com a incorporação. Schreffler \& Sharpe (2003) estudando o efeito da aplicação de calagem na composição química da solução do solo cultivado com floresta, na região sudoeste da Pensilvânia (EUA), também observaram que o calcário promoveu o aumento do $\mathrm{pH}$ da solução do solo. Os resultados discordam dos obtidos por Cambri (2004), num Latossolo Vermelho distrófico sob SPD localizado em Ponta Grossa/PR, que não observou efeito da aplicação de calcário em superfície nos valores de pH da solução do solo na camada de 0-0,2 m. Esses resultados discordantes podem ser devidos ao maior tempo de instalação do experimento (11 anos), fazendo com que os efeitos do corretivo desaparecessem.

O gesso, mesmo não sendo corretivo da acidez, promoveu pequena elevação do pH da solução na profundidade de 0,6-0,8 m. A aplicação de $1 \mathrm{t} \mathrm{ha}^{-1} \mathrm{de}$ gesso elevou o pH em 0,03 unidade (Figura 2). A explicação para essa pequena elevação 
do pH é a reação de troca de ligantes na superfície das partículas de solo, envolvendo os óxidos hidratados de ferro e de alumínio, com o $\mathrm{SO}^{-2}{ }_{4}$ deslocando o $\mathrm{OH}^{-}$para solução do solo.

Tabela 3. Valores de pH da solução do solo em função das formas de aplicação do calcário

\begin{tabular}{|c|c|c|}
\hline Profundidade & Tratamento & Média* \\
\hline $\mathrm{m}$ & $\mathrm{t} \mathrm{ha}^{-1}$ & \\
\hline \multirow[t]{4}{*}{$0-0,05$} & Sem calcário & $4,9 \mathrm{c}$ \\
\hline & $4,5 \mathrm{em}$ superfície parcelado $\left(1,5 \mathrm{ano}^{-1}\right)$ & $6,1 \mathrm{a}$ \\
\hline & 4,5 em superfície & $5,9 \mathrm{a}$ \\
\hline & 4,5 incorporado & $5,5 \mathrm{~b}$ \\
\hline \multirow[t]{4}{*}{$0,05-0,1$} & Sem calcário & $4,8 \mathrm{~b}$ \\
\hline & $4,5 \mathrm{em}$ superfície parcelado $\left(1,5 \mathrm{ano}^{-1}\right)$ & $5,3 \mathrm{a}$ \\
\hline & 4,5 em superfície & $5,1 \mathrm{a}$ \\
\hline & 4,5 incorporado & $5,4 \mathrm{a}$ \\
\hline \multirow[t]{4}{*}{$0,1-0,2$} & Sem calcário & $4,7 \mathrm{c}$ \\
\hline & 4,5 em superfície parcelado $\left(1,5 \mathrm{ano}^{-1}\right)$ & $4,8 \mathrm{bc}$ \\
\hline & 4,5 em superfície & $4,9 \mathrm{~b}$ \\
\hline & 4,5 incorporado & $5,2 \mathrm{a}$ \\
\hline \multirow[t]{4}{*}{$0,2-0,4$} & Sem calcário & $4,7 \mathrm{a}$ \\
\hline & 4,5 em superfície parcelado $\left(1,5\right.$ ano $\left.^{-1}\right)$ & $4,9 \mathrm{a}$ \\
\hline & 4,5 em superfície & $4,8 \mathrm{a}$ \\
\hline & 4,5 incorporado & 4,9 a \\
\hline \multirow{4}{*}{$0,4-0,6$} & Sem calcário & $4,7 \mathrm{a}$ \\
\hline & 4,5 em superfície parcelado $\left(1,5 \mathrm{ano}^{-1}\right)$ & $5,0 \mathrm{a}$ \\
\hline & 4,5 em superfície & $4,9 \mathrm{a}$ \\
\hline & 4,5 incorporado & 4,9 a \\
\hline \multirow[t]{4}{*}{$0,6-0,8$} & Sem calcário & $4,9 \mathrm{a}$ \\
\hline & 4,5 em superfície parcelado $\left(1,5\right.$ ano $\left.^{-1}\right)$ & $5,0 \mathrm{a}$ \\
\hline & 4,5 em superfície & $4,9 \mathrm{a}$ \\
\hline & 4,5 incorporado & $5,0 \mathrm{a}$ \\
\hline
\end{tabular}

*Significativo pelo teste Tukey a 5\%. Médias seguidas pela mesma letra não diferem dentro de cada profundidade.

Em todas as profundidades, os valores médios de $\mathrm{pH}$ da solução do solo foram maiores do que os valores médios de $\mathrm{pH}$ em $\mathrm{CaCl}_{2} 0,01 \mathrm{~mol} \mathrm{~L}^{-1}$, devido ao efeito depressivo do $\mathrm{CaCl}_{2}$ sobre o $\mathrm{pH}$ do solo. Como esperado, em todas as profundidades 
houve correlações significativas entre essas duas medidas $(r=0,97, P<0,0001 ; r=0,97$, $P<0,0001 ; \mathrm{r}=0,83, P<0,0001 ; \mathrm{r}=0,91, P<0,0001 ; \mathrm{r}=0,64, P=0,008 ; \mathrm{r}=0,65$, $P=0,006$, para as camadas de $0-0,05 ; 0,05-0,1 ; 0,1-0,2 ; 0,2-0,4 ; 0,4-0,6$ e 0,6-0,8 m, respectivamente). Ernani et al. (2001) também observaram que o pH de solução obtida por lixiviação, em solos acondicionados em coluna, foi sempre maior que o $\mathrm{pH}$ da fase sólida.

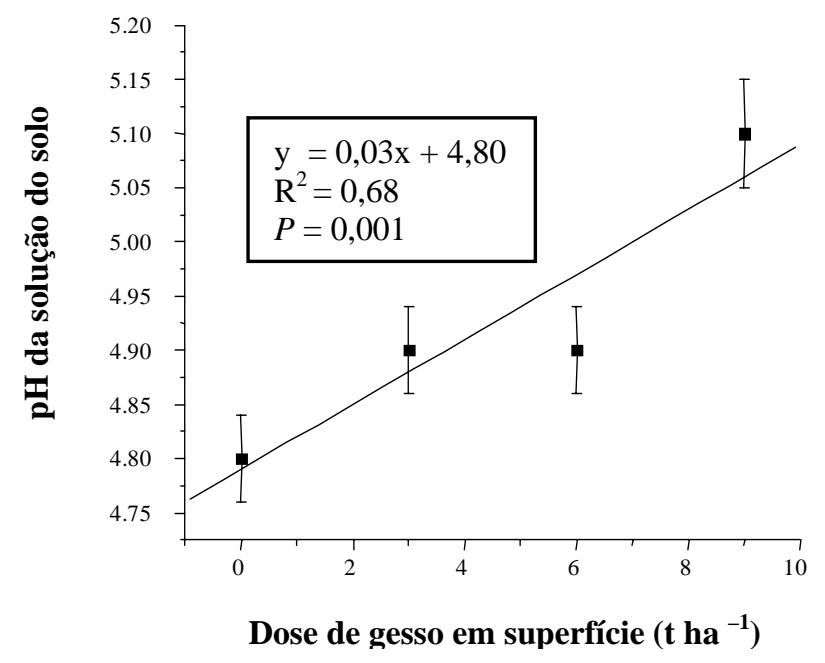

Figura 2 - Variação do pH da solução do solo, em função da aplicação de gesso, na profundidade de $0,6-0,8 \mathrm{~m}$

\subsubsection{Carbono orgânico dissolvido}

A aplicação de calcário e gesso não afetou a concentração de carbono orgânico dissolvido (COD) na solução do solo. Ciotta et al. (2004) e Cambri (2004) também não observaram o efeito da calagem superficial nos teores de COD em solo cultivado sob sistema de plantio direto. Há uma competição entre COD e $\mathrm{SO}_{4}^{-2}$ pelos sítios de adsorção no solo, indicando que, em ambientes onde há o aumento da concentração de sulfato na solução do solo (aplicação de gesso) seria esperado aumento do COD em solução (Guggenberger \& Zech, 1992), o que não foi observado. A ausência de efeito do gesso em elevar o COD pode ser consequência dos teores já relativamente 
elevados de COD em solução, fazendo com que possíveis efeitos do gesso não fossem detectados, prevalecendo adsorção de COD em relação ao sulfato.

Os valores de COD diminuíram com o aumento da profundidade, apresentando distribuição muito semelhante à dos teores de MO do solo (Figura 3). O efeito do tamponamento e equilíbrio da matéria orgânica total do solo com o carbono solúvel foi confirmado pela alta correlação obtida entre essas duas variáveis, ao longo das profundidades estudadas ( $\mathrm{r}=0,98, P=0,0005)$. Ciotta et al. (2004), relacionando os teores de carbono em solução com os teores totais de carbono ao longo do perfil do solo, também observaram relação significativa entre ambos, enfatizando a importância do acúmulo de matéria orgânica no solo para o aumento dos teores de carbono orgânico solúvel. A produção e o consumo de COD são dependentes principalmente da atividade microbiológica e do equilíbrio com a fase sólida da MO (Chantigny, 2003). Desta maneira, práticas conservacionistas de manejo do solo, como o SPD, contribuem para maior acúmulo de MO no solo e conseqüentes acréscimos em sua fração solúvel.
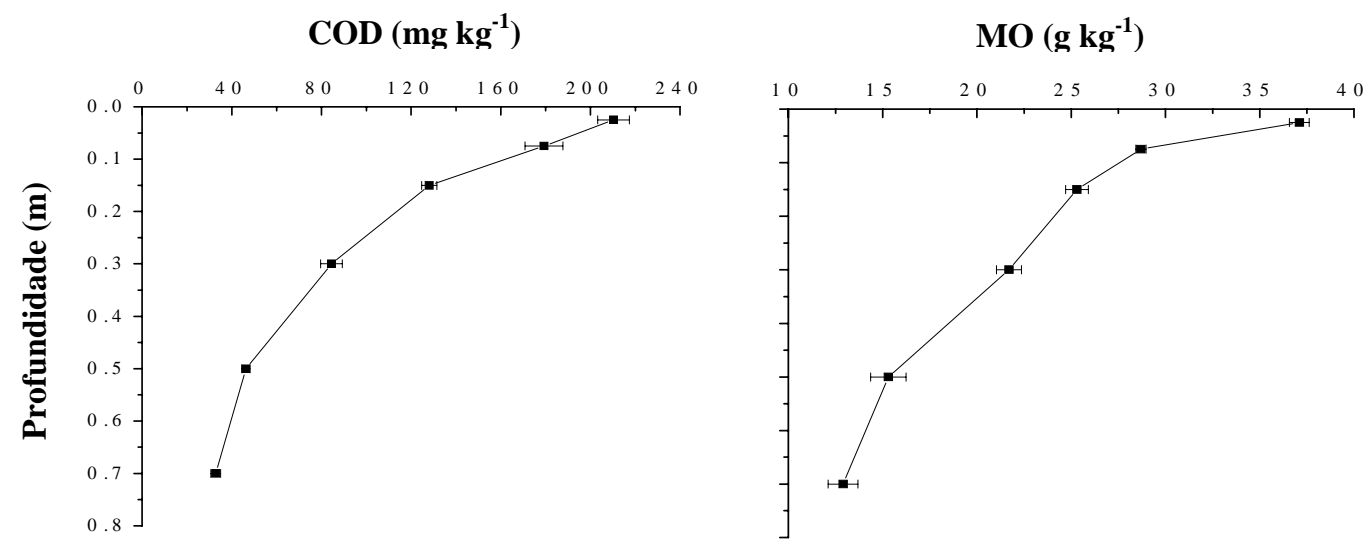

Figura 3 - Variação nos teores de carbono orgânico dissolvido (COD) e de matéria orgânica (MO) nas profundidades de amostragem. Barras horizontais indicam o erro padrão da média

Os valores de COD, principalmente até $0,2 \mathrm{~m}$ de profundidade, estão bem acima dos freqüentemente encontrados em solos agrícolas (faixa de 0 a $70 \mathrm{mg} \mathrm{L}^{-1}$ ) (Chantigny, 2003). Normalmente, em solos florestais os valores de COD são muito mais elevados, atingindo $440 \mathrm{mg} \mathrm{L}^{-1}$ (Chantigny, 2003). Os valores de COD em solos sob 
florestas são mais coerentes com os resultados aqui encontrados, confirmando uma tendência de maior estabilidade ao sistema de produção com a adoção do SPD.

\subsubsection{Força iônica da solução do solo}

A força iônica da solução do solo (I) foi influenciada apenas pela aplicação de gesso nas profundidades de 0,2-0,4 e 0,4-0,6 m (Figura 4). O aumento da I pela aplicação de gesso ocorreu em função do aumento da concentração de íons na solução. O valor de I na camada de 0-0,05 m (Figura 5) está bem próximo dos encontrados por Salet (1994) $\left(\mathrm{I}=5,5 \mathrm{mmol} \mathrm{kg}{ }^{-1}\right)$, e $6,0 \mathrm{mmol} \mathrm{kg}^{-1}$ na camada de 0-0,08 m (Salet, 1998) também em solos cultivados sob SPD.

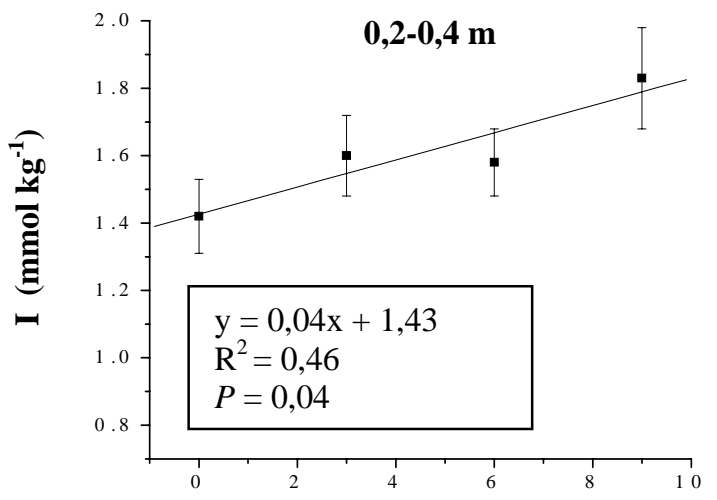

Dose de gesso em superfície (t ha $\left.{ }^{-1}\right)$

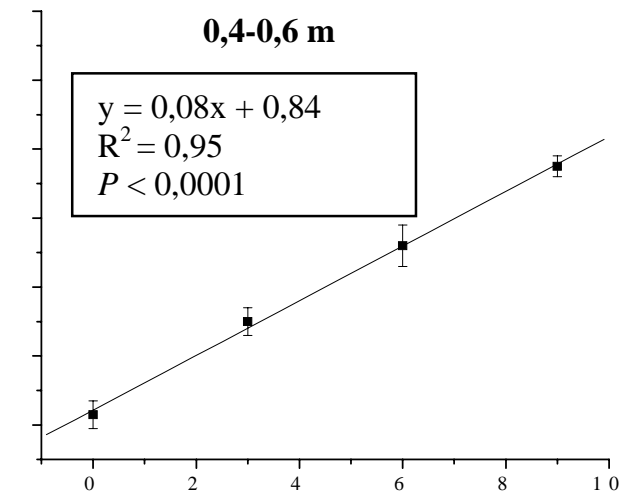

Dose de gesso em superfície (t ha $\left.{ }^{-1}\right)$

Figura 4 - Variação da força iônica (I) da solução do solo, em função da aplicação de gesso, em duas profundidades. Barras verticais indicam o erro padrão da média

Nas demais camadas, um possível efeito da gessagem foi diminuído devido ao aumento da concentração de íons mediante outros mecanismos, como adubações, deposição e decomposição de resíduos orgânicos. Besso \& Bell (1992), em estudo de incubação de solos com resíduos orgânicos e $\mathrm{CaCO}_{3}$, observaram que ambos promoveram acréscimos na força iônica da solução do solo. O aumento da I pelos resíduos foi atribuído à significativa presença de bases, principalmente de $\mathrm{K}$, o que 
também explica em parte a redução da I com o aumento da profundidade (Figura 5). A I apresenta clara tendência de redução com o aprofundamento no perfil do solo, sendo que valor de I da última camada representou apenas $20 \%$ do valor da camada mais superficial, indicando que sua influência na redução da atividade dos elementos em solução também deve variar, assumindo menor importância em camadas mais profundas.

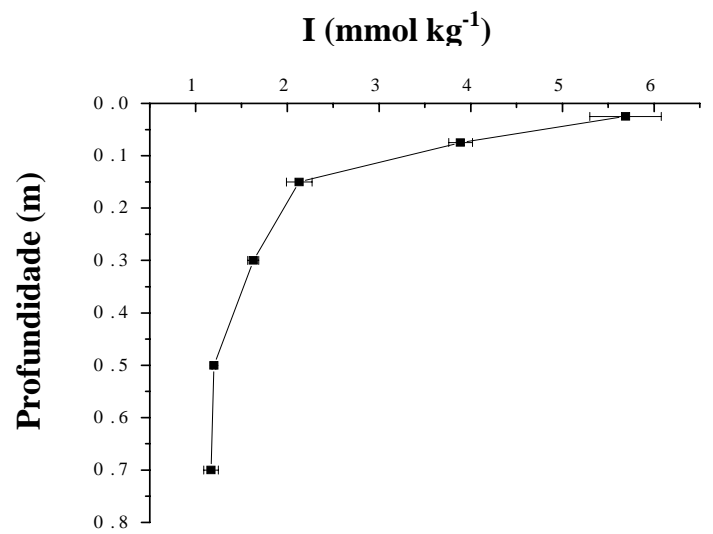

Figura 5 - Variação da força iônica (I) na solução do solo nas profundidades de amostragem. Barras horizontais indicam o erro padrão da média

\subsubsection{Cátions na Solução do solo}

\subsubsection{Alumínio}

Os teores de Al na solução do solo (Figura 6) não foram afetados pelos tratamentos, corroborando Cambri (2004), que não observou efeito da calagem superficial nos teores de Al em solução na camada de 0-0,2 m, mas discordaram de Ernani \& Barber (1993), que num experimento desenvolvido em laboratório com amostras de um solo ácido americano (Hapludalf), empregando dois sais de cálcio (cloreto e sulfato) nas doses de 0,500 e $1000 \mathrm{mg} \mathrm{kg}^{-1} \mathrm{de}$ Ca, equivalentes a 0,5 e $10 \mathrm{t}$ $\mathrm{ha}^{-1}$ de sulfato de cálcio e $0,3,1$ e 6,2 $\mathrm{t} \mathrm{ha}^{-1}$ de cloreto de cálcio, observaram que com a aplicação desses sais, houve aumentos na concentração e atividade iônica de todos os cátion avaliados ( $\mathrm{K}, \mathrm{Al}, \mathrm{Ca}$ e $\mathrm{Mg})$, sendo este aumento atribuído à substituição parcial de 
$\mathrm{K}, \mathrm{Al}$ e $\mathrm{Mg}$ das cargas negativas pelo cálcio aplicado, e, no Ca, à sua incorporação pelos sais. Os resultados discordantes dos encontrados por Ernani \& Barber (1993), quanto ao efeito da aplicação de sulfato de cálcio (gesso agrícola) nos teores de Al na solução, ocorreram talvez, porque outros mecanismos que causam este deslocamento atuaram em maior intensidade, como o COD e a própria força iônica, este último como um efeito indireto do gesso. Além disto, os teores em solução de Al são afetados por muitos fatores, gerando elevados coeficientes de variação (C.V. médio de $73 \%$ ), o que dificulta a detecção de diferença significativa entre os tratamentos.

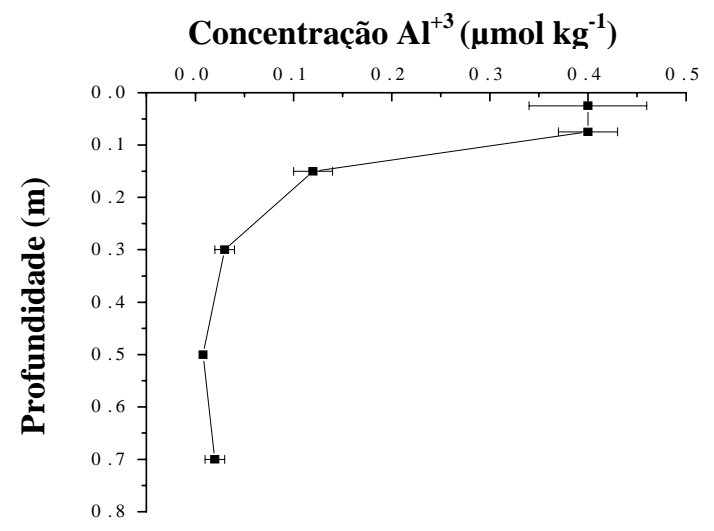

Figura 6 - Variação da concentração de $\mathrm{Al}^{+3}$ na solução do solo, nas profundidades de amostragem. Barras horizontais indicam o erro padrão da média

Os teores de $\mathrm{Al}$ apresentaram redução com o aumento da profundidade do solo (Figura 6), o que pode ser consequiência da ação do COD. Shamshuddin et al. (2004) constataram o efeito marcante da variação da profundidade do solo na concentração de Al solúvel, o qual foi mais alto na superfície rica em MO. Os ligantes orgânicos na solução do solo têm a propriedade de complexar o Al constituinte da fase sólida, desprendendo-o e tornando-o solúvel. Numa condição em que há mais ligantes orgânicos em solução, consequientemente haverá mais alumínio total solúvel. Este comportamento caracteriza o caráter ambíguo do COD, pois de um lado podem complexar o alumínio solúvel e diminuir a sua disponibilidade biológica, de outro eles podem aumentar o teor na solução (Salet, 1998), o que foi mais evidente para as duas primeiras camadas, pela maior concentração de COD. Esta ação dos ânions orgânicos 
pode ser confirmada pelas correlações positivas obtidas entre teor de Al na solução do solo e o COD, nas profundidades de 0-0,05 $\mathrm{m}(\mathrm{r}=0,77, P=0,0005)$ e de $0,2-0,4 \mathrm{~m}(\mathrm{r}=$ $0,55, P=0,03)$.

A maior concentração de Al na solução do solo, principalmente nas duas primeiras camadas, pode ser explicada ainda pelos maiores valores de I na solução. Uma alta concentração de sal na solução do solo desloca o $\mathrm{Al}^{+3}$ do complexo de troca para a solução (Mokolobate \& Haynes, 2002). Resultados semelhantes foram encontrados por Bessho \& Bell (1992), com incrementos de concentração de Al em solução pela ação de outros cátions. $\mathrm{O}$ teor de $\mathrm{Al}$ em solução também se correlacionou de forma positiva com a força iônica nas profundidades de 0-0,05 ( $\mathrm{r}=0,77, P=0,0005), 0,05-0,1(\mathrm{r}=0,77, P=$ $0,0005), 0,1-0,2(\mathrm{r}=0,93, P<0,0001)$ e $0,6-0,8 \mathrm{~m}(\mathrm{r}=0,55, P=0,03)$.

$\mathrm{A}$ atividade do $\mathrm{Al}$ foi muito maior nas duas primeiras camadas em relação às demais (Figura 7), dada pelas concentrações muito mais elevadas de $\mathrm{Al}$ até 0,1 m. Esses valores estão bem próximos dos níveis críticos (redução de $10 \%$ do crescimento radicular) de atividade de $\mathrm{Al}$ na solução do solo para algumas culturas como a cevada, que é de $1,5 \mu \mathrm{mol} \mathrm{L} \mathrm{L}^{-1}$ (Cameron et al., 1986), e o algodão de $2,0 \mu \mathrm{mol} \mathrm{L^{-1 }}$ (Adams \& Lund, 1966) mas, no entanto, bem abaixo do valor de nível crítico

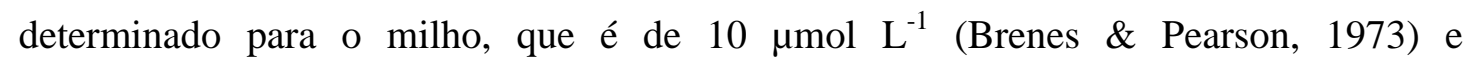
24-27 $\mu \mathrm{mol} \mathrm{L}{ }^{-1}$ (Diatloff et al., 1986) e $4 \mu \mathrm{mol} \mathrm{L}^{-1}$ para soja (Bruce et al., 1988).

\section{Atividade $\mathrm{Al}^{+3}\left(\boldsymbol{\mu m o l} \mathbf{~ k g}^{-1}\right)$}

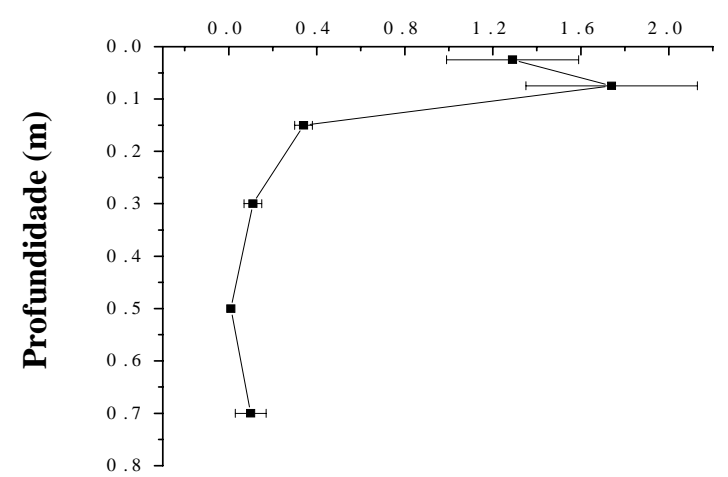

Figura 7 - Variação da atividade do $\mathrm{Al}^{+3}$ na solução do solo nas profundidades de amostragem. Barras horizontais indicam o erro padrão da média 
A atividade do Al correlacionou-se com a sua concentração total na solução do solo apenas nas camadas de $0-0,05(\mathrm{r}=0,65, P=0,006)$ e de $0,4-0,6 \mathrm{~m}$ ( $\mathrm{r}=0,95, P<0,0001)$, demonstrando que possíveis aumentos na concentração deste elemento não foram necessariamente acompanhados de acréscimos na atividade, a qual depende do grau e do número de interações que o Al realiza com os demais constituintes da solução.

Apenas o pH da solução do solo correlacionou-se de forma negativa com a atividade do $\mathrm{Al}$, e somente nas duas primeiras camadas $(\mathrm{r}=-0,59, P=0,03$ e $\mathrm{r}=-0,53$, $P=0,04$ para 0-0,05 e 0,05-0,1 m, respectivamente). Bessho \& Bell (1992) também obtiveram redução linear da atividade de $\mathrm{Al}^{+3}$ com o aumento do $\mathrm{pH}$ da solução do solo. Esta correlação negativa indica, que mesmo, no SPD, em que ocorrem grandes alterações no sistema solo e encontram-se baixos valores de atividade de elementos fitotóxicos, a correção do $\mathrm{pH}$ continua a ter fundamental importância no controle de tal atividade.

A diferenças entre a concentração total e a atividade de $\mathrm{Al}^{+3}$ na solução do solo foram muito altas, confirmando que apenas a concentração total não reflete a real disponibilidade do elemento, e que uma fração muito baixa encontra-se verdadeiramente ativa. A atividade deste cátion representou em relação à sua concentração total 0,$3 ; 0,5 ; 0,3 ; 0,4 ; 0,1 ; 0,5 \%$ nas profundidades de $0-0,05 ; 0,05-0,1$; $0,1-0,2 ; 0,2-0,4 ; 0,4-0,6$ e $0,6-0,8 \mathrm{~m}$, respectivamente.

As diferenças entre as profundidades, em termos absolutos, para a concentração total ou atividade foram muito maiores do que as diferenças da relação atividade/concentração, que variou apenas de 0,1 a $0,5 \%$. Essa alta diferença entre concentração e atividade não foi encontrada por Cambri (2004), o qual observou, que a atividade do íon $\mathrm{Al}^{+3}$ foi cerca de $40 \%$ menor do que a sua concentração total em solução. Esses valores discrepantes podem ser consequiência dos menores valores de COD encontrados pelo referido autor e também pelo mesmo não ter incluído o ânion fluoreto no cálculo da atividade do Al. Bessho \& Bell (1992), em amostras de solo incubadas com resíduos orgânicos e com $\mathrm{CaCO}_{3}$, constataram que a adição desses 
materiais reduziram a atividade da espécie monomérica de $\mathrm{Al}^{+3}$ e que a atividade representou $20 \%$ da concentração média de $\mathrm{Al}$ na solução.

\subsubsection{Cálcio, magnésio e potássio}

O teor de Ca na solução do solo foi afetado pelos tratamentos em todas as profundidades estudadas (Tabela 4 e Figura 8), sem ocorrer, no entanto, interação significativa. $\mathrm{O}$ efeito da calagem se restringiu às três primeiras camadas, enquanto à do gesso se deu ao longo de todo perfil, com aumento linear da concentração de Ca na solução. $\mathrm{O}$ aumento do $\mathrm{Ca}$ em solução até a profundidade de $0,8 \mathrm{~m}$ confirma a maior mobilidade do cálcio originado da aplicação de gesso em relação ao do calcário. A limitada mobilidade de cálcio na forma de carbonato é devida à sua baixa solubilidade ( $\mathrm{pK}=8,32)$, à capacidade de cátions dependente do $\mathrm{pH}$ e também à ausência de um ânion solúvel estável na reação do $\mathrm{CaCO}_{3}$. A reação química do $\mathrm{CaCO}_{3}$ em solo ácido, produz um cátion $\left(\mathrm{Ca}^{+2}\right)$ e um ânion instável $\left(\mathrm{HCO}_{3}{ }^{-}\right)$, que se decompõe em $\mathrm{CO}_{2}$ e $\mathrm{H}_{2} \mathrm{O}$. Com o aumento da $\mathrm{CTC}$ efetiva pelo $\mathrm{CaCO}_{3}$, é diminuída a mobilidade do Ca devido à força de atração do cátion pelas cargas negativas livres do solo (Ziglio et al., 1999).

A forma de aplicação do calcário também afetou o teor de Ca na solução do solo. Na camada de 0-0,05 m, a aplicação de calcário incorporado não promoveu aumento do cálcio, possivelmente devido a uma maior diluição desse elemento ao longo do perfil com a incorporação mecânica. Na profundidade de $0,05-0,1 \mathrm{~m}$, todas as formas de aplicação diferiram da testemunha, ocorrendo, contudo, efeito do parcelamento da dose de calcário em superfície em relação ao calcário incorporado. A calagem promoveu também o aumento do Ca na solução na camada de 0,1-0,2 m, independentemente da forma de aplicação. Ciotta et al. (2004), em um experimento de longa duração de calagem em sistema de plantio direto (21 anos), constando da aplicação de calcário incorporado a 0,2 m e em superfície num Latossolo Bruno alumínico, observaram que a calagem promoveu o aumento dos teores de Ca e em solução até $0,4 \mathrm{~m}$, sendo que os maiores teores ocorreram após incorporação do calcário. O aumento dos teores solúveis de Ca até 0,2 m com aplicação superficial de calcário, demonstra a movimentação deste 
cátion no perfil do solo e o potencial da calagem superficial em aumentar a concentração de Ca em solução além do seu local de aplicação, tal fato, possivelmente favorecido pelo aumento da concentração de ânions orgânicos, que complexam este nutriente, e contribuem para sua movimentação vertical (Franchini et al., 1999)

Tabela 4. Teores de cálcio na solução do solo em função das formas de aplicação do calcário

\begin{tabular}{|c|c|c|}
\hline Profundidade & Tratamento & Média* \\
\hline $\mathrm{m}$ & $\mathrm{tha}^{-1}$ & $\mathrm{mmol} \mathrm{kg}$ \\
\hline \multirow[t]{4}{*}{$0-0,05$} & Sem calcário & $0,44 \mathrm{~b}$ \\
\hline & 4,5 em superfície parcelado $\left(1,5 \mathrm{ano}^{-1}\right)$ & 0,69 a \\
\hline & 4,5 em superfície & $0,65 \mathrm{a}$ \\
\hline & 4,5 incorporado & $0,50 \mathrm{~b}$ \\
\hline \multirow[t]{4}{*}{$0,05-0,1$} & Sem calcário & $0,25 \mathrm{c}$ \\
\hline & 4,5 em superfície parcelado $\left(1,5 \mathrm{ano}^{-1}\right)$ & $0,32 \mathrm{~b}$ \\
\hline & 4,5 em superfície & $0,33 \mathrm{ba}$ \\
\hline & 4,5 incorporado & $0,39 \mathrm{a}$ \\
\hline \multirow[t]{4}{*}{$0,1-0,2$} & Sem calcário & $0,20 \mathrm{~b}$ \\
\hline & 4,5 em superfície parcelado $\left(1,5\right.$ ano $\left.^{-1}\right)$ & $0,23 \mathrm{~b}$ \\
\hline & 4,5 em superfície & $0,23 \mathrm{~b}$ \\
\hline & 4,5 incorporado & $0,28 \mathrm{a}$ \\
\hline \multirow[t]{4}{*}{$0,2-0,4$} & Sem calcário & $0,20 \mathrm{a}$ \\
\hline & 4,5 em superfície parcelado $\left(1,5 \mathrm{ano}^{-1}\right)$ & $0,25 \mathrm{a}$ \\
\hline & 4,5 em superfície & $0,23 \mathrm{a}$ \\
\hline & 4,5 incorporado & $0,22 \mathrm{a}$ \\
\hline \multirow[t]{4}{*}{$0,4-0,6$} & Sem calcário & $0,16 \mathrm{a}$ \\
\hline & 4,5 em superfície parcelado $\left(1,5 \mathrm{ano}^{-1}\right)$ & $0,19 \mathrm{a}$ \\
\hline & 4,5 em superfície & $0,19 \mathrm{a}$ \\
\hline & 4,5 incorporado & $0,16 \mathrm{a}$ \\
\hline \multirow[t]{4}{*}{$0,6-0,8$} & Sem calcário & $0,14 \mathrm{a}$ \\
\hline & 4,5 em superfície parcelado $\left(1,5 \mathrm{ano}^{-1}\right)$ & $0,14 \mathrm{a}$ \\
\hline & 4,5 em superfície & $0,16 \mathrm{a}$ \\
\hline & 4,5 incorporado & $0,14 \mathrm{a}$ \\
\hline
\end{tabular}

*Significativo pelo teste Tukey a 5\% . Médias seguidas pela mesma letra não diferem dentro de cada profundidade.

A calagem, mesmo aumentando os teores de cálcio na solução do solo até os 0,2 m, não apresentou, ao mesmo tempo, o efeito de elevar a atividade da forma livre deste nutriente na solução $\left(\mathrm{Ca}^{+2}\right)$. Esse resultado indica que a calagem, ao elevar os 
teores de Ca, também estimulou um aumento no número de interações entre os íons na solução do solo, por incrementar a I (fornecimento de $\mathrm{Mg}$, deslocamento de outros cátions do complexo de troca e estímulo a decomposição da MO). A calagem, ao mesmo tempo em que eleva os teores de Ca em solução, também eleva a CTC do solo, aumentando a adsorção deste cátion. Assim, os aumentos de Ca solúvel talvez não foram suficientes para superar a interação do mesmo com os demais constituintes da solução, não resultando, portanto, numa porção livre que ocasionasse aumentos significativos de atividade.

A aplicação de $1 \mathrm{t} \mathrm{ha}^{-1}$ de gesso elevou os níveis de Ca na solução do solo em 0,$026 ; 0,016 ; 0,017 ; 0,021 ; 0,022$ e $0,019 \mathrm{mmol} \mathrm{kg}^{-1}$ nas profundidades de 0-0,05; $0,05-0,1 ; 0,1-0,2 ; 0,2-0,4 ; 0,4-0,6$ e $0,6-0,8 \mathrm{~m}$, respectivamente (Figura 8). Wadt \& Wadt (1999), estudando a movimentação de cátions em colunas de solo com amostras de um Latossolo Vermelho amarelo álico cultivado com floresta secundária e grama batatais (Paspalum notatum L.), também observaram que a incubação com sulfato de cálcio foi efetiva em promover aumentos no teor de cálcio trocável em profundidade. Ernani \& Barber (1993) relataram, em estudo de composição da solução lixiviada, que a aplicação de cloreto e sulfato de cálcio proporcionou rápido movimento vertical de $\mathrm{Ca}$ no solo, com aumento do Ca extraível (Ca trocável + Ca na solução + Ca que dissolve durante o processo analítico), sendo esse movimento explicado pela presença de ânions acompanhantes na solução.

Ao contrário da calagem, a gessagem promoveu aumento linear da atividade do $\mathrm{Ca}^{+2}$ (Figura 9). A diferença entre o gesso e o calcário em elevar a atividade do Ca em solução pode ser conseqüência dos maiores incrementos de Ca solúvel com a gessagem. A maior habilidade do gesso em aumentar o Ca na solução do solo, relativamente ao calcário, se deve ao efeito diferenciado quanto à disponibilidade de cargas elétricas no solo e à permanência de seus ânions na solução do solo (Ernani et al., 2001). O gesso não eleva a CTC do solo, e mantém o sulfato em solução, fatos que favorecem a manutenção do Ca na solução do solo. 
0-0,05 m

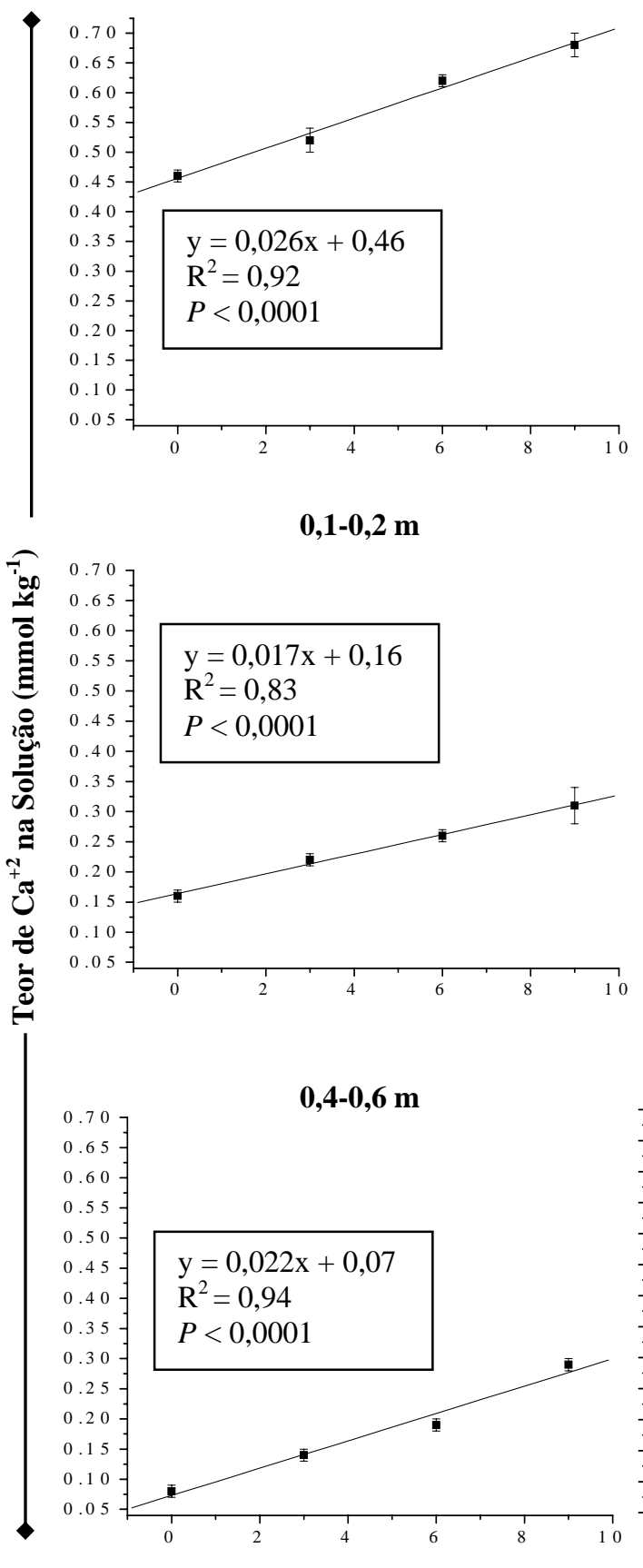

Dose de gesso em superfície (t ha ${ }^{-1}$ )
0,05-0,1 m

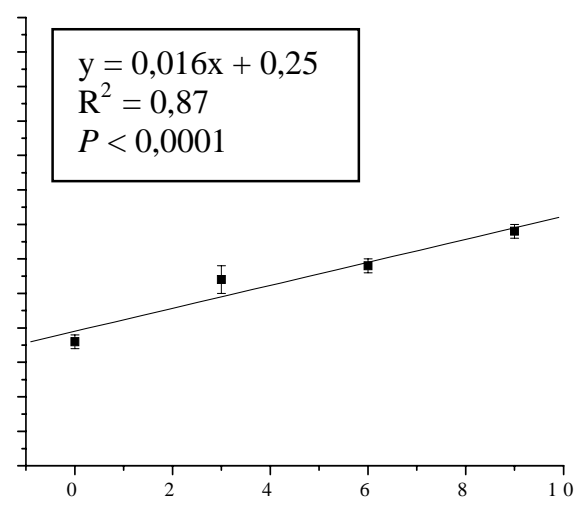

0,2-0,4 m

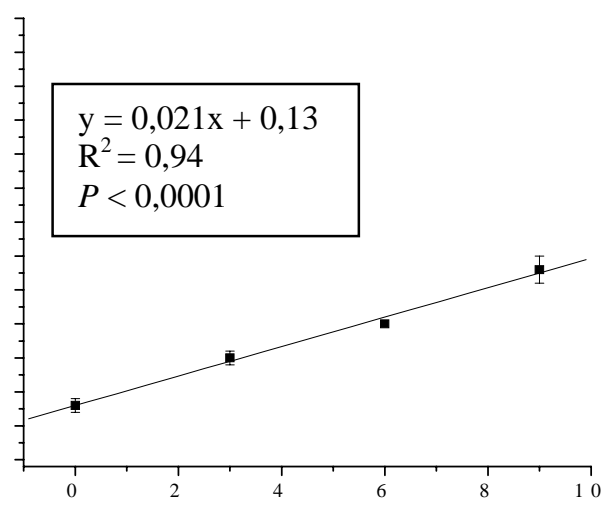

0,6-0,8 m

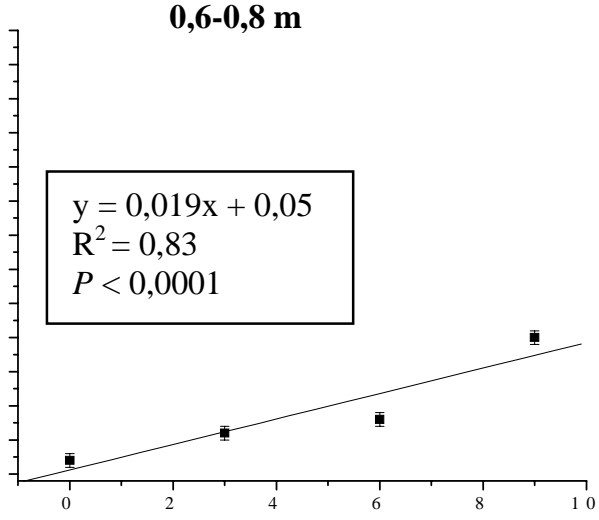

Dose de gesso em superfície (t ha $\left.{ }^{-1}\right)$

Figura 8 - Variação dos teores de cálcio na solução do solo, em função da aplicação de gesso, nas profundidades de amostragem. Barras verticais indicam o erro padrão da média 

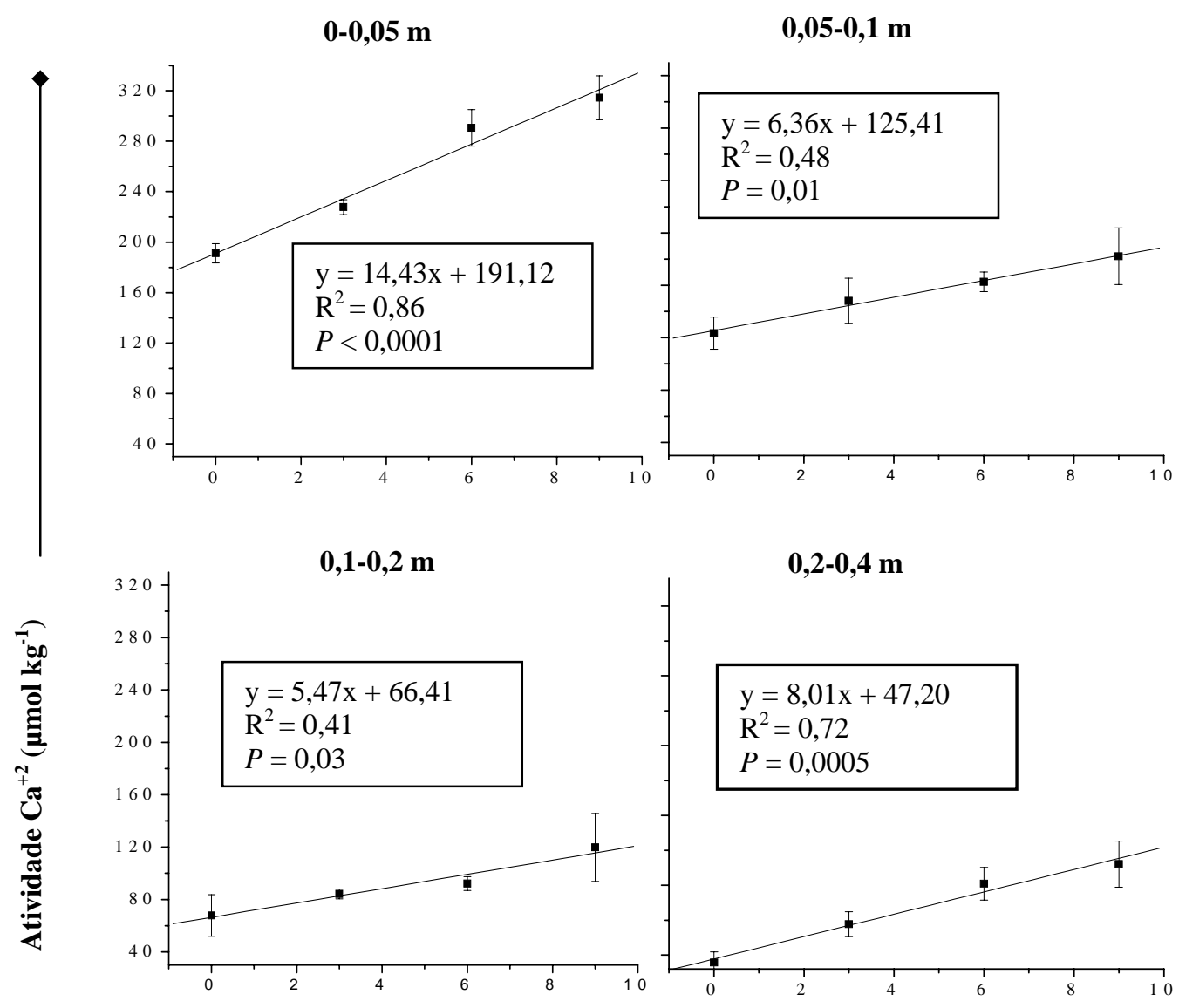

0,4-0,6 m
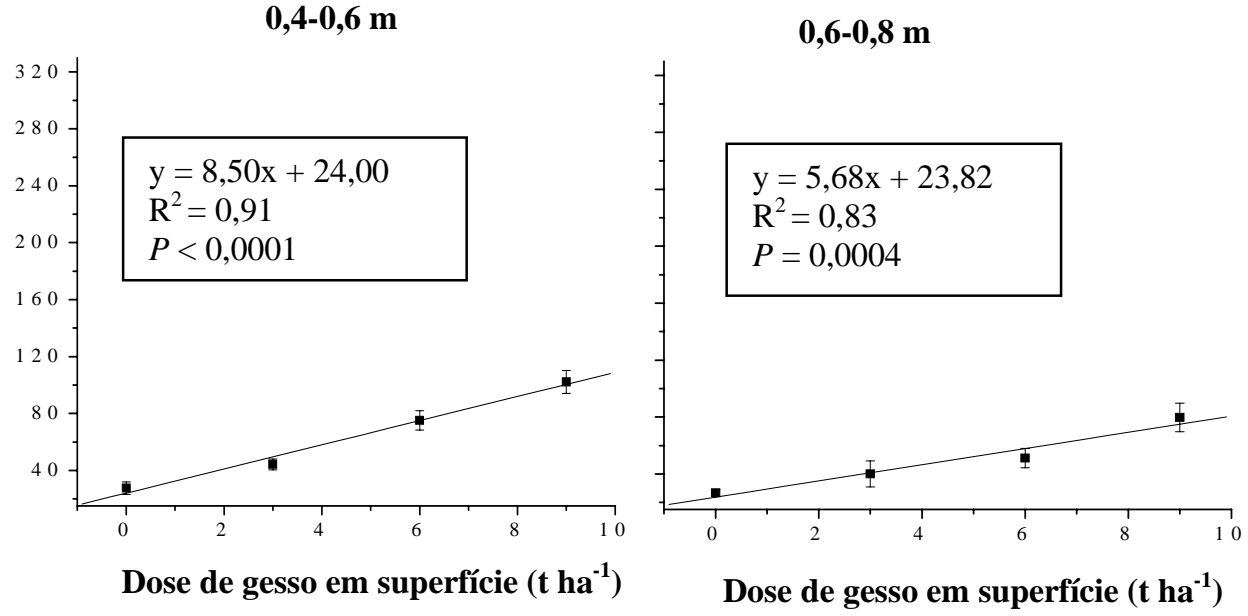

Figura 9 - Variação da atividade de $\mathrm{Ca}^{+2}$ na solução do solo, em função da aplicação de gesso, nas profundidades de amostragem. Barras verticais indicam o erro padrão da média 
Exceto na última profundidade, concentração e atividade de $\mathrm{Ca}$ se correlacionaram de forma positiva e altamente significativa $(r=0,86, P<0,0001$; $\mathrm{r}=0,90, P<0,0001 ; \mathrm{r}=0,90, P<0,0001 ; \mathrm{r}=0,91, P<0,0001 ; \mathrm{r}=0,91, P<0,0001$ nas profundidades de $0-0,05 ; 0,05-0,1 ; 0,1-0,2 ; 0,2-0,4$; e 0,4-0,6 m, respectivamente).

O teor de magnésio na solução do solo foi afetado pela calagem e/ou gessagem, sem ocorrer, no entanto, interação entre ambas. A calagem provocou aumento do $\mathrm{Mg}$ em solução até a profundidade de $0,6 \mathrm{~m}$, sendo, no entanto, esse aumento dependente da forma pela qual a calagem foi realizada (Tabela 5). O incremento de $\mathrm{Mg}$ até a profundidade de 0,6 m indica que a movimentação deste elemento foi maior do que para o $\mathrm{Ca}$, talvez, devido à adsorção preferencial do $\mathrm{Ca}$ em relação ao $\mathrm{Mg}$ nas cargas negativas do solo. Dal Bó et al. (1986) estudaram a movimentação de base no solo com a aplicação de diferentes sais de cálcio e também observaram maior movimentação de $\mathrm{Mg}$, atribuído à menor adsorção do $\mathrm{Mg}$ em relação ao $\mathrm{Ca}$, de acordo com a série liotrópica.

Como aconteceu para o $\mathrm{Ca}$, na camada mais superficial, a incorporação do corretivo não promoveu aumento de $\mathrm{Mg}$ em solução, possivelmente, devido à maior diluição do $\mathrm{Mg}$ oriundo do corretivo após a incorporação. Nas camadas de 0,05-0,1 e 0,2-0,4 e 0,4-0,6 m o incremento de Mg independeu da forma de aplicação, enquanto na camada de 0,1-0,2 m, houve diferença entre as formas de aplicação, com maior teor para a calagem incorporada. Ciotta et al. (2004) observaram que a aplicação de calcário no SPD aumentou os teores de $\mathrm{Mg}$ até $0,4 \mathrm{~m}$ de profundidade e que os teores mais elevados foram observados após a calagem superficial. 
Tabela 5. Teores de magnésio na solução do solo em função das formas de aplicação do calcário

\begin{tabular}{|c|c|c|}
\hline Profundidade & Tratamento & Média* \\
\hline $\mathrm{m}$ & $\mathrm{t} \mathrm{ha}^{-1}$ & $\mathrm{mmol} \mathrm{kg}^{-1}$ \\
\hline \multirow[t]{4}{*}{$0-0,05$} & Sem calcário & $0,33 \mathrm{~b}$ \\
\hline & 4,5 em superfície parcelado $\left(1,5 \mathrm{ano}^{-1}\right)$ & $0,70 \mathrm{a}$ \\
\hline & 4,5 em superfície & $0,70 \mathrm{a}$ \\
\hline & 4,5 incorporado & $0,43 \mathrm{~b}$ \\
\hline \multirow[t]{4}{*}{$0,05-0,1$} & Sem calcário & $0,12 \mathrm{~b}$ \\
\hline & 4,5 em superfície parcelado $\left(1,5\right.$ ano $\left.^{-1}\right)$ & $0,31 \mathrm{a}$ \\
\hline & 4,5 em superfície & $0,32 \mathrm{a}$ \\
\hline & 4,5 incorporado & $0,33 \mathrm{a}$ \\
\hline \multirow[t]{4}{*}{$0,1-0,2$} & Sem calcário & $0,10 \mathrm{c}$ \\
\hline & 4,5 em superfície parcelado $\left(1,5 \mathrm{ano}^{-1}\right)$ & $0,21 \mathrm{~b}$ \\
\hline & 4,5 em superfície & $0,20 \mathrm{~b}$ \\
\hline & 4,5 incorporado & $0,27 \mathrm{a}$ \\
\hline \multirow[t]{4}{*}{$0,2-0,4$} & Sem calcário & $0,10 \mathrm{~b}$ \\
\hline & 4,5 em superfície parcelado $\left(1,5 \mathrm{ano}^{-1}\right)$ & $0,22 \mathrm{a}$ \\
\hline & 4,5 em superfície & $0,22 \mathrm{a}$ \\
\hline & 4,5 incorporado & $0,23 \mathrm{a}$ \\
\hline \multirow[t]{4}{*}{$0,4-0,6$} & Sem calcário & $0,11 \mathrm{~b}$ \\
\hline & 4,5 em superfície parcelado $\left(1,5\right.$ ano $\left.^{-1}\right)$ & $0,17 \mathrm{a}$ \\
\hline & 4,5 em superfície & $0,16 \mathrm{a}$ \\
\hline & 4,5 incorporado & $0,16 \mathrm{a}$ \\
\hline \multirow[t]{4}{*}{$0,6-0,8$} & Sem calcário & $0,12 \mathrm{a}$ \\
\hline & 4,5 em superfície parcelado $\left(1,5\right.$ ano $\left.^{-1}\right)$ & $0,17 \mathrm{a}$ \\
\hline & 4,5 em superfície & $0,17 \mathrm{a}$ \\
\hline & 4,5 incorporado & $0,21 \mathrm{a}$ \\
\hline
\end{tabular}

*Significativo pelo teste Tukey a 5\% . Médias seguidas pela mesma letra não diferem dentro de cada profundidade.

$\mathrm{O}$ gesso ocasionou redução dos teores de $\mathrm{Mg}$ em solução nas profundidades de 0,05-0,1 e 0,1-0,2 m (Figura 10), possivelmente por acentuar a lixiviação deste cátion para camadas mais profundas do solo. Caires et al. (1998) testaram combinação de doses de calcário e gesso num Latossolo Vermelho Escuro distrófico e observaram o efeito de gesso na lixiviação de $\mathrm{Mg}$ das camadas superficiais para as mais profundas. Ernani et al. (2001), num trabalho estudando a composição da solução do solo percolada com aplicação de diferentes sais, notaram aumento dos teores de $\mathrm{Mg}$ na solução percolada quando foi aplicado gesso. Em função do efeito negativo do 
gesso na concentração de $\mathrm{Mg}$ nas camadas mais superficiais, Caires (2004) recomendou que para aplicação de doses elevadas de gesso devem ser desenvolvidas estratégias que minimizem as perdas de $\mathrm{Mg}$ trocável, como aplicação de calcário dolomítico.

0,05-0,1 m

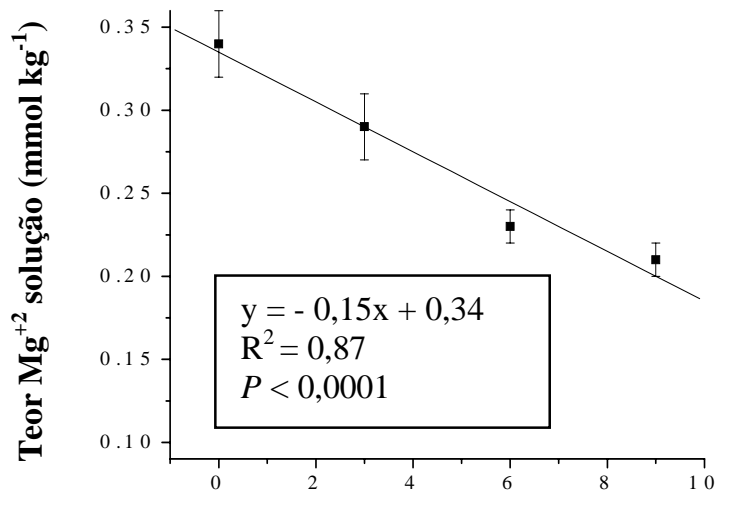

Dose de gesso em superfície (t ha $\left.{ }^{-1}\right)$
0,1-0,2 m

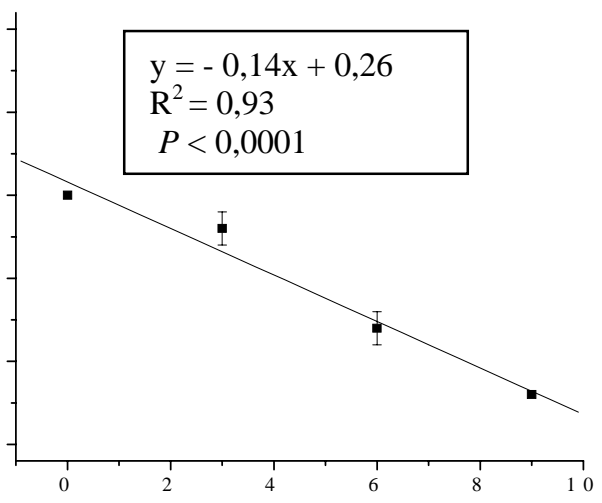

Dose de gesso em superfície ( $\mathrm{tha}^{-1}$ )

Figura 10 - Variação dos teores de magnésio na solução do solo, em função das doses de gesso, em duas profundidades. Barras verticais indicam o erro padrão da média

A atividade do $\mathrm{Mg}^{+2}$ na solução do solo foi elevada com a aplicação de calcário até 0,6 m (Tabela 6), devido à elevação dos teores de $\mathrm{Mg}$ em solução. O efeito da calagem em aumentar a concentração de $\mathrm{Mg}$ ocorreu em maior magnitude do que para o $\mathrm{Ca}$, pois este último é preferencialmente adsorvido às cargas negativas incrementadas pela calagem. Como será mostrado no próximo item de discussão dos resultados, o Ca se combinou em muito maior intensidade com os demais constituintes da solução do solo, principalmente os ânions orgânicos, quando comparado ao $\mathrm{Mg}, \mathrm{o}$ que também interferiu no resultado final de atividade de cada elemento.

Nas profundidades de 0,05-0,1,0,1-0,2 m, concomitantemente à redução dos teores de $\mathrm{Mg}$ em solução, o gesso reduziu a atividade do $\mathrm{Mg}^{+2}$ (Figura 11), como consequiência tanto do fornecimento de sulfato, que forma par iônico com o $\mathrm{Mg}$, quanto da própria redução dos teores deste cátion devido à lixiviação. Para o $\mathrm{Mg}$, o aumento da concentração na solução do solo correspondeu também ao aumento da atividade, obtendo-se correlações positivas e significativas em todas as profundidades $(r=0,85$, 
$P<0,0001 ; \mathrm{r}=0,99, P<0,0001 ; \mathrm{r}=0,98, P<0,0001 ; \mathrm{r}=0,98, P<0,0001 ; \mathrm{r}=0,99$, $P<0,0001 ; \mathrm{r}=0,66, P=0,005$ nas profundidades de $0-0,05 ; 0,05-0,1 ; 0,1-0,2 ; 0,2-0,4$; 0,4-0,6 e 0,6-0,8 m, respectivamente).
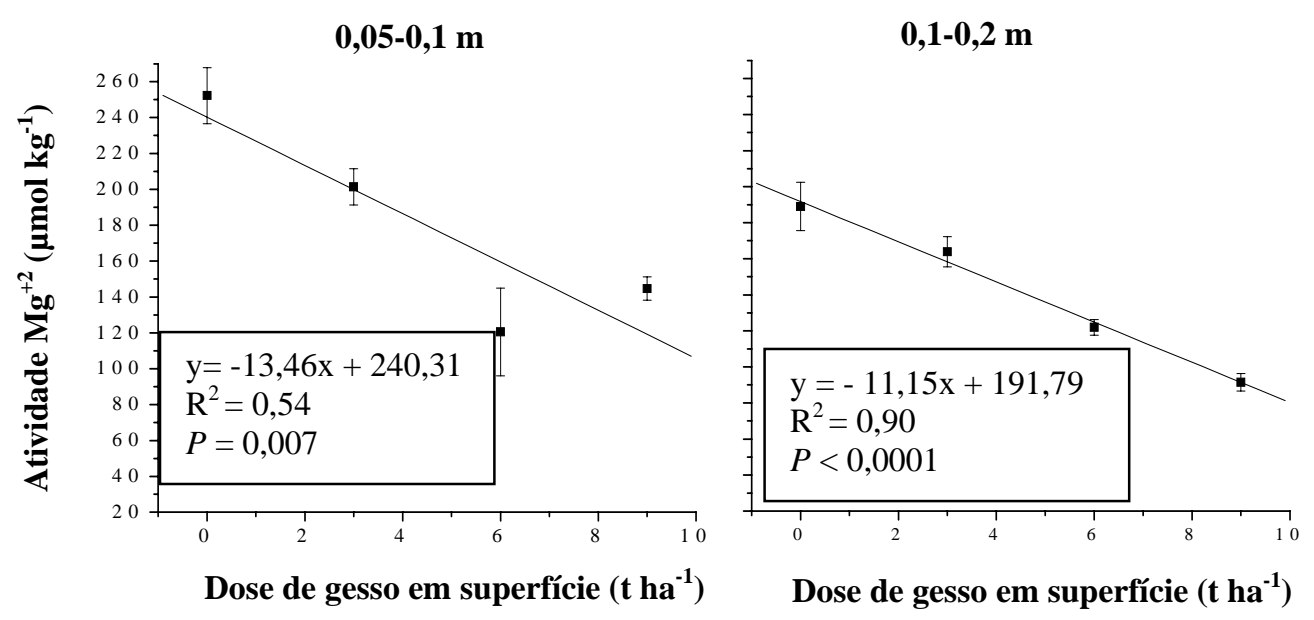

Figura 11 - Variação da atividade do magnésio na solução do solo, em função das doses de gesso, em duas profundidades. Barras verticais indicam o erro padrão da média

Os teores de K na solução do solo foram afetados pela calagem apenas nas duas últimas profundidades $(0,4-0,6$ e $0,6-0,8 \mathrm{~m})$ (Tabela 7). A calagem proporcionou decréscimo na concentração de K na solução do solo, sem diferença entre as formas de aplicação. Nas profundidades em que a calagem diminuiu os teores de $\mathrm{K}$ em solução, o efeito pode ser atribuído ao aumento da CTC nos sítios de carga variável, devido ao aumento do pH e da força iônica (Sposito, 1989). Desta maneira, como os teores de K nessas camadas foram muito baixos, pequenos aumentos na CTC do solo por ação da calagem foram suficientes para reduzir significativamente a concentração de $\mathrm{K}$ na solução.

Não houve efeito dos tratamentos nas demais profundidades, indicando que um possível aumento da CTC com a calagem não foi suficiente para incrementar significativamente a adsorção de $\mathrm{K}$ e uma conseqüente redução na solução do solo. Os resultados discordam dos encontrados por Ciotta $^{1}$, citado por Ciotta et al. (2004), que 
nos tratamentos sem calcário, encontraram-se maiores teores de $\mathrm{K}$ na solução, em relação aos tratamentos com calagem, devido a menor CTC efetiva.

Tabela 6. Valores da atividade de $\mathrm{Mg}^{+2}$ na solução do solo em função das formas de aplicação do calcário

\begin{tabular}{|c|c|c|}
\hline Profundidade & Tratamento & Média* \\
\hline $\mathrm{m}$ & $\mathrm{tha}^{-1}$ & $\mu \mathrm{mol} \mathrm{kg}{ }^{-1}$ \\
\hline \multirow[t]{4}{*}{$0-0,05$} & Sem calcário & $205,3 \mathrm{~b}$ \\
\hline & 4,5 em superfície parcelado $\left(1,5 \mathrm{ano}^{-1}\right)$ & 487,3 a \\
\hline & 4,5 em superfície & $406,0 \mathrm{a}$ \\
\hline & 4,5 incorporado & $292,1 \mathrm{c}$ \\
\hline \multirow[t]{4}{*}{$0,05-0,1$} & Sem calcário & $87,9 \mathrm{~b}$ \\
\hline & 4,5 em superfície parcelado $\left(1,5 \mathrm{ano}^{-1}\right)$ & $217,4 \mathrm{a}$ \\
\hline & 4,5 em superfície & $227,5 \mathrm{a}$ \\
\hline & 4,5 incorporado & $189,5 \mathrm{a}$ \\
\hline \multirow[t]{4}{*}{$0,1-0,2$} & Sem calcário & $79,7 \mathrm{~b}$ \\
\hline & 4,5 em superfície parcelado $\left(1,5 \mathrm{ano}^{-1}\right)$ & $152,1 \mathrm{a}$ \\
\hline & 4,5 em superfície & $151,1 \mathrm{a}$ \\
\hline & 4,5 incorporado & $189,5 \mathrm{a}$ \\
\hline \multirow[t]{4}{*}{$0,2-0,4$} & Sem calcário & $74,3 \mathrm{~b}$ \\
\hline & 4,5 em superfície parcelado $\left(1,5 \mathrm{ano}^{-1}\right)$ & $157,3 \mathrm{a}$ \\
\hline & 4,5 em superfície & 156,4 a \\
\hline & 4,5 incorporado & $155,4 \mathrm{a}$ \\
\hline \multirow[t]{4}{*}{$0,4-0,6$} & Sem calcário & $80,8 \mathrm{~b}$ \\
\hline & 4,5 em superfície parcelado $\left(1,5 \mathrm{ano}^{-1}\right)$ & $122,0 \mathrm{a}$ \\
\hline & 4,5 em superfície & 119,8 a \\
\hline & 4,5 incorporado & $121,8 \mathrm{a}$ \\
\hline \multirow[t]{4}{*}{$0,6-0,8$} & Sem calcário & 90,0 a \\
\hline & 4,5 em superfície parcelado $\left(1,5\right.$ ano $\left.^{-1}\right)$ & $120,1 \mathrm{a}$ \\
\hline & 4,5 em superfície & $110,3 \mathrm{a}$ \\
\hline & 4,5 incorporado & $120,2 \mathrm{a}$ \\
\hline
\end{tabular}

*Significativo pelo teste Tukey a 5\% . Médias seguidas pela mesma letra não diferem dentro de cada profundidade.

${ }^{1}$ CIOTTA, M.N. Componentes da acidez do solo e calagem superficial em um Latossolo Bruno alumínico sob plantio direto há 20 anos. Lages, 100p. Dissertação (Mestrado) - Universidade do Estado de Santa Catarina. 
Tabela 7. Teores de potássio na solução do solo em função das formas de aplicação de calcário

\begin{tabular}{|c|c|c|}
\hline Profundidade & Tratamento & Média* \\
\hline $\mathrm{m}$ & $\mathrm{tha}^{-1}$ & $\mathrm{mmol} \mathrm{kg}^{-1}$ \\
\hline \multirow[t]{4}{*}{$0-0,05$} & Sem calcário & $0,73 \mathrm{a}$ \\
\hline & 4,5 em superfície parcelado $\left(1,5 \mathrm{ano}^{-1}\right)$ & $0,65 \mathrm{a}$ \\
\hline & 4,5 em superfície & $0,66 \mathrm{a}$ \\
\hline & 4,5 incorporado & $0,69 \mathrm{a}$ \\
\hline \multirow[t]{4}{*}{$0,05-0,1$} & Sem calcário & $0,38 \mathrm{a}$ \\
\hline & 4,5 em superfície parcelado $\left(1,5 \mathrm{ano}^{-1}\right)$ & $0,31 \mathrm{a}$ \\
\hline & 4,5 em superfície & $0,33 \mathrm{a}$ \\
\hline & 4,5 incorporado & $0,33 \mathrm{a}$ \\
\hline \multirow[t]{4}{*}{$0,1-0,2$} & Sem calcário & $0,26 \mathrm{a}$ \\
\hline & 4,5 em superfície parcelado $\left(1,5 \mathrm{ano}^{-1}\right)$ & $0,22 \mathrm{a}$ \\
\hline & 4,5 em superfície & $0,20 \mathrm{a}$ \\
\hline & 4,5 incorporado & $0,20 \mathrm{a}$ \\
\hline \multirow[t]{4}{*}{$0,2-0,4$} & Sem calcário & $0,20 \mathrm{a}$ \\
\hline & 4,5 em superfície parcelado $\left(1,5 \mathrm{ano}^{-1}\right)$ & $0,13 \mathrm{a}$ \\
\hline & 4,5 em superfície & $0,13 \mathrm{a}$ \\
\hline & 4,5 incorporado & $0,14 \mathrm{a}$ \\
\hline \multirow[t]{4}{*}{$0,4-0,6$} & Sem calcário & $0,09 \mathrm{a}$ \\
\hline & 4,5 em superfície parcelado $\left(1,5 \mathrm{ano}^{-1}\right)$ & $0,06 \mathrm{~b}$ \\
\hline & 4,5 em superfície & $0,05 \mathrm{~b}$ \\
\hline & 4,5 incorporado & $0,05 \mathrm{~b}$ \\
\hline \multirow[t]{4}{*}{$0,6-0,8$} & Sem calcário & $0,05 \mathrm{a}$ \\
\hline & 4,5 em superfície parcelado $\left(1,5 \mathrm{ano}^{-1}\right)$ & $0,03 \mathrm{~b}$ \\
\hline & 4,5 em superfície & $0,03 \mathrm{~b}$ \\
\hline & 4,5 incorporado & $0,02 \mathrm{~b}$ \\
\hline
\end{tabular}

*Significativo pelo teste Tukey a 5\% . Médias seguidas pela mesma letra não diferem dentro de cada profundidade.

Ao contrário, do que aconteceu para $\mathrm{o} \mathrm{Mg}$, o gesso não promoveu a redução do K na solução em nenhuma camada. Estes resultados estão de acordo com os encontrados por Quaggio et al. (1993), que trabalhando com até $9 \mathrm{t} \mathrm{ha}^{-1}$ não observaram lixiviação de $\mathrm{K}$, mas apenas de $\mathrm{Mg}$ da camada arável para as mais profundas. Contrariamente, Caires et al. (1998) registraram a lixiviação de potássio para as camadas mais profundas com a aplicação de gesso, em amostragem realizada oito meses após a gessagem. Trabalhando na mesma área em que foram coletadas as amostras para a 
realização do presente trabalho, Caires et al (2004), aos 43 meses após a gessagem, também não observou influência do gesso na lixiviação do K trocável do solo.

A ausência de efeito do gesso na lixiviação de K, segundo Ernani (1993), está relacionado ao poder tampão do solo (relação entre K trocável e K em solução), sendo que em solos com elevado poder tampão, não deve ser observada a lixiviação de $\mathrm{K}$ no solo, enquanto em solos de baixo poder tampão, a aplicação de doses baixas ou moderadas de gesso (iguais ou inferiores a $2 \mathrm{t} \mathrm{ha}^{-1}$ ) promove lixiviação deste nutriente. No entanto, não é possível afirmar se realmente estaria existindo um poder tamponante de K nesse solo e qual seria esse valor. Mas os valores de poder tampão de K em solos altamente intemperizados são considerados baixos (Prezotti et al., 1988). Por outro lado, o poder tampão de K pode ser aumentado no SPD com o aumento da CTC pelo acúmulo de $\mathrm{MO}$ e dos teores de K com adubações sucessivas e manutenção dos resíduos vegetais no solo.

A atividade do $\mathrm{K}^{+}$na solução do solo não foi afetada pelos tratamentos, mesmo nas duas últimas profundidades, quando a calagem reduziu os teores deste cátion na solução, mesmo porque a redução foi pequena em relação ao tratamento sem calagem. Além disso, o K deve ter apresentado muito baixa associação com outros componentes da solução do solo (formação de pares iônicos), como o sulfato, fornecido via gesso. A atividade média do $\mathrm{K}^{+}$na solução do solo foi $630 ; 320,7 ; 211,1 ; 148,5$; 73,1 e $50,3 \mu \mathrm{mol} \mathrm{kg}{ }^{-1}$ nas profundidades de $0-0,05 ; 0,05-0,1 ; 0,1-0,2 ; 0,2-0,4 ; 0,4-0,6$ e 0,6-0,8 m, respectivamente. Exceto nas profundidades em que a calagem reduziu a concentração de $\mathrm{K}$ na solução, a atividade e teores em solução de $\mathrm{K}$ apresentaram correlação positiva e significativa. Considerando que a atividade reflete melhor a disponibilidade de um elemento em solução, o aumento da concentração de K normalmente corresponderá a um aumento da disponibilidade às plantas. No entanto, isto só poderia ser confirmado com a correlação com os teores foliares deste nutriente, o que deve ser aplicado também aos demais nutrientes. 


\subsubsection{Micronutrientes catiônicos}

Não foi possível a determinação dos teores de zinco $(\mathrm{Zn})$ e cobre $(\mathrm{Cu})$ na solução do solo, devido às concentrações muito baixas, estando abaixo do limite de detecção do aparelho empregado (ICP-OES). O manganês (Mn) foi o único micronutriente catiônico em que foi detectado o efeito dos tratamentos (Tabela 8), com efeito, apenas da calagem. Os teores de Mn encontrados, em muitos casos estão acima dos valores mencionados por Boekert (1991) para oitos Latossolos no estado do Paraná $\left(0,2\right.$ a $\left.1,1 \mu \mathrm{mol} \mathrm{L}{ }^{-1}\right)$. É valido salientar, que mesmo nas duas primeiras camadas, onde a calagem reduziu significativamente os teores de Mn em solução, os mesmos estão dentro dos limites apresentados pelo referido autor.

$\mathrm{O} \mathrm{Fe}$, apesar de ter um comportamento muito semelhante ao do $\mathrm{Mn}$ quanto à variação do $\mathrm{pH}$ do solo, não foi afetado pela calagem e pela gessagem. Mesmo apresentando uma elevada variação de seus valores, indicado pelo erro padrão, o teor de Fe apresentou pequena tendência de queda com a profundidade (Figura 12), com maior diferença entre os teores encontrados nas duas primeiras camadas para as demais. Esta distribuição ao longo das camadas pode ser explicada pelos maiores valores de COD e I na superfície, promovendo maior deslocamento de Fe para a solução.

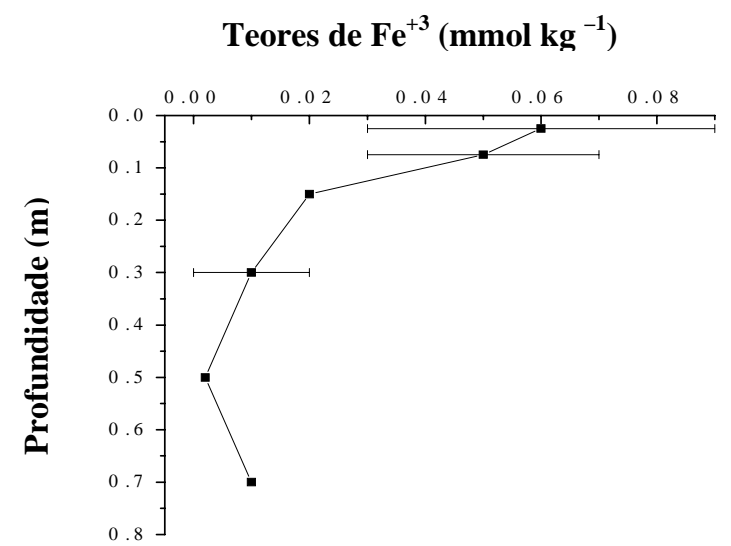

Figura 12 - Variação da concentração de $\mathrm{Fe}^{+3}$ na solução do solo nas profundidades de amostragem. Barras horizontais indicam o erro padrão da média 
Uma das preocupações com a realização da calagem superficial em SPD, principalmente na aplicação de altas doses em aplicação única, é a elevação exagerada do $\mathrm{pH}$ e conseqüente redução da disponibilidade de micronutrientes catiônicos, como o $\mathrm{Mn}$, gerando assim, vários questionamentos quanto à necessidade de parcelamento das doses. No entanto, a redução da disponibilidade deste elemento aos 58 meses após a realização da calagem, não se correlacionou com a forma de aplicação. Mas, por falta de informações ao longo deste período, não é possível avaliar o efeito da forma de aplicação, principalmente nos estágios iniciais. Pode-se afirmara apenas, que o efeito do calcário perdurou até no mínimo 58 meses, independentemente da forma que foi aplicado. Curtin \& Simillie (1983), avaliando a alteração da composição da solução da camada superficial de vários solos americanos incubados com $\mathrm{CaCO}_{3}$ durante uma semana, obtiveram redução dos teores de Mn na solução do solo nas amostras incubadas, ficando os teores abaixo de $0,005 \mathrm{mg} \mathrm{L}^{-1}$. 
Tabela 8. Valores de manganês na solução do solo em função das formas de aplicação do calcário

\begin{tabular}{|c|c|c|}
\hline Profundidade & Tratamento & Média* \\
\hline $\mathrm{m}$ & $\mathrm{tha}^{-1}$ & $\mu \mathrm{mol} \mathrm{kg}{ }^{-1}$ \\
\hline \multirow[t]{4}{*}{$0-0,05$} & Sem calcário & $3,2 \mathrm{a}$ \\
\hline & 4,5 em superfície parcelado $\left(1,5\right.$ ano $\left.^{-1}\right)$ & $0,8 \mathrm{~b}$ \\
\hline & 4,5 em superfície & $1,0 \mathrm{~b}$ \\
\hline & 4,5 incorporado & $1,0 \mathrm{~b}$ \\
\hline \multirow[t]{4}{*}{$0,05-0,1$} & Sem calcário & $1,4 \mathrm{a}$ \\
\hline & 4,5 em superfície parcelado $\left(1,5 \mathrm{ano}^{-1}\right)$ & $0,6 \mathrm{~b}$ \\
\hline & 4,5 em superfície & $0,7 \mathrm{~b}$ \\
\hline & 4,5 incorporado & $0,8 \mathrm{~b}$ \\
\hline \multirow[t]{4}{*}{$0,1-0,2$} & Sem calcário & $0,9 \mathrm{a}$ \\
\hline & 4,5 em superfície parcelado $\left(1,5 \mathrm{ano}^{-1}\right)$ & $0,6 \mathrm{a}$ \\
\hline & 4,5 em superfície & $1,2 \mathrm{a}$ \\
\hline & 4,5 incorporado & $0,3 \mathrm{a}$ \\
\hline \multirow[t]{4}{*}{$0,2-0,4$} & Sem calcário & $3,2 \mathrm{a}$ \\
\hline & 4,5 em superfície parcelado $\left(1,5 \mathrm{ano}^{-1}\right)$ & $1,6 \mathrm{a}$ \\
\hline & 4,5 em superfície & $1,4 \mathrm{a}$ \\
\hline & 4,5 incorporado & $1,2 \mathrm{a}$ \\
\hline \multirow[t]{4}{*}{$0,4-0,6$} & Sem calcário & $2,5 \mathrm{a}$ \\
\hline & 4,5 em superfície parcelado $\left(1,5 \mathrm{ano}^{-1}\right)$ & $3,5 \mathrm{a}$ \\
\hline & 4,5 em superfície & $1,9 \mathrm{a}$ \\
\hline & 4,5 incorporado & $2,2 \mathrm{a}$ \\
\hline \multirow[t]{4}{*}{$0,6-0,8$} & Sem calcário & $3,5 \mathrm{a}$ \\
\hline & 4,5 em superfície parcelado $\left(1,5 \mathrm{ano}^{-1}\right)$ & $3,2 \mathrm{a}$ \\
\hline & 4,5 em superfície & $3,2 \mathrm{a}$ \\
\hline & 4,5 incorporado & $3,3 \mathrm{a}$ \\
\hline
\end{tabular}

*Significativo pelo teste Tukey a 5\% . Médias seguidas pela mesma letra não diferem dentro de cada profundidade.

\subsection{5 Ânions na solução do solo}

A calagem não promoveu alteração na concentração dos ânions na solução do solo em nenhuma das profundidades amostradas (Figura 13). Cambri (2004) também não observou efeito da aplicação de calcário nos teores de ânions na solução de solos cultivados sob SPD na camada de 0-0,2 m. Schreffler (2003) registrou que a calagem causa aumento da concentração de nitrato e de sulfato na solução do solo, 
atribuído ao estímulo dos processos de mineralização após a adição carbonato de cálcio. Devido a esse estímulo à decomposição da $\mathrm{MO}$ nas camadas mais superficiais, $\mathrm{o} \mathrm{SO}_{4}{ }^{-2}$ pode ficar mais sujeito á lixiviação. Mesmo, não tendo ocorrido efeito da calagem, observa-se maior acúmulo de sulfato nas camadas de 0,2-0,4 e 0,4-0,6 m, como resultado da lixiviação deste ânion das camadas superficiais. Caires et al. (1999) observaram que, após 40 meses, a calagem reduziu os teores de $\mathrm{SO}_{4}^{-2}$ na camada de 00,05 $\mathrm{m}$ e os aumentou no subsolo (0,4-0,6 e 0,6-0,8 m). Em solos oxídicos, com propriedades anfóteras, o número e o sinal das cargas e o potencial elétrico de superfície são alteradas por práticas de manejo como a calagem e adubação fosfatada, modificando a capacidade de adsorção do $\mathrm{SO}_{4}{ }^{-2}$, com reflexos na sua disponibilidade e movimentação no perfil do solo (Dinya \& Camargo, 1995). A lixiviação de $\mathrm{SO}_{4}{ }^{-2}$ para camadas mais profundas é consequiência da competição pelos sítios de adsorção com fosfato e ânions orgânicos, maior recobrimento dos óxidos pela $\mathrm{MO}$, diminuindo a adsorção, $\mathrm{pH}$ mais elevado e menor CTA encontrados nas primeiras camadas.

A distribuição do $\mathrm{Cl}^{-}$possivelmente está relacionada ao seu fornecimento ao solo na adubação potássica como $\mathrm{KCl}$ e com sua dinâmica de movimentação no solo, ou seja, aumento da concentração na primeira camada com a adubações seguidas e ausência do revolvimento do solo, e lixiviação para a subsuperfície, onde acumula-se. Em termos de mobilidade no solo, $\mathrm{o} \mathrm{NO}_{3}^{-}$tem um comportamento muito similar ao do $\mathrm{Cl}^{-}$, com tendência de lixiviação para maiores profundidades. $\mathrm{O} \mathrm{NO}_{3}^{-}$apresentou distribuição muito semelhante à de COD e de MO do solo, devido à alta relação entre teor de $\mathrm{NO}_{3}^{-}$e a decomposição da MO. O método de extração da solução do solo usado neste trabalho não parece adequado para estudos da dinâmica de nitrato na solução do solo, devido principalmente às alterações do comportamento da MO (mineralização durante a extração), além do que, $\mathrm{o} \mathrm{NO}_{3}^{-}$é uma dos componentes da solução do solo que apresenta grande variação temporal em sua concentração, devido à grande dependência das condições climáticas. Portanto, métodos que coletam a solução diretamente no campo, como no uso de lisímetros, podem ser mais indicados.

$\mathrm{O} \mathrm{F} \mathrm{F}^{-}$e $\mathrm{PO}_{4}^{-3}$ ao contrário dos dois ânions anteriores, apresentam mobilidade muito menor no solo e grande interação com a fase sólida. A redução de F 
com o aumento da profundidade pode ser explicada pelo seu fornecimento via adubação fosfatada (contém F como impureza), que tende a se concentrar na superfície. Contrariamente ao $\mathrm{F}^{-},{\mathrm{o} \mathrm{PO}^{-3}}_{4}$ não apresentou diferença tão acentuada da primeira em relação às demais camadas. Seria esperado para esse nutriente, que seus teores em solução diminuíssem com o aumento da profundidade, pois no SPD, os maiores teores disponíveis de $\mathrm{P}$ encontram-se na camada mais superficial do solo. Contudo, apesar de pouco comum, pode ter ocorrido movimentação de fósforo no solo, intensificado pela forte competição com os ânions orgânicos pelos sítios de adsorção do solo e ao recobrimento dos óxidos pela MO, reduzindo a adsorção desse nutriente.

A aplicação de gesso eleva a concentração de $\mathrm{SO}_{4}{ }^{-2}$ na solução do solo (Alva \& Sumner, 1988). Isto foi confirmado com o aumento linear da concentração de sulfato na solução do solo até na profundidade de $0,6 \mathrm{~m}$ e de forma exponencial de 0,6-0,8 m (Figura 14). A aplicação de $1 \mathrm{t} \mathrm{ha}^{-1}$ elevou a concentração de sulfato em 0,34 ; 0,$6 ; 0,7 ; 1,81$ e $2,19 \mathrm{mmol} \mathrm{kg}^{-1}$ nas camadas de $0-0,05 ; 0,05-0,1 ; 0,1-0,2 ; 0,2-0,4$ e $0,4-$ 0,6 m, respectivamente. $\mathrm{Na}$ camada de 0,6-0,8 $\mathrm{m}$, foram observados incrementos significativos na concentração de sulfato somente a partir da penúltima dose aplicada. Caires et al. (1999) também observaram o incremento de $\mathrm{SO}_{4}{ }^{-2}$ em todo o perfil do solo com a aplicação de gesso e com maior acúmulo nas profundidades de 0,4-0,6 e 0,6-0,8 m. Deve-se destacar o efeito residual da aplicação de gesso, que mesmo após 55 meses de sua aplicação, continuou a incrementar os teores de sulfato na solução do solo. 


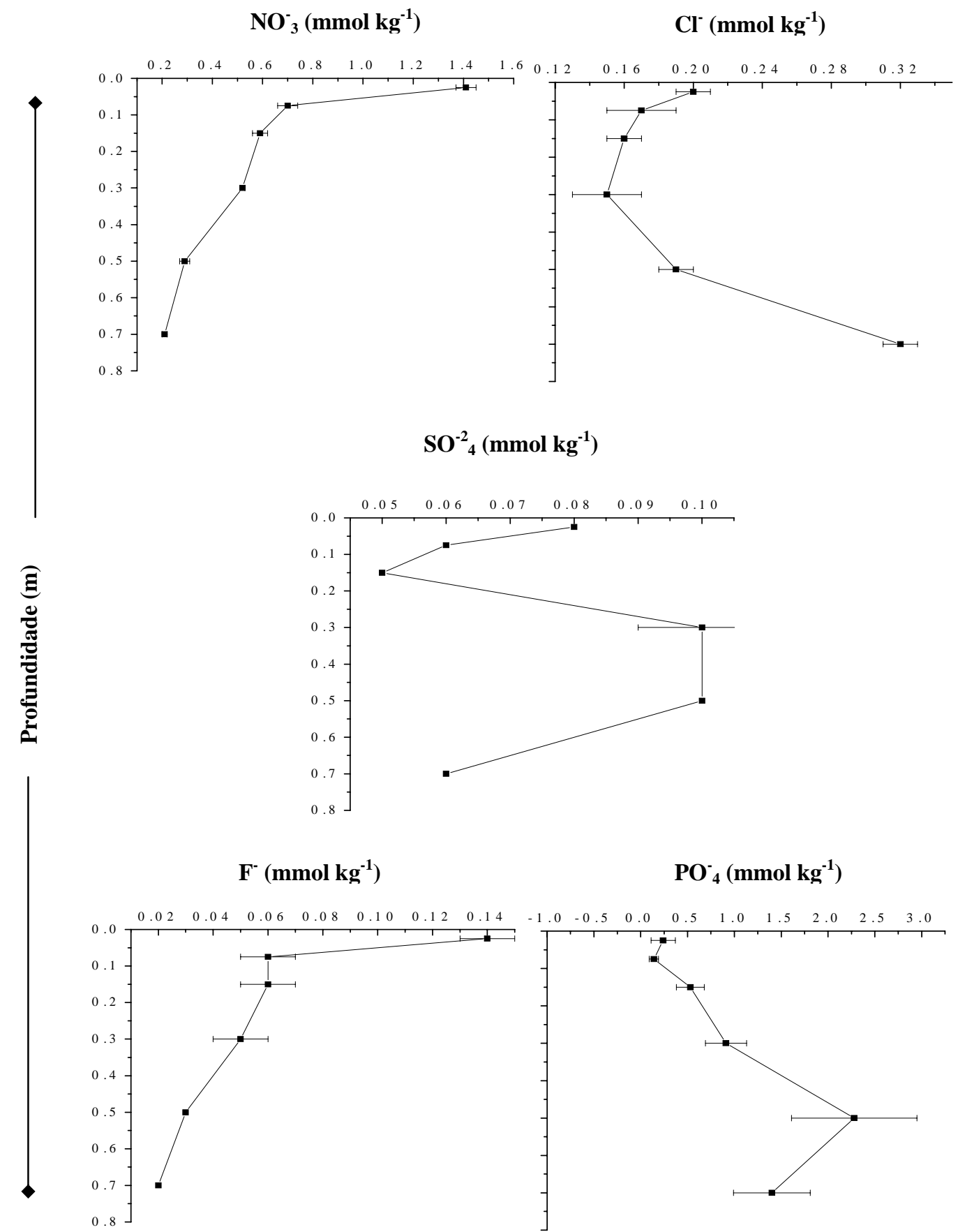

Figura 13 - Variação dos teores de ânions analisados na solução do solo, nas profundidades de amostragem. Barras horizontais indicam o erro padrão 

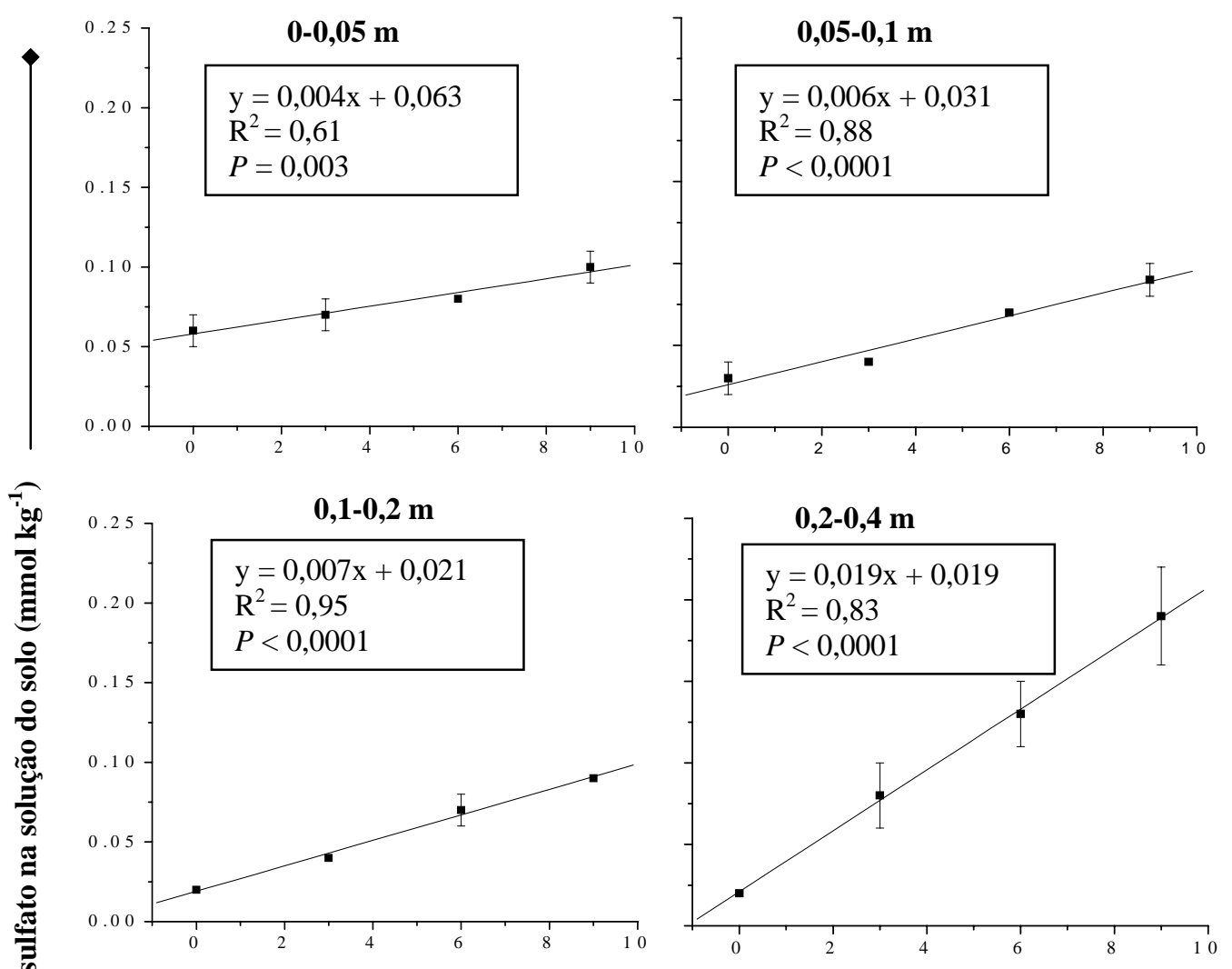

ปัن
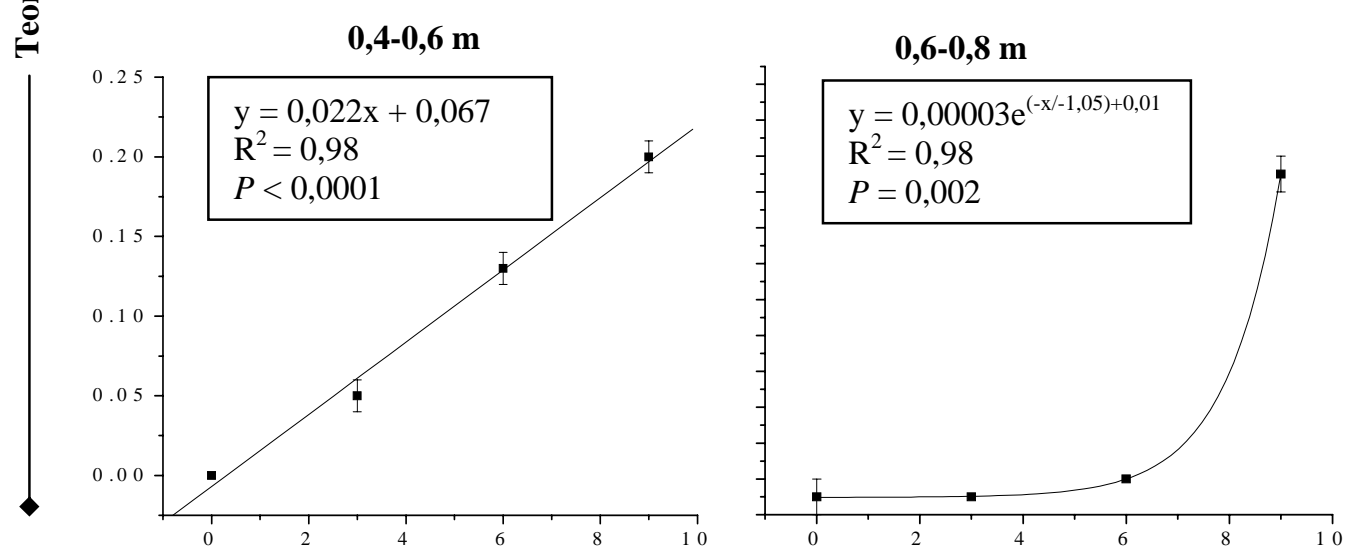

Dose de gesso em superfície (t ha $\left.{ }^{-1}\right)$

Dose de gesso em superfície (t ha ${ }^{-1}$ )

Figura 14 - Variação nos teores de sulfato na solução do solo nas diferentes profundidades em função da aplicação de gesso em superfície. Barras verticais indicam o erro padrão da média 


\subsection{Especiação iônica dos elementos na solução do solo}

\subsubsection{Distribuição das espécies de alumínio}

A forma $\mathrm{Al}^{+3}$, considerada mais tóxica as plantas, esteve presente em baixas porcentagens, no máximo 5,5\% das espécies, mesmo no tratamento que não recebeu calagem ou gessagem (Tabelas 9, 10 e 11). Esta espécie foi de maior ocorrência nas duas primeiras camadas, devido aos maiores teores de $\mathrm{Al}^{+3}$. A espécie Al-COD foi, na média dos tratamentos, a espécie predominante até $0,4 \mathrm{~m}$, camada que concentra a maioria do sistema radicular das culturas de interesse agrícola. Abaixo desta profundidade passou a alternar com Al-F na predominância de ligação com o Al.

A complexação do $\mathrm{Al}$ pelo $\mathrm{F}^{-}$é de fundamental importância, principalmente em condições de acidez elevada $(\mathrm{pH}<4,8)$ devido à baixa toxicidade da espécie formada (Alva \& Summer, 1988). É importante salientar a magnitude de complexação do Al pelo F na solução do solo sob SPD encontrado no presente estudo. O $\mathrm{F}^{-}$apresentou papel muito mais importante do que o sulfato, que é o ânion considerado o principal responsável pela amenização da toxicidade do $\mathrm{Al}$, principalmente após aplicação de gesso.

A participação intensa do $\mathrm{F}^{-}$na complexação do $\mathrm{Al}$ poderia ser indicativo de ocorrência de contaminação na área do experimento, ou durante a obtenção da solução do solo. No entanto, os teor médio de $\mathrm{F}^{-}$encontrado nas as amostras foi de $1,5 \mathrm{mg} \mathrm{L}^{-1}$, o qual está bem próximo do normalmente presente em condições naturais, ao redor de $1 \mathrm{mg} \mathrm{L}^{-1}$, e bem abaixo dos teores de áreas consideradas como poluídas (10 mg L $\mathrm{m}^{-1}$ ) (Noemmik, 1953). A principal entrada de F nos sistemas agrícolas é por meio da aplicação de superfosfatos, mas possíveis efeitos nas plantas são geralmente insignificantes, já que a concentração é pequena (Adriano, 1986).

No SPD, ânions orgânicos apresentam papel fundamental na química do Al (Salet, 1998), sendo os principais responsáveis pela redução da atividade do Al na solução do solo. O COD, juntamente com $\mathrm{F}^{-}$, apresentam o maior papel na complexação do Al em águas naturais (Shamshuddin, 2004). Cambri (2004) encontrou no SPD que a 
proporção Al-COD na solução do solo era de aproximadamente de $85 \%$, e esta distribuição foi pouco afetada pela calagem superficial.

Tabela 9. Porcentagem das espécies de alumínio na solução do solo, em função das formas de aplicação do calcário

\begin{tabular}{|c|c|c|c|c|c|c|}
\hline Tratamento* & $\mathrm{Al}^{+3}$ & $\mathrm{Al}-\mathrm{OH}$ & $\mathrm{AlSO}_{4}^{+}$ & $\mathrm{Al}-\mathrm{H}_{2} \mathrm{PO}_{4}$ & Al-F & Al-COD \\
\hline & \multicolumn{6}{|c|}{ 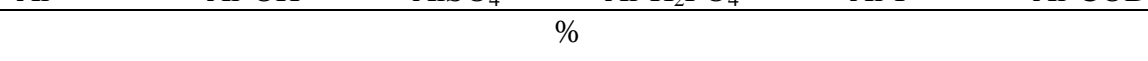 } \\
\hline & \multicolumn{6}{|c|}{$0-0,05 \mathrm{~m}$} \\
\hline $\mathrm{T} 1$ & 0,7 & 0,8 & 0,1 & $<0,1$ & 29,8 & 68,4 \\
\hline $\mathrm{T} 2$ & 0,3 & 25,1 & $<0,1$ & - & 33,4 & 40,8 \\
\hline $\mathrm{T} 3$ & 0,4 & 18,2 & $<0,1$ & - & 35,0 & 46,2 \\
\hline \multirow[t]{2}{*}{$\mathrm{T} 4$} & 3,4 & 22,8 & 0,3 & - & 9,9 & 61,8 \\
\hline & \multicolumn{6}{|c|}{$0,05-0,1 \mathrm{~m}$} \\
\hline $\mathrm{T} 1$ & 1,1 & 0,8 & 0,1 & $<0,1$ & 10,3 & 87,4 \\
\hline $\mathrm{T} 2$ & 0,8 & 5,6 & 0,1 & - & 6,9 & 86,3 \\
\hline T3 & 1,0 & 1,7 & 0,2 & $<0,1$ & 16,5 & 80,4 \\
\hline \multirow[t]{2}{*}{$\mathrm{T} 4$} & 2,8 & 8,1 & 0,2 & - & 5,4 & 83,2 \\
\hline & \multicolumn{6}{|c|}{$0,1-0,2 \mathrm{~m}$} \\
\hline $\mathrm{T} 1$ & 0,2 & 0,2 & $<0,1$ & - & 38,7 & 60,6 \\
\hline $\mathrm{T} 2$ & 0,3 & 0,3 & $<0,1$ & - & 28,8 & 70,4 \\
\hline T3 & 0,2 & 0,2 & $<0,1$ & - & 39,4 & 59,9 \\
\hline \multirow[t]{2}{*}{$\mathrm{T} 4$} & 1,5 & 2,9 & 0,19 & - & 10,9 & 84,3 \\
\hline & \multicolumn{6}{|c|}{$0,2-0,4 \mathrm{~m}$} \\
\hline $\mathrm{T} 1$ & 0,2 & 0,2 & $<0,1$ & - & 38,7 & 60,6 \\
\hline $\mathrm{T} 2$ & 0,0 & $<0,1$ & $<0,1$ & - & 92,1 & 7,7 \\
\hline T3 & 0,0 & $<0,1$ & - & - & 94,2 & 5,6 \\
\hline \multirow[t]{2}{*}{$\mathrm{T} 4$} & 0,3 & 0,3 & 0,1 & - & 30,7 & 68,5 \\
\hline & \multicolumn{6}{|c|}{$0,4-0,6 \mathrm{~m}$} \\
\hline $\mathrm{T} 1$ & $<0,1$ & $<0,1$ & $<0,1$ & - & 85,4 & 14,4 \\
\hline $\mathrm{T} 2$ & 0,1 & 0,2 & $<0,1$ & $<0,1$ & 53,8 & 45,7 \\
\hline $\mathrm{T} 3$ & $<0,1$ & $<0,1$ & $<0,1$ & - & 82,8 & 17,0 \\
\hline \multirow[t]{2}{*}{$\mathrm{T} 4$} & $<0,1$ & $<0,1$ & $<0,1$ & - & 79,3 & 20,5 \\
\hline & \multicolumn{6}{|c|}{$0,6-0,8 \mathrm{~m}$} \\
\hline $\mathrm{T} 1$ & 0,1 & $<0,1$ & $<0,1$ & - & 64,0 & 35,7 \\
\hline $\mathrm{T} 2$ & 0,1 & 0,2 & $<0,1$ & $<0,1$ & 50,0 & 49,5 \\
\hline $\mathrm{T} 3$ & 0,3 & 0,3 & 0,1 & - & 16,3 & 82,8 \\
\hline $\mathrm{T} 4$ & 0,2 & 0,2 & $<0,1$ & - & 36,7 & 62,8 \\
\hline
\end{tabular}


Adams et al. (1999) verificaram em solos ácidos da Nova Zelândia que o Al ligado ao COD se correlacionou fortemente com a concentração de substâncias húmicas dissolvidas. No SPD, com o aumento dos teores de MO no solo e conseqüente aumento da fração em solução da MO, o Al-COD também aumenta.

A proporção de Al-COD é variável ao longo do ano agrícola, porque tal complexação é estritamente dependente da presença da fração mais reativa da MO na solução, que por sua vez depende da atividade microbiana (Shamshuddin et al., 2004). Espera-se que ao longo de um ano agrícola, a fração Al-COD ocorra em maior proporção no verão (época de maior temperatura e umidade), do que na estação seca ou em períodos de veranicos, quando a participação de ânions inorgânicos pode apresentar maior relevância.

Os ligantes orgânicos apresentam grande variação na estabilidade do complexo com alumínio, devido às diferenças estruturais e de grupos funcionais (Salet, 1998). No entanto, no presente trabalho, não foi realizado o fracionamento dos tipos de ligantes orgânicos presentes na solução do solo, sendo apenas determinado o COD total, sem distinção entre ligantes de baixa ou alta massa molecular. Salet (1998) encontrou que os ligantes orgânicos de alta massa molecular (ácido fúlvico) foram os principais componentes orgânicos responsáveis pela redução da toxidez do Al no SPD. Resultados semelhantes foram encontrados por Cambri (2004), com aproximadamente $80 \%$ do $\mathrm{Al}$ complexado com ácidos orgânicos de alta massa molecular. Em Espodossolos sob floresta, Hess et al. (2000) observaram que cerca de $80 \%$ do Al presente na solução do solo estavam complexados com ânions orgânicos e que somente 5 a $29 \%$ estavam ligados a ânions de baixa massa molecular. Portanto, acredita-se que, no presente trabalho, a maior parte do Al-COD também esteja representada pela fração do Al ligado a ânions de elevada massa molecular. 
A calagem, devido ao aumento do $\mathrm{pH}$ da solução, principalmente na primeira camada, promoveu aumento das formas hidroxiladas de Al (Al-OH), consideradas menos tóxicas aos vegetais do que a forma livre $\left(\mathrm{Al}^{+3}\right)$ (Tabela 9). A faixa de variação do $\mathrm{pH}$ nesta camada foi de menor valor para a testemunha ( $\mathrm{pH} 4,1)$ e maior para o calcário aplicado em superfície e parcelado em três anos (T2) ( $\mathrm{pH} \mathrm{6,1),} \mathrm{que}$ corresponderam respectivamente aos menores e maiores concentrações de $\mathrm{Al}-\mathrm{OH}$. As hidroxilas competem de forma intensa com outros ânions inorgânicos para complexarem o $\mathrm{Al}$ e em valores de $\mathrm{pH}$ 5,5 ou maiores, competem com sucesso com o $\mathrm{F}^{-}$pelo $\mathrm{Al}$ (Shamshuddin et al., 2004). Esses mesmos autores, com uso de regressão linear do tipo stepwise, verificaram que o pH da solução e a concentração total de F explicaram $91 \%$ da variação na concentração dos complexos Al-F.

$\mathrm{O} \mathrm{Al}-\mathrm{SO}_{4}$ e Al- $\mathrm{H}_{2} \mathrm{PO}_{4}$ encontraram-se em proporção muito menor. Tanto o sulfato como o fosfato apresentam valores de constantes de ligação muito próximas, contudo, bem menores do que o par Al-F. Esses complexos seguem a ordem decrescente de estabilidade $\mathrm{AlF}^{2+}>\mathrm{AlH}_{2} \mathrm{PO}_{4}{ }^{2+}>\mathrm{AlSO}_{4}{ }^{+}$com valores de $\log \mathrm{K}^{0}$ iguais a 6,98, 3,50 e 3,10, respectivamente (Lindsay \& Walthall, 1995). Conseqüentemente, o sulfato e o fosfato ligaram-se em pequena proporção com o Al. Em muitos casos, o par iônico entre alumínio e fosfato praticamente não existiu, devido à concentração muito baixa de fosfato na solução do solo. Tanto o sulfato como o fosfato, para as condições deste estudo, apresentaram pouca influência no comportamento do Al. 
Tabela 10. Porcentagem das espécies de alumínio na solução do solo, em função da dose de gesso

\begin{tabular}{|c|c|c|c|c|c|c|}
\hline Dose de gesso & $\mathrm{Al}^{+3}$ & $\mathrm{Al}-\mathrm{OH}$ & $\mathrm{Al}-\mathrm{SO}_{4}{ }^{+}$ & $\mathrm{Al}-\mathrm{H}_{2} \mathrm{PO}_{4}$ & $\mathrm{Al}-\mathrm{F}$ & $\mathrm{Al}-\mathrm{COD}$ \\
\hline $\mathrm{t} \mathrm{ha}^{-1}$ & \multicolumn{6}{|c|}{$\%$} \\
\hline & \multicolumn{6}{|c|}{$0-0,05 \mathrm{~m}$} \\
\hline 0 & 0,7 & 0,7 & 0,1 & $<0,1$ & 29,8 & 68,4 \\
\hline 3 & 5,4 & 3,4 & 0,8 & - & 14,3 & 75,9 \\
\hline 6 & 2,3 & 1,5 & 0,5 & - & 19,6 & 75,9 \\
\hline \multirow[t]{2}{*}{9} & 1,1 & 4,0 & 0,2 & $<0,1$ & 28,0 & 66,5 \\
\hline & \multicolumn{6}{|c|}{$0,05-0,1 \mathrm{~m}$} \\
\hline 0 & 1,1 & 0,8 & 0,1 & $<0,1$ & 10,3 & 87,4 \\
\hline 3 & 0,9 & 0,4 & 0,1 & - & 12,3 & 86,1 \\
\hline 6 & 1,6 & 0,9 & 0,2 & - & 9,5 & 87,6 \\
\hline \multirow{2}{*}{9} & 1,0 & 0,7 & 0,2 & - & 12,5 & 85,4 \\
\hline & \multicolumn{6}{|c|}{$0,1-0,2 \mathrm{~m}$} \\
\hline 0 & 0,2 & 0,2 & $<0,1$ & - & 38,7 & 60,6 \\
\hline 3 & 0,7 & 0,2 & $<0,1$ & - & 17,8 & 81,0 \\
\hline 6 & 0,3 & 0,1 & $<0,1$ & - & 48,1 & 51,2 \\
\hline \multirow[t]{2}{*}{9} & 0,3 & 0,2 & $<0,1$ & - & 36,8 & 62,4 \\
\hline & \multicolumn{6}{|c|}{$0,2-0,4 \mathrm{~m}$} \\
\hline 0 & 0,2 & $<0,1$ & $<0,1$ & - & 65,0 & 34,8 \\
\hline 3 & 0,1 & $<0,1$ & $<0,1$ & - & 69,7 & 29,9 \\
\hline 6 & $<0,1$ & $<0,1$ & $<0,1$ & - & 89,8 & 10,0 \\
\hline \multirow[t]{2}{*}{9} & $<0,1$ & $<0,1$ & $<0,1$ & - & 94,6 & 5,2 \\
\hline & \multicolumn{6}{|c|}{$0,4-0,6 \mathrm{~m}$} \\
\hline 0 & $<0,1$ & $<0,1$ & $<0,1$ & $<0,1$ & 85,4 & 14,4 \\
\hline 3 & $<0,1$ & $<0,1$ & $<0,1$ & $<0,1$ & 81,2 & 18,6 \\
\hline 6 & $<0,1$ & $<0,1$ & $<0,1$ & - & 92,5 & 7,3 \\
\hline \multirow[t]{2}{*}{9} & $<0,1$ & $<0,1$ & $<0,1$ & $<0,1$ & 87,3 & 12,4 \\
\hline & \multicolumn{6}{|c|}{$0,6-0,8 \mathrm{~m}$} \\
\hline 0 & 0,1 & $<0,1$ & $<0,1$ & - & 64,0 & 35,7 \\
\hline 3 & 0,1 & 0,1 & - & - & 58,6 & 41,1 \\
\hline 6 & $<0,1$ & $<0,1$ & - & $<0,1$ & 82,7 & 17,1 \\
\hline 9 & $<0,1$ & 0,1 & $<0,1$ & $<0,1$ & 80,3 & 19,3 \\
\hline
\end{tabular}

Em comparação ao tratamento com apenas aplicação de calcário, na primeira camada, a aplicação de gesso ocasionou pequeno incremento da participação da 
espécie $\mathrm{Al}_{-} \mathrm{SO}_{4}{ }^{+}$, especialmente para das doses de 3 e $6 \mathrm{t} \mathrm{ha}^{-1}$. A forma de $\mathrm{Al}$ complexado com o $\mathrm{SO}_{4}^{-2}$ não é tóxico aos vegetais (Pavan et al., 1982). Conseqüentemente, em $\mathrm{pH}$ menores do que 4,8, este par iônico parece ser o principal responsável pela amenização da toxicidade de Al quando é aplicado o gesso (Alva \& Sumner, 1988). No entanto, essa destacada participação do $\mathrm{SO}_{4}^{-2}$ não foi observada, sendo o COD e o $\mathrm{F}^{-}$em maior ou menor magnitude, os maiores responsáveis pela complexação do $\mathrm{Al}$, dependendo da profundidade avaliada.

Quando foi aplicado apenas gesso, em relação à aplicação exclusiva de calcário, a principal alteração foi a redução da proporção ocupada pelas espécies hidroxiladas de Al. O pH do solo tem importante papel na formação de pares iônicos ou na precipitação do Al (Alva \& Sumner, 1988). Conseqüentemente, a magnitude da amenização da toxicidade de $\mathrm{Al}$ pelo gesso é dependente do pH da solução do solo.

A combinação de aplicação de calcário e gesso, também não alterou em grande intensidade a distribuição das espécies, em relação à aplicação exclusiva de cada um (Tabela 11), pois os principais ligantes do $\mathrm{Al}$ (COD e $\mathrm{F}^{-}$) não foram influenciados pelos tratamentos. O que parece, dentre as espécies de Al formadas na solução do solo, as formas hidroxiladas, de $\mathrm{Al}$ são as mais sensíveis às práticas de manejo, devido à sua correlação com o pH do solo. 
Tabela 11. Porcentagem das espécies de alumínio na solução do solo, em função da dose de gesso no tratamento $4,5 \mathrm{t} \mathrm{ha}^{-1}$ de calcário em superfície (aplicação única)

\begin{tabular}{|c|c|c|c|c|c|c|}
\hline Dose de gesso & $\mathrm{Al}^{+3}$ & $\mathrm{Al}-\mathrm{OH}$ & $\mathrm{Al}-\mathrm{SO}_{4}$ & Al- $\mathrm{H}_{2} \mathrm{PO}_{4}$ & Al-F & $\mathrm{Al}-\mathrm{COD}$ \\
\hline $\mathrm{t} \mathrm{ha}^{-1}$ & \multicolumn{6}{|c|}{$\%$} \\
\hline & \multicolumn{6}{|c|}{$0-0,05 \mathrm{~m}$} \\
\hline 0 & 0,4 & 18,2 & $<0,1$ & - & 35,0 & 46,2 \\
\hline 3 & 0,5 & 5,9 & 0,1 & $<0,1$ & 37,9 & 55,2 \\
\hline 6 & 0,6 & 37,9 & 0,1 & - & 21,6 & 39,6 \\
\hline \multirow[t]{2}{*}{9} & 0,4 & 25,4 & 0,1 & $<0,1$ & 32,2 & 41,7 \\
\hline & \multicolumn{6}{|c|}{$0,05-0,1 \mathrm{~m}$} \\
\hline 0 & 1,0 & 1,7 & 0,2 & $<0,1$ & 16,5 & 80,4 \\
\hline 3 & 1,0 & 1,1 & 0,1 & - & 17,4 & 80,2 \\
\hline 6 & 1,3 & 2,3 & 0,2 & - & 15,8 & 80,1 \\
\hline \multirow[t]{2}{*}{9} & 0,9 & 3,7 & 0,2 & - & 16,4 & 78,7 \\
\hline & \multicolumn{6}{|c|}{$0,1-0,2 \mathrm{~m}$} \\
\hline 0 & 0,2 & 0,2 & $<0,1$ & $<0,1$ & 39,4 & 59,9 \\
\hline 3 & 0,2 & 0,1 & $<0,1$ & $<0,1$ & 53,7 & 45,7 \\
\hline 6 & 0,6 & 0,3 & 0,1 & 0,3 & 3,37 & 95,4 \\
\hline \multirow[t]{2}{*}{9} & 0,3 & 0,3 & 0,1 & 0,3 & 42,1 & 57,0 \\
\hline & \multicolumn{6}{|c|}{$0,2-0,4 \mathrm{~m}$} \\
\hline 0 & $<0,1$ & $<0,1$ & $<0,1$ & - & 94,2 & 5,6 \\
\hline 3 & $<0,1$ & $<0,1$ & $<0,1$ & - & 94,3 & 5,6 \\
\hline 6 & $<0,1$ & $<0,1$ & $<0,1$ & - & 95,8 & 4,1 \\
\hline \multirow[t]{2}{*}{9} & $<0,1$ & $<0,1$ & $<0,1$ & - & 93,2 & 6,6 \\
\hline & \multicolumn{6}{|c|}{$0,4-0,6 \mathrm{~m}$} \\
\hline 0 & $<0,1$ & $<0,1$ & $<0,1$ & - & 82,8 & 17,0 \\
\hline 3 & $<0,1$ & $<0,1$ & $<0,1$ & $<0,1$ & 77,9 & 21,9 \\
\hline 6 & $<0,1$ & $<0,1$ & $<0,1$ & $<0,1$ & 85,8 & 13,9 \\
\hline \multirow[t]{2}{*}{9} & $<0,1$ & $<0,1$ & $<0,1$ & $<0,1$ & 90,9 & 8,9 \\
\hline & \multicolumn{6}{|c|}{$0,6-0,8 \mathrm{~m}$} \\
\hline 0 & 0,3 & 0,2 & 0,1 & - & 16,3 & 82,8 \\
\hline 3 & 0,1 & $<0,1$ & $<0,1$ & - & 66,3 & 33,4 \\
\hline 6 & 0,1 & 0,1 & $<0,1$ & $<0,1$ & 69,3 & 30,3 \\
\hline 9 & $<0,1$ & $<0,1$ & $<0,1$ & - & 89,1 & 10,6 \\
\hline
\end{tabular}




\subsubsection{Distribuição das espécies de cálcio}

A forma livre $\mathrm{Ca}^{+2}$ foi a predominante até a camada de $0,1 \mathrm{~m}$, seguida pelo Ca ligado ao carbono orgânico dissolvido (Ca-COD) (Tabelas 12, 13 e 14). Nas demais profundidades, em quase todos os tratamentos, o Ca-COD superou a concentração de sua forma livre. Esta alteração pode ser explicada pela queda acentuada dos teores de $\mathrm{Ca}^{+2}$ na solução do solo com o aumento da profundidade, e a manutenção de concentrações relativamente elevadas de COD, além de menor competição de outros cátions, por exemplo, o Al, pela ligação com COD. Este fato realça a importância do COD na dinâmica de cátions no SPD, principalmente quanto à alteração no potencial de movimentação desses cátions ao longo do perfil do solo. Até $0,2 \mathrm{~m}$, a incorporação do calcário elevou a participação da forma livre de Ca e reduziu a porcentagem combinada com ânions orgânicos (Ca-COD).

O Ca forma complexos na solução do solo com vários ânions inorgânicos $\left(\mathrm{F}^{-}, \mathrm{NO}_{3}^{-}, \mathrm{Cl}^{-}, \mathrm{SO}_{4}^{-2}, \mathrm{PO}_{4}^{-3}\right)$ (Lindsay, 1979), e dentre os ânions inorgânicos, o $\mathrm{SO}_{4}^{-2}$ foi o par iônico em maior proporção com o cálcio. Os resultados de complexação de Ca com ânions inorgânicos estão de acordo com Chaves et al. (1991), ou seja, o $\mathrm{NO}_{3}^{-}, \mathrm{Cl}^{-} \mathrm{e}$ $\mathrm{o} \mathrm{SO}_{4}^{-2}$ são os principais ligantes inorgânicos do $\mathrm{Ca}$ em solução, porque estão na composição da maioria dos fertilizantes de uso agrícola. A ligação de Ca com ânions inorgânicos segue a seguinte ordem de estabilidade: $\mathrm{SO}_{4}^{-2}>\mathrm{Cl}>\mathrm{NO}_{3}^{-}$. A estabilidade do complexo formado é dependente da atividade dos ânions em solução (Lindsay, 1979). A formação desses pares iônicos, além de atuar diretamente na mobilidade do cálcio (lixiviação), interfere na disponibilidade aos vegetais. Com esses pareamentos iônicos, o potencial químico ou a disponibilidade real do íon são diminuídos. Isso foi confirmado por Chaves et al. (1991), que concluíram que a absorção de Ca pelas raízes de cafeeiro diminuiu com a redução da sua valência, obtendo-se a seguinte ordem de absorção: $\mathrm{Ca}^{+2}>\mathrm{CaNO}_{3}{ }^{+}>\mathrm{CaCl}^{+}>\mathrm{CaSO}_{4}{ }^{0}$.

A gessagem, mesmo elevando os teores de $\mathrm{SO}^{-2}{ }_{4}$ na solução do solo, não conferiu incrementos significativos na porcentagem do $\mathrm{CaSO}_{4}{ }^{0}$, que apresentou 
distribuição constante ao longo dos tratamentos e das profundidades de amostragem. A calagem, gessagem ou aplicação conjunta não apresentaram efeitos evidentes na distribuição das espécies de cálcio, sendo as mudanças mais notadas na comparação entre as profundidades. Por exemplo, o $\mathrm{Ca}$ ligado ao nitrato apresentou maior participação na primeira camada, enquanto e o Ca-COD apresentou maior concentração nas maiores profundidades. A forma livre por sua vez diminuiu com o aprofundamento no perfil do solo.

\subsubsection{Distribuição das espécies de magnésio}

Ao contrário do observado para o $\mathrm{Ca}$, a proporção de $\mathrm{Mg}$ livre foi muito maior do que a sua associação com ânions orgânicos e principalmente inorgânicos (Tabelas 15, 16 e 17). Dos ânions inorgânicos, o nitrato não formou par iônico em proporções significativas com o Mg, indicando pouca participação na movimentação em profundidade deste nutriente. Ânions orgânicos devem apresentar contribuição significativa ao movimento de $\mathrm{Mg}$, pois foram os componentes da solução do solo que se combinaram em maior proporção com este cátion ao longo de todas as profundidades estudadas.

O ânion inorgânico que possivelmente apresente maior participação na movimentação do $\mathrm{Mg}$ é o $\mathrm{SO}_{4}^{-2}$, o que pode explicar a intensificação da lixiviação de $\mathrm{Mg}$ quando é aplicado gesso no solo. O par iônico $\mathrm{MgSO}_{4}{ }^{0}$ contribui significativamente para a concentração total deste cátion em solução quando a concentração $\mathrm{SO}^{-2}{ }_{4}$ aumenta até acima de $10^{-4} \mathrm{~mol} \mathrm{~L}^{-1}$ (Lindsay, 1979). Segundo este autor, os complexos de $\mathrm{Mg}$ com $\mathrm{Cl}^{-}$e $\mathrm{NO}_{3}^{-}$apresentam constantes de estabilidade semelhantes, mas ocuparão proporções insignificantes para as concentrações normalmente encontradas desses dois ânions em solução. 
Tabela 12. Porcentagem das espécies de cálcio na solução do solo, em função das formas de aplicação do calcário

\begin{tabular}{|c|c|c|c|c|c|}
\hline Tratamento* & $\mathrm{Ca}^{+2}$ & $\mathrm{Ca}-\mathrm{COD}$ & $\mathrm{CaNO}_{3}^{+}$ & $\mathrm{CaCl}^{+}$ & $\mathrm{CaSO}^{0}{ }_{4}$ \\
\hline & \multicolumn{5}{|c|}{$\%$} \\
\hline & \multicolumn{5}{|c|}{$0-0,05 \mathrm{~m}$} \\
\hline $\mathrm{T} 1$ & 58,3 & 40,9 & 0,1 & $<0,1$ & 0,5 \\
\hline $\mathrm{T} 2$ & 51,9 & 47,4 & 0,1 & $<0,1$ & 0,4 \\
\hline $\mathrm{T} 3$ & 53,7 & 45,6 & 0,1 & $<0,1$ & 0,4 \\
\hline \multirow[t]{2}{*}{$\mathrm{T} 4$} & 86,1 & 13,1 & 0,2 & $<0,1$ & 0,4 \\
\hline & \multicolumn{5}{|c|}{$0,05-0,1 \mathrm{~m}$} \\
\hline $\mathrm{T} 1$ & 65,2 & 34,2 & 0,1 & $<0,1$ & 0,3 \\
\hline $\mathrm{T} 2$ & 57,6 & 41,8 & $<0,1$ & $<0,1$ & 0,4 \\
\hline $\mathrm{T} 3$ & 62,4 & 36,7 & 0,1 & $<0,1$ & 0,5 \\
\hline \multirow[t]{2}{*}{$\mathrm{T} 4$} & 80,8 & 18,7 & $<0,1$ & $<0,1$ & 0,3 \\
\hline & \multicolumn{5}{|c|}{$0,1-0,2 \mathrm{~m}$} \\
\hline $\mathrm{T} 1$ & 42,2 & 57,4 & $<0,1$ & $<0,1$ & 0,2 \\
\hline $\mathrm{T} 2$ & 39,5 & 60,0 & $<0,1$ & $<0,1$ & 0,2 \\
\hline $\mathrm{T} 3$ & 39,9 & 59,6 & $<0,1$ & $<0,1$ & 0,2 \\
\hline \multirow[t]{2}{*}{$\mathrm{T} 4$} & 70,6 & 28,8 & 0,1 & $<0,1$ & 0,3 \\
\hline & \multicolumn{5}{|c|}{$0,2-0,4 \mathrm{~m}$} \\
\hline $\mathrm{T} 1$ & 37.9 & 61.6 & $<0,1$ & 0.04 & 0.3 \\
\hline $\mathrm{T} 2$ & 33,6 & 65,6 & $<0,1$ & $<0,1$ & 0,7 \\
\hline $\mathrm{T} 3$ & 38,2 & 61,0 & $<0,1$ & $<0,1$ & 0,6 \\
\hline \multirow[t]{2}{*}{$\mathrm{T} 4$} & 41,3 & 58,0 & $<0,1$ & $<0,1$ & 0,5 \\
\hline & \multicolumn{5}{|c|}{$0,4-0,6 \mathrm{~m}$} \\
\hline $\mathrm{T} 1$ & 34,9 & 64,6 & $<0,1$ & $<0,1$ & 0,3 \\
\hline $\mathrm{T} 2$ & 31,9 & 67,5 & $<0,1$ & $<0,1$ & 0,4 \\
\hline $\mathrm{T} 3$ & 37,5 & 61,7 & $<0,1$ & $<0,1$ & 0,5 \\
\hline \multirow[t]{2}{*}{$\mathrm{T} 4$} & 37,0 & 62,4 & $<0,1$ & $<0,1$ & 0,4 \\
\hline & \multicolumn{5}{|c|}{$0,6-0,8 \mathrm{~m}$} \\
\hline $\mathrm{T} 1$ & 36,0 & 63,6 & $<0,1$ & $<0,1$ & 0,2 \\
\hline $\mathrm{T} 2$ & 31,6 & 67,9 & $<0,1$ & $<0,1$ & 0,4 \\
\hline $\mathrm{T} 3$ & 39,0 & 60,2 & $<0,1$ & $<0,1$ & 0,7 \\
\hline $\mathrm{T} 4$ & 36,0 & 63,5 & $<0,1$ & $<0,1$ & 0,3 \\
\hline
\end{tabular}


Tabela 13. Porcentagem das espécies de cálcio na solução do solo, em função da dose de gesso

\begin{tabular}{|c|c|c|c|c|c|}
\hline Dose de gesso & $\mathrm{Ca}^{+2}$ & $\mathrm{Ca}-\mathrm{COD}$ & $\mathrm{CaNO}_{3}^{+}$ & $\mathrm{CaCl}^{+}$ & $\mathrm{CaSO}_{4}{ }_{4}$ \\
\hline \multirow[t]{2}{*}{$\mathrm{t} \mathrm{ha}^{-1}$} & \multicolumn{5}{|c|}{$\%$} \\
\hline & \multicolumn{5}{|c|}{$0-0,05 \mathrm{~m}$} \\
\hline 0 & 58,3 & 40,9 & 0,1 & $<0,1$ & 0,5 \\
\hline 3 & 88,7 & 10,2 & 0,3 & $<0,1$ & 0,6 \\
\hline 6 & 79,0 & 19,8 & 0,2 & $<0,1$ & 0,7 \\
\hline \multirow[t]{2}{*}{9} & 68,0 & 31,0 & 0,2 & $<0,1$ & 0,6 \\
\hline & \multicolumn{5}{|c|}{$0,05-0,1 \mathrm{~m}$} \\
\hline 0 & 65,2 & 34,2 & $<0,1$ & $<0,1$ & 0,3 \\
\hline 3 & 61,0 & 38,4 & $<0,1$ & $<0,1$ & 0,3 \\
\hline 6 & 71,2 & 28,1 & 0,1 & $<0,1$ & 0,4 \\
\hline \multirow[t]{2}{*}{9} & 62,1 & 37,1 & 0,1 & $<0,1$ & 0,6 \\
\hline & \multicolumn{5}{|c|}{$0,1-0,2 \mathrm{~m}$} \\
\hline 0 & 42,2 & 57,4 & $<0,1$ & $<0,1$ & 0,2 \\
\hline 3 & 57,9 & 41,7 & $<0,1$ & $<0,1$ & 0,2 \\
\hline 6 & 49,5 & 49,9 & $<0,1$ & $<0,1$ & 0,4 \\
\hline \multirow[t]{2}{*}{9} & 47,5 & 51,9 & $<0,1$ & $<0,1$ & 0,4 \\
\hline & \multicolumn{5}{|c|}{$0,2-0,4 \mathrm{~m}$} \\
\hline 0 & 44,2 & 52,4 & $<0,1$ & $<0,1$ & 0,1 \\
\hline 3 & 44,2 & 55,3 & $<0,1$ & $<0,1$ & 0,3 \\
\hline 6 & 46,2 & 53,2 & $<0,1$ & $<0,1$ & 0,4 \\
\hline \multirow[t]{2}{*}{9} & 45,0 & 54,0 & $<0,1$ & $<0,1$ & 0,8 \\
\hline & \multicolumn{5}{|c|}{$0,4-0,6 \mathrm{~m}$} \\
\hline 0 & 34,9 & 64,6 & $<0,1$ & $<0,1$ & 0,3 \\
\hline 3 & 43,2 & 56,3 & $<0,1$ & $<0,1$ & 0,3 \\
\hline 6 & 41,4 & 58,0 & 0,4 & $<0,1$ & $<0,1$ \\
\hline \multirow[t]{2}{*}{9} & 42,5 & 56,1 & $<0,1$ & $<0,1$ & 1,2 \\
\hline & \multicolumn{5}{|c|}{$0,6-0,8 \mathrm{~m}$} \\
\hline 0 & 36,0 & 63,6 & $<0,1$ & $<0,1$ & 0,2 \\
\hline 3 & 37,9 & 61,9 & $<0,1$ & $<0,1$ & $<0,1$ \\
\hline 6 & 36,8 & 63,0 & $<0,1$ & $<0,1$ & $<0,1$ \\
\hline 9 & 35,1 & 63,9 & $<0,1$ & $<0,1$ & 0,8 \\
\hline
\end{tabular}


Tabela 14. Porcentagem das espécies de cálcio na solução do solo, em função da dose de gesso no tratamento $4,5 \mathrm{t} \mathrm{ha}^{-1}$ de calcário em superfície (aplicação única)

\begin{tabular}{|c|c|c|c|c|c|}
\hline Dose de gesso & $\mathrm{Ca}^{+2}$ & $\mathrm{Ca}-\mathrm{COD}$ & $\mathrm{CaNO}_{3}^{+}$ & $\mathrm{CaCl}^{+}$ & $\mathrm{CaSO}_{4}{ }_{4}$ \\
\hline \multirow[t]{2}{*}{$\mathrm{t} \mathrm{ha}^{-1}$} & \multicolumn{5}{|c|}{$\%$} \\
\hline & \multicolumn{5}{|c|}{$0-0,05 \mathrm{~m}$} \\
\hline 0 & 53,7 & 45,6 & 0,1 & $<0,1$ & 0,4 \\
\hline 3 & 57,0 & 42,3 & 0,2 & $<0,1$ & 0,4 \\
\hline 6 & 65,2 & 33,8 & 0,2 & $<0,1$ & 0,5 \\
\hline \multirow[t]{2}{*}{9} & 58,1 & 41,0 & 0,2 & $<0,1$ & 0,5 \\
\hline & \multicolumn{5}{|c|}{$0,05-0,1 \mathrm{~m}$} \\
\hline 0 & 62,4 & 36,7 & 0,1 & $<0,1$ & 0,5 \\
\hline 3 & 63,1 & 36,4 & 0,1 & $<0,1$ & 0,3 \\
\hline 6 & 69,0 & 30,3 & 0,1 & $<0,1$ & 0,4 \\
\hline \multirow[t]{2}{*}{9} & 60,5 & 38,7 & $<0,1$ & $<0,1$ & 0,5 \\
\hline & \multicolumn{5}{|c|}{$0,1-0,2 \mathrm{~m}$} \\
\hline 0 & 39,9 & 59,6 & $<0,1$ & $<0,1$ & 0,2 \\
\hline 3 & 47,8 & 51,7 & $<0,1$ & $<0,1$ & 0,3 \\
\hline 6 & 50,0 & 49,4 & $<0,1$ & $<0,1$ & 0,3 \\
\hline \multirow[t]{2}{*}{9} & 43,8 & 55,4 & $<0,1$ & $<0,1$ & 0,6 \\
\hline & \multicolumn{5}{|c|}{$0,2-0,4 \mathrm{~m}$} \\
\hline 0 & 38,2 & 61,0 & $<0,1$ & $<0,1$ & 0,6 \\
\hline 3 & 45,7 & 53,5 & $<0,1$ & $<0,1$ & 0,6 \\
\hline 6 & 44,2 & 54,6 & $<0,1$ & $<0,1$ & 1,0 \\
\hline \multirow[t]{2}{*}{9} & 44,4 & 54,2 & $<0,1$ & $<0,1$ & 1,1 \\
\hline & \multicolumn{5}{|c|}{$0,6-0,8 \mathrm{~m}$} \\
\hline 0 & 37,5 & 61,7 & $<0,1$ & $<0,1$ & 0,5 \\
\hline 3 & 38,8 & 60,8 & $<0,1$ & $<0,1$ & 0,1 \\
\hline 6 & 35,3 & 63,9 & $<0,1$ & $<0,1$ & 0,6 \\
\hline \multirow[t]{2}{*}{9} & 42,3 & 56,5 & $<0,1$ & $<0,1$ & 1,1 \\
\hline & \multicolumn{5}{|c|}{$0,6-0,8 \mathrm{~m}$} \\
\hline 0 & 39,0 & 60,2 & $<0,1$ & $<0,1$ & 0,7 \\
\hline 3 & 37,2 & 62,5 & $<0,1$ & $<0,1$ & 0,1 \\
\hline 6 & 34,5 & 65,1 & $<0,1$ & $<0,1$ & 0,1 \\
\hline 9 & 40,8 & 58,2 & $<0,1$ & $<0,1$ & 0,7 \\
\hline
\end{tabular}


Tabela 15. Porcentagem das espécies de magnésio na solução do solo, em função das formas de aplicação do calcário

\begin{tabular}{|c|c|c|c|c|c|}
\hline Tratamento & $\mathrm{Mg}^{+2}$ & Mg-COD & $\mathrm{MgF}^{+}$ & $\mathrm{MgCl}^{+}$ & $\mathrm{MgSO}_{4}^{0}$ \\
\hline & \multicolumn{5}{|c|}{$\%$} \\
\hline & \multicolumn{5}{|c|}{$0-0,05 \mathrm{~m}$} \\
\hline $\mathrm{T} 1$ & 92,8 & 6,5 & $<0,1$ & $<0,1$ & 0,7 \\
\hline $\mathrm{T} 2$ & 91,0 & 8,3 & $<0,1$ & $<0,1$ & 0,6 \\
\hline $\mathrm{T} 3$ & 91,6 & 7,8 & $<0,1$ & $<0,1$ & 0,5 \\
\hline \multirow[t]{2}{*}{$\mathrm{T} 4$} & 98,0 & 1,5 & - & $<0,1$ & 0,4 \\
\hline & \multicolumn{5}{|c|}{$0,05-0,1 \mathrm{~m}$} \\
\hline $\mathrm{T} 1$ & 94,6 & 5,0 & - & $<0,1$ & 0,4 \\
\hline $\mathrm{T} 2$ & 92,7 & 6,7 & - & $<0,1$ & 0,5 \\
\hline $\mathrm{T} 3$ & 93,8 & 5,5 & $<0,1$ & $<0,1$ & 0,7 \\
\hline \multirow[t]{2}{*}{$\mathrm{T} 4$} & 97,4 & 2,2 & - & $<0,1$ & 0,3 \\
\hline & \multicolumn{5}{|c|}{$0,1-0,2 \mathrm{~m}$} \\
\hline $\mathrm{T} 1$ & 87,6 & 11,9 & $<0,1$ & $<0,1$ & 0,4 \\
\hline $\mathrm{T} 2$ & 86,3 & 13,1 & $<0,1$ & $<0,1$ & 0,5 \\
\hline $\mathrm{T} 3$ & 86,5 & 12,9 & $<0,1$ & $<0,1$ & 0,5 \\
\hline \multirow[t]{2}{*}{$\mathrm{T} 4$} & 95,6 & 3,9 & - & $<0,1$ & 0,4 \\
\hline & \multicolumn{5}{|c|}{$0,2-0,4 \mathrm{~m}$} \\
\hline $\mathrm{T} 1$ & 85,4 & 13,9 & 0,1 & 0,10 & 0,6 \\
\hline $\mathrm{T} 2$ & 82,3 & 16,6 & 0,2 & $<0,1$ & 1,8 \\
\hline $\mathrm{T} 3$ & 85,0 & 13,6 & 0,2 & $<0,1$ & 1,2 \\
\hline \multirow[t]{2}{*}{$\mathrm{T} 4$} & 86,8 & 12,2 & $<0,1$ & $<0,1$ & 0,9 \\
\hline & \multicolumn{5}{|c|}{$0,4-0,6 \mathrm{~m}$} \\
\hline $\mathrm{T} 1$ & 83,7 & 15,5 & 0,2 & $<0,1$ & 0,6 \\
\hline $\mathrm{T} 2$ & 81,7 & 17,3 & $<0,1$ & $<0,1$ & 0,9 \\
\hline $\mathrm{T} 3$ & 84,8 & 13,9 & 0,2 & $<0,1$ & 1,0 \\
\hline \multirow[t]{2}{*}{$\mathrm{T} 4$} & 84,7 & 14,2 & 0,1 & $<0,1$ & 0,8 \\
\hline & \multicolumn{5}{|c|}{$0,6-0,8 \mathrm{~m}$} \\
\hline $\mathrm{T} 1$ & 84,4 & 14,9 & 0,1 & $<0,1$ & 0,5 \\
\hline $\mathrm{T} 2$ & 81,5 & 17,5 & $<0,1$ & $<0,1$ & 0,8 \\
\hline $\mathrm{T} 3$ & 85,5 & 13,2 & $<0,1$ & $<0,1$ & 1,2 \\
\hline $\mathrm{T} 4$ & 84,3 & 14,9 & $<0,1$ & $<0,1$ & 0,7 \\
\hline
\end{tabular}


Tabela 16. Porcentagem das espécies de magnésio na solução do solo, em função da dose de gesso

\begin{tabular}{|c|c|c|c|c|c|}
\hline Doses de gesso & $\mathrm{Mg}^{+2}$ & $\mathrm{Mg}-\mathrm{COD}$ & $\mathrm{MgF}^{+}$ & $\mathrm{MgCl}^{+}$ & $\mathrm{MgSO}_{4}^{0}$ \\
\hline \multirow[t]{2}{*}{$\mathrm{tha}^{-\mathrm{I}}$} & \multicolumn{5}{|c|}{$\%$} \\
\hline & \multicolumn{5}{|c|}{$0-0,05 \mathrm{~m}$} \\
\hline 0 & 92,8 & 6,5 & $<0,1$ & $<0,1$ & 0,7 \\
\hline 3 & 98,2 & 1,1 & - & $<0,1$ & 0,6 \\
\hline 6 & 96,7 & 2,4 & - & $<0,1$ & 0,7 \\
\hline \multirow[t]{2}{*}{9} & 94,9 & 4,3 & $<0,1$ & $<0,1$ & 0,7 \\
\hline & \multicolumn{5}{|c|}{$0,05-0,1 \mathrm{~m}$} \\
\hline 0 & 94,6 & 5,0 & $<0,1$ & $<0,1$ & 0,4 \\
\hline 3 & 93,6 & 5,9 & $<0,1$ & $<0,1$ & 0,4 \\
\hline 6 & 95,6 & 3,8 & $<0,1$ & $<0,1$ & 0,5 \\
\hline \multirow[t]{2}{*}{9} & 93,6 & 5,6 & $<0,1$ & $<0,1$ & 0,7 \\
\hline & \multicolumn{5}{|c|}{$0,1-0,2 \mathrm{~m}$} \\
\hline 0 & 87,6 & 11,9 & $<0,1$ & $<0,1$ & 0,4 \\
\hline 3 & 92,9 & 6,7 & $<0,1$ & $<0,1$ & 0,3 \\
\hline 6 & 90,1 & 9,1 & $<0,1$ & $<0,1$ & 0,6 \\
\hline \multirow[t]{2}{*}{9} & 89,4 & 9,8 & $<0,1$ & $<0,1$ & 0,7 \\
\hline & \multicolumn{5}{|c|}{$0,2-0,4 \mathrm{~m}$} \\
\hline 0 & 88,5 & 10,9 & $<0,1$ & $<0,1$ & 0,3 \\
\hline 3 & 88,2 & 11,0 & $<0,1$ & $<0,1$ & 0,6 \\
\hline 6 & 88,9 & 10,2 & 0,2 & $<0,1$ & 0,6 \\
\hline \multirow[t]{2}{*}{9} & 87,9 & 10,5 & 0,3 & $<0,1$ & 1,3 \\
\hline & \multicolumn{5}{|c|}{$0,4-0,6$} \\
\hline 0 & 83,6 & 15,5 & 0,2 & $<0,1$ & 0,6 \\
\hline 3 & 87,8 & 11,4 & 0,1 & $<0,1$ & 0,5 \\
\hline 6 & 86,8 & 12,1 & 0,2 & $<0,1$ & 0,7 \\
\hline \multirow[t]{2}{*}{9} & 86,4 & 11,4 & 0,2 & $<0,1$ & 1,9 \\
\hline & \multicolumn{5}{|c|}{$0,6-0,8$} \\
\hline 0 & 84,4 & 14,9 & 0,1 & 0,10 & 0,5 \\
\hline 3 & 85,7 & 14,0 & $<0,1$ & 0,13 & $<0,1$ \\
\hline 6 & 85,0 & 14,6 & 0,2 & $<0,1$ & $<0,1$ \\
\hline 9 & 83,1 & 15,1 & 0,1 & $<0,1$ & 1,6 \\
\hline
\end{tabular}


Tabela 17. Porcentagem das espécies de magnésio na solução do solo, em função da dose de gesso no tratamento $4,5 \mathrm{t} \mathrm{ha}^{-1}$ de calcário em superfície (aplicação única)

\begin{tabular}{|c|c|c|c|c|c|}
\hline Doses de gesso & $\mathrm{Mg}^{+2}$ & $\mathrm{Mg}-\mathrm{COD}$ & $\mathrm{MgF}^{+}$ & $\mathrm{MgCl}^{+}$ & $\mathrm{MgSO}_{4}^{0}$ \\
\hline \multirow[t]{2}{*}{$\mathrm{tha}^{-\mathrm{-}}$} & \multicolumn{5}{|c|}{$\%$} \\
\hline & \multicolumn{5}{|c|}{$0-0,05 \mathrm{~m}$} \\
\hline 0 & 91,5 & 7,7 & $<0,1$ & $<0,1$ & 0,6 \\
\hline 3 & 92,5 & 6,8 & $<0,1$ & $<0,1$ & 0,6 \\
\hline 6 & 94,4 & 4,9 & $<0,1$ & $<0,1$ & 0,6 \\
\hline \multirow[t]{2}{*}{9} & 95,2 & 4,1 & $<0,1$ & $<0,1$ & 0,6 \\
\hline & \multicolumn{5}{|c|}{$0,05-0,1 \mathrm{~m}$} \\
\hline 0 & 93,7 & 5,5 & $<0,1$ & $<0,1$ & 0,7 \\
\hline 3 & 94,1 & 5,4 & $<0,1$ & $<0,1$ & 0,4 \\
\hline 6 & 95,2 & 4,1 & $<0,1$ & $<0,1$ & 0,5 \\
\hline \multirow[t]{2}{*}{9} & 93,2 & 5,9 & $<0,1$ & $<0,1$ & 0,7 \\
\hline & \multicolumn{5}{|c|}{$0,1-0,2 \mathrm{~m}$} \\
\hline 0 & 86,5 & 12,9 & $<0,1$ & $<0,1$ & 0,4 \\
\hline 3 & 89,7 & 9,6 & $<0,1$ & $<0,1$ & 0,4 \\
\hline 6 & 90,4 & 8,9 & $<0,1$ & $<0,1$ & 0,5 \\
\hline \multirow[t]{2}{*}{9} & 87,7 & 11,1 & $<0,1$ & $<0,1$ & 1,0 \\
\hline & \multicolumn{5}{|c|}{$0,2-0,4 \mathrm{~m}$} \\
\hline 0 & 84,9 & 13,5 & 0,2 & $<0,1$ & 1,1 \\
\hline 3 & 88,4 & 10,3 & 0,2 & $<0,1$ & 1,0 \\
\hline 6 & 87,3 & 10,7 & 0,2 & $<0,1$ & 1,6 \\
\hline \multirow[t]{2}{*}{9} & 87,2 & 10,6 & 0,2 & $<0,1$ & 1,9 \\
\hline & \multicolumn{5}{|c|}{$0,4-0,6 \mathrm{~m}$} \\
\hline 0 & 84,7 & 13,9 & 0,2 & $<0,1$ & 1,0 \\
\hline 3 & 86,0 & 13,4 & 0,12 & $<0,1$ & 0,3 \\
\hline 6 & 83,5 & 15,1 & 0,2 & $<0,1$ & 1,1 \\
\hline \multirow[t]{2}{*}{9} & 86,4 & 11,5 & 0,2 & $<0,1$ & 1,8 \\
\hline & \multicolumn{5}{|c|}{$0,6-0,8 \mathrm{~m}$} \\
\hline 0 & 85,5 & 13,1 & $<0,1$ & $<0,1$ & 1,2 \\
\hline 3 & 85,1 & 14,2 & 0,1 & 0,1 & 0,3 \\
\hline 6 & 83,6 & 15,7 & 0,1 & 0,2 & 0,3 \\
\hline 9 & 86,0 & 12,2 & 0,3 & $<0,1$ & 1,3 \\
\hline
\end{tabular}




\subsubsection{Distribuição das espécies de potássio}

$\mathrm{O} \mathrm{K}$, ao contrário do $\mathrm{Ca}$ e $\mathrm{Mg}$, encontrou-se predominantemente na forma iônica, sem combinar-se com os ânions orgânicos em solução (Tabelas 18, 19 e 20). A porcentagem de pares iônicos de $\mathrm{K}$ foi de, no máximo, $0,1 \%$ do total, ficando o restante o K como íon livre em solução, independentemente do tratamento empregado ou da profundidade de amostragem. Mesmo com aplicação de gesso, não foi observado o incremento da participação da forma de $\mathrm{K}$ ligado ao $\mathrm{SO}^{-2}$, podendo-se inferir, que essa pequena proporção refletiu na ausência de efeito do gesso na lixiviação deste cátion para camadas mais profundas. Geralmente, em solos bem drenados, os complexos formados com o K são de muito pouca importância e podem ser ignorados (Lindsay, 1979).

\subsubsection{Distribuição das espécies de ferro}

O Fe presente na solução do solo encontra-se predominantemente em duas formas: ligado à hidroxila e ao COD (Tabelas 21, 22 e 23). Uma participação muito baixa das espécies Fe-F foi constatada, e representam em média, menos de 0,01\% da especiação do ferro em solução.

Nos tratamentos em que houve a aplicação de calcário (Tabelas 21 e 23), principalmente nas duas primeiras camadas, houve efeito marcante da calagem em aumentar as formas hidroxiladas de Fe, dado pelo aumento do $\mathrm{pH}$. A partir de 0,1 m, esta acentuada diferença deixou de existir ou foi diminuída, ocorrendo uma condição de equivalência entre as espécies $\mathrm{Fe}-\mathrm{OH}$ e $\mathrm{Fe}-\mathrm{COD}$, ou até mesmo, maior proporção para esta última.

Amaral (1997) realizou a especiação de solução percolada após a aplicação de $\mathrm{CaF}_{2}$ e observou que as formas predominantes de $\mathrm{Fe}$ na solução do solo eram as hidroxiladas, cerca de 99,9\%, sendo o restante formas de ferro ligado ao nitrato ou fluoreto. Na especiação o autor, aparentemente não considerou a fração da matéria orgânica dissolvida na solução do solo, o que superestimou a participação das espécies de Fe ligado ao $\mathrm{OH}^{-}$. 
Tabela 18. Porcentagem das espécies de potássio na solução do solo, em função das formas de aplicação do calcário

\begin{tabular}{|c|c|c|c|}
\hline Tratamento* & $\mathrm{K}^{+}$ & $\mathrm{KSO}_{4}^{-}$ & $\mathrm{KNO}_{3}$ \\
\hline \multicolumn{4}{|c|}{$\%$} \\
\hline \multicolumn{4}{|c|}{$0-0,05 \mathrm{~m}$} \\
\hline $\mathrm{T} 1$ & 99,9 & $<0,1$ & $<0,1$ \\
\hline $\mathrm{T} 2$ & 99,9 & $<0,1$ & $<0,1$ \\
\hline $\mathrm{T} 3$ & 99,9 & $<0,1$ & $<0,1$ \\
\hline $\mathrm{T} 4$ & 99,9 & $<0,1$ & $<0,1$ \\
\hline \multicolumn{4}{|c|}{$0,05-0,1 \mathrm{~m}$} \\
\hline $\mathrm{T} 1$ & 99,9 & $<0,1$ & $<0,1$ \\
\hline $\mathrm{T} 2$ & 99,9 & $<0,1$ & $<0,1$ \\
\hline $\mathrm{T} 3$ & 99,9 & $<0,1$ & $<0,1$ \\
\hline $\mathrm{T} 4$ & 99,9 & $<0,1$ & $<0,1$ \\
\hline \multicolumn{4}{|c|}{$0,1-0,2 \mathrm{~m}$} \\
\hline $\mathrm{T} 1$ & 99,9 & $<0,1$ & $<0,1$ \\
\hline $\mathrm{T} 2$ & 99,9 & $<0,1$ & $<0,1$ \\
\hline $\mathrm{T} 3$ & 99,9 & $<0,1$ & $<0,1$ \\
\hline $\mathrm{T} 4$ & 99,9 & $<0,1$ & $<0,1$ \\
\hline \multicolumn{4}{|c|}{$0,2-0,4 \mathrm{~m}$} \\
\hline $\mathrm{T} 1$ & 99,9 & $<0,1$ & $<0,1$ \\
\hline $\mathrm{T} 2$ & 99,8 & $<0,1$ & $<0,1$ \\
\hline $\mathrm{T} 3$ & 99,9 & $<0,1$ & $<0,1$ \\
\hline $\mathrm{T} 4$ & 99,9 & $<0,1$ & $<0,1$ \\
\hline \multicolumn{4}{|c|}{$0,4-0,6 \mathrm{~m}$} \\
\hline $\mathrm{T} 1$ & 99,9 & $<0,1$ & $<0,1$ \\
\hline $\mathrm{T} 2$ & 99,9 & $<0,1$ & $<0,1$ \\
\hline $\mathrm{T} 3$ & 99,9 & $<0,1$ & $<0,1$ \\
\hline $\mathrm{T} 4$ & 99,9 & $<0,1$ & $<0,1$ \\
\hline \multicolumn{4}{|c|}{$0,6-0,8 \mathrm{~m}$} \\
\hline $\mathrm{T} 1$ & 99,9 & $<0,1$ & $<0,1$ \\
\hline $\mathrm{T} 2$ & 99,9 & $<0,1$ & $<0,1$ \\
\hline $\mathrm{T} 3$ & 99,9 & $<0,1$ & $<0,1$ \\
\hline $\mathrm{T} 4$ & 99,9 & $<0,1$ & $<0,1$ \\
\hline
\end{tabular}

*T1=testemunha; T2= 4,5 $\mathrm{t} \mathrm{ha}^{-1}\left(3\right.$ aplicações de $\left.1,5 \mathrm{t} \mathrm{ha}^{-1} \mathrm{ano}^{-1}\right) ; \mathrm{T} 3=4,5 \mathrm{t} \mathrm{ha}^{-1}$ aplicado em superfície;T4= $4,5 \mathrm{t} \mathrm{ha}^{-1}$ incorporado ao solo. 
Tabela 19. Porcentagem das espécies de potássio na solução do solo, em função da dose de gesso

\begin{tabular}{|c|c|c|c|}
\hline Doses de gesso & $\mathrm{K}^{+}$ & $\mathrm{KSO}_{4}^{-}$ & $\mathrm{KNO}_{3}$ \\
\hline \multirow[t]{2}{*}{$\mathrm{tha}^{-1}$} & \multicolumn{3}{|c|}{$\%$} \\
\hline & \multicolumn{3}{|c|}{$0-0,05 \mathrm{~m}$} \\
\hline 0 & 99,9 & $<0,1$ & $<0,1$ \\
\hline 3 & 99,9 & $<0,1$ & $<0,1$ \\
\hline 6 & 99,9 & $<0,1$ & $<0,1$ \\
\hline \multirow[t]{2}{*}{9} & 99,9 & $<0,1$ & $<0,1$ \\
\hline & \multicolumn{3}{|c|}{$0,05-0,1 \mathrm{~m}$} \\
\hline 0 & 99,9 & $<0,1$ & $<0,1$ \\
\hline 3 & 99,9 & $<0,1$ & $<0,1$ \\
\hline 6 & 99,9 & $<0,1$ & $<0,1$ \\
\hline \multirow[t]{2}{*}{9} & 99,9 & $<0,1$ & $<0,1$ \\
\hline & \multicolumn{3}{|c|}{$0,1-0,2 \mathrm{~m}$} \\
\hline 0 & 99,9 & $<0,1$ & $<0,1$ \\
\hline 3 & 99,9 & $<0,1$ & $<0,1$ \\
\hline 6 & 99,9 & $<0,1$ & $<0,1$ \\
\hline \multirow[t]{2}{*}{9} & 99,9 & $<0,1$ & $<0,1$ \\
\hline & \multicolumn{3}{|c|}{$0,2-0,4 \mathrm{~m}$} \\
\hline 0 & 99,9 & $<0,1$ & $<0,1$ \\
\hline 3 & 99,9 & $<0,1$ & $<0,1$ \\
\hline 6 & 99,9 & $<0,1$ & $<0,1$ \\
\hline \multirow[t]{2}{*}{9} & 99,9 & $<0,1$ & $<0,1$ \\
\hline & \multicolumn{3}{|c|}{$0,4-0,6 \mathrm{~m}$} \\
\hline 0 & 99,9 & $<0,1$ & $<0,1$ \\
\hline 3 & 99,9 & $<0,1$ & $<0,1$ \\
\hline 6 & 99,9 & $<0,1$ & $<0,1$ \\
\hline \multirow[t]{2}{*}{9} & 99,8 & $<0,1$ & $<0,1$ \\
\hline & \multicolumn{3}{|c|}{$0,6-0,8 \mathrm{~m}$} \\
\hline 0 & 99,9 & $<0,1$ & $<0,1$ \\
\hline 3 & 99,9 & $<0,1$ & $<0,1$ \\
\hline 6 & 99,9 & $<0,1$ & - \\
\hline 9 & 99,8 & $<0,1$ & $<0,1$ \\
\hline
\end{tabular}


Tabela 20. Porcentagem das espécies de potássio na solução do solo, em função da dose de gesso no tratamento $4,5 \mathrm{t} \mathrm{ha}^{-1}$ de calcário em superfície (aplicação única)

\begin{tabular}{|c|c|c|c|}
\hline Dose de gesso & $\mathrm{K}^{+}$ & $\mathrm{KSO}_{4}^{-}$ & $\mathrm{KNO}_{3}$ \\
\hline \multirow[t]{2}{*}{$\mathrm{tha}^{-1}$} & \multicolumn{3}{|c|}{$\%$} \\
\hline & \multicolumn{3}{|c|}{$0-0,05 \mathrm{~m}$} \\
\hline 0 & 99,9 & $<0,1$ & $<0,1$ \\
\hline 3 & 99,9 & $<0,1$ & $<0,1$ \\
\hline 6 & 99,9 & $<0,1$ & $<0,1$ \\
\hline \multirow[t]{2}{*}{9} & 99,9 & $<0,1$ & $<0,1$ \\
\hline & \multicolumn{3}{|c|}{$0,5-0,1 \mathrm{~m}$} \\
\hline 0 & 99,9 & $<0,1$ & $<0,1$ \\
\hline 3 & 99,9 & $<0,1$ & $<0,1$ \\
\hline 6 & 99,9 & $<0,1$ & $<0,1$ \\
\hline \multirow[t]{2}{*}{9} & 99,9 & $<0,1$ & $<0,1$ \\
\hline & \multicolumn{3}{|c|}{$0,1-0,2 \mathrm{~m}$} \\
\hline 0 & 99,9 & $<0,1$ & $<0,1$ \\
\hline 3 & 99,9 & $<0,1$ & $<0,1$ \\
\hline 6 & 99,9 & $<0,1$ & $<0,1$ \\
\hline \multirow[t]{2}{*}{9} & 99,9 & $<0,1$ & $<0,1$ \\
\hline & \multicolumn{3}{|c|}{$0,2-0,4 \mathrm{~m}$} \\
\hline 0 & 99,9 & $<0,1$ & $<0,1$ \\
\hline 3 & 99,9 & $<0,1$ & $<0,1$ \\
\hline 6 & 99,8 & $<0,1$ & $<0,1$ \\
\hline \multirow[t]{2}{*}{9} & 99,8 & $<0,1$ & $<0,1$ \\
\hline & \multicolumn{3}{|c|}{$0,4-0,6 \mathrm{~m}$} \\
\hline 0 & 99,9 & $<0,1$ & $<0,1$ \\
\hline 3 & 99,9 & $<0,1$ & $<0,1$ \\
\hline 6 & 99,9 & $<0,1$ & $<0,1$ \\
\hline \multirow[t]{2}{*}{9} & 99,8 & $<0,1$ & $<0,1$ \\
\hline & \multicolumn{3}{|c|}{$0,6-0,8 \mathrm{~m}$} \\
\hline 0 & 99,9 & $<0,1$ & $<0,1$ \\
\hline 3 & 99,9 & $<0,1$ & $<0,1$ \\
\hline 6 & 99,9 & $<0,1$ & $<0,1$ \\
\hline 9 & 99,9 & $<0,1$ & $<0,1$ \\
\hline
\end{tabular}


Tabela 21. Porcentagem das espécies de ferro na solução do solo, em função das formas de aplicação do calcário

\begin{tabular}{|c|c|c|}
\hline Tratamento* & $\mathrm{Fe}-\mathrm{OH}$ & $\mathrm{Fe}-\mathrm{COD}$ \\
\hline \multicolumn{3}{|c|}{$\%$} \\
\hline \multicolumn{3}{|c|}{$0-0,05 \mathrm{~m}$} \\
\hline $\mathrm{T} 1$ & 80,9 & 19,1 \\
\hline $\mathrm{T} 2$ & 99,7 & 0,2 \\
\hline $\mathrm{T} 3$ & 99,6 & 0,3 \\
\hline $\mathrm{T} 4$ & 99,6 & 0,4 \\
\hline \multicolumn{3}{|c|}{$0,05-0,1 \mathrm{~m}$} \\
\hline $\mathrm{T} 1$ & 75,2 & 24,8 \\
\hline $\mathrm{T} 2$ & 97,6 & 2,3 \\
\hline $\mathrm{T} 3$ & 90,9 & 9,1 \\
\hline $\mathrm{T} 4$ & 98,1 & 1,8 \\
\hline \multicolumn{3}{|c|}{$0,1-0,2 \mathrm{~m}$} \\
\hline $\mathrm{T} 1$ & 51,9 & 48,0 \\
\hline $\mathrm{T} 2$ & 69,1 & 30,9 \\
\hline $\mathrm{T} 3$ & 56,1 & 43,8 \\
\hline $\mathrm{T} 4$ & 94,3 & 5,65 \\
\hline \multicolumn{3}{|c|}{$0,2-0,4 \mathrm{~m}$} \\
\hline $\mathrm{T} 1$ & 54,2 & 45,8 \\
\hline $\mathrm{T} 2$ & 61,1 & 38,9 \\
\hline $\mathrm{T} 3$ & 49,1 & 50,9 \\
\hline $\mathrm{T} 4$ & 59,7 & 40,3 \\
\hline \multicolumn{3}{|c|}{$0,4-0,6 \mathrm{~m}$} \\
\hline $\mathrm{T} 1$ & 45,4 & 54,6 \\
\hline $\mathrm{T} 2$ & 59,3 & 40,6 \\
\hline $\mathrm{T} 3$ & 40,8 & 59,1 \\
\hline $\mathrm{T} 4$ & 40,4 & 59,6 \\
\hline \multicolumn{3}{|c|}{$0,6-0,8 \mathrm{~m}$} \\
\hline $\mathrm{T} 1$ & 43,6 & 56,4 \\
\hline $\mathrm{T} 2$ & 54,7 & 45,3 \\
\hline $\mathrm{T} 3$ & 53,4 & 46,6 \\
\hline $\mathrm{T} 4$ & 40,5 & 59,5 \\
\hline
\end{tabular}

*T1=testemunha; T2= 4,5 $\mathrm{t} \mathrm{ha}^{-1}\left(3\right.$ aplicações de 1,5 $\mathrm{t} \mathrm{ha}^{-1}$ ano $\left.^{-1}\right)$; T3=4,5 $\mathrm{t} \mathrm{ha}^{-1}$ aplicado em superfície; $\mathrm{T} 4=4,5 \mathrm{t} \mathrm{ha}^{-1}$ incorporado ao solo. 
Tabela 22. Porcentagem das espécies de ferro na solução do solo, em função da dose de gesso

\begin{tabular}{|c|c|c|}
\hline Dose de gesso & $\mathrm{Fe}-\mathrm{OH}$ & $\mathrm{Fe}-\mathrm{COD}$ \\
\hline $\mathrm{t} \mathrm{ha}^{-1}$ & \multicolumn{2}{|c|}{$\%$} \\
\hline \multicolumn{3}{|c|}{$0-0,05 \mathrm{~m}$} \\
\hline 0 & 80,6 & 19,1 \\
\hline 3 & 92,6 & 7,2 \\
\hline 6 & 85,9 & 14,1 \\
\hline 9 & 97,1 & 2,9 \\
\hline \multicolumn{3}{|c|}{$0,05-0,1 \mathrm{~m}$} \\
\hline 0 & 75,2 & 24,8 \\
\hline 3 & 57,4 & 42,6 \\
\hline 6 & 73,5 & 26,5 \\
\hline 9 & 74,6 & 25,4 \\
\hline \multicolumn{3}{|c|}{$0,1-0,2 \mathrm{~m}$} \\
\hline 0 & 52,0 & 48,0 \\
\hline 3 & 43,7 & 56,3 \\
\hline 6 & 38,6 & 61,4 \\
\hline 9 & 51,2 & 48,8 \\
\hline \multicolumn{3}{|c|}{$0,2-0,4 \mathrm{~m}$} \\
\hline 0 & 37,6 & 54,6 \\
\hline 3 & 38,2 & 61,8 \\
\hline 6 & 37,8 & 62,1 \\
\hline 9 & 46,8 & 53,2 \\
\hline \multicolumn{3}{|c|}{$0,4-0,6 \mathrm{~m}$} \\
\hline 0 & 45,4 & 54,9 \\
\hline 3 & 33,5 & 66,4 \\
\hline 6 & 44,3 & 55,6 \\
\hline 9 & 50,2 & 49,8 \\
\hline \multicolumn{3}{|c|}{$0,6-0,8 \mathrm{~m}$} \\
\hline 0 & 43,6 & 56,4 \\
\hline 3 & 39,9 & 60,1 \\
\hline 6 & 46,5 & 53,4 \\
\hline 9 & 73,5 & 26,5 \\
\hline
\end{tabular}


Tabela 23. Porcentagem das espécies de ferro na solução do solo, em função da dose de gesso no tratamento 4,5 $\mathrm{t} \mathrm{ha}^{-1}$ de calcário em superfície (aplicação única)

\begin{tabular}{|c|c|c|}
\hline Dose de gesso & $\mathrm{Fe}-\mathrm{OH}$ & Fe-COD \\
\hline $\mathrm{tha}^{-1}$ & \multicolumn{2}{|c|}{$\%$} \\
\hline \multicolumn{3}{|c|}{$0-0,05 \mathrm{~m}$} \\
\hline 0 & 99,6 & 0,4 \\
\hline 3 & 98,6 & 1,4 \\
\hline 6 & 99,8 & 0,2 \\
\hline 9 & 99,7 & 0,3 \\
\hline \multicolumn{3}{|c|}{$0,05-0,1 \mathrm{~m}$} \\
\hline 0 & 90,9 & 9,1 \\
\hline 3 & 83,8 & 16,2 \\
\hline 6 & 93,1 & 6,9 \\
\hline 9 & 96,5 & 3,5 \\
\hline \multicolumn{3}{|c|}{$0,1-0,2 \mathrm{~m}$} \\
\hline 0 & 56,1 & 43,9 \\
\hline 3 & 51,1 & 48,9 \\
\hline 6 & 50,2 & 49,8 \\
\hline 9 & 70,5 & 29,5 \\
\hline \multicolumn{3}{|c|}{$0,2-0,4 \mathrm{~m}$} \\
\hline 0 & 49,1 & 50,7 \\
\hline 3 & 50,5 & 49,4 \\
\hline 6 & 48,1 & 51,8 \\
\hline 9 & 59,3 & 40,5 \\
\hline \multicolumn{3}{|c|}{$0,4-0,6 \mathrm{~m}$} \\
\hline 0 & 59,1 & 40,8 \\
\hline 3 & 52,6 & 47,4 \\
\hline 6 & 35,1 & 64,9 \\
\hline 9 & 35,7 & 64,2 \\
\hline \multicolumn{3}{|c|}{$0,6-0,8 \mathrm{~m}$} \\
\hline 0 & 46,6 & 53,1 \\
\hline 3 & 53,1 & 46,9 \\
\hline 6 & 40,2 & 59,8 \\
\hline 9 & 35,2 & 64,7 \\
\hline
\end{tabular}




\subsubsection{Distribuição das espécies de manganês}

O Mn apresentou a combinação com vários ânions inorgânicos na solução do solo, sem se combinar, no entanto, com o COD (tabelas 24, 25 e 26). A forma predominante foi a livre $\left(\mathrm{Mn}^{+2}\right)$, concordando com Camargo (1991), de que o $\mathrm{Mn}$ ocorre em solução sob diversas espécies $\left(\mathrm{Mn}^{+2}, \mathrm{MnCl}^{+}, \mathrm{MnCO}^{0}\right.$ e $\left.\mathrm{MnSO}^{0}{ }_{4}\right)$, mas nas condições redox de solos bem drenados, a espécie $\mathrm{Mn}^{+2}$ é a mais abundante, sendo as demais espécies, como as resultantes da hidrólise de $\mathrm{Mn}, \mathrm{Mn}(\mathrm{OH})^{+}$e $\mathrm{Mn}(\mathrm{OH})_{2}{ }_{2}$, de menor importância.

A proporção de pares iônicos formados entre o Mn e demais íons em solução seguiu a seguinte ordem: sulfato $>$ nitrato $=$ cloreto $=$ fluoreto Praticamente, não foi encontrada variação das formas entre os tratamentos, doses e mesmo profundidades, o que demonstra que o Mn tem sua especiação química pouco alterada pelas práticas de manejo do solo ou pela composição da solução. 
Tabela 24. Porcentagem das espécies de manganês na solução do solo, em função das formas de aplicação do calcário

\begin{tabular}{|c|c|c|c|c|c|}
\hline Tratamento* & $\mathrm{Mn}^{+2}$ & $\mathrm{MnCl}^{+}$ & $\mathrm{MnSO}_{4}$ & $\mathrm{MnNO}_{3}^{+}$ & $\mathrm{MnF}^{+}$ \\
\hline & \multicolumn{5}{|c|}{$\%$} \\
\hline & \multicolumn{5}{|c|}{$0-0,05 \mathrm{~m}$} \\
\hline $\mathrm{T} 1$ & 99,1 & $<0,1$ & 0,6 & 0,1 & - \\
\hline $\mathrm{T} 2$ & 99,1 & $<0,1$ & 0,6 & $<0,1$ & $<0,1$ \\
\hline $\mathrm{T} 3$ & 99,2 & $<0,1$ & 0,6 & $<0,1$ & $<0,1$ \\
\hline \multirow[t]{2}{*}{$\mathrm{T} 4$} & 99,4 & $<0,1$ & 0,4 & $<0,1$ & - \\
\hline & \multicolumn{5}{|c|}{$0,05-0,1 \mathrm{~cm}$} \\
\hline $\mathrm{T} 1$ & 99,5 & $<0,1$ & 0,3 & $<0,1$ & - \\
\hline $\mathrm{T} 2$ & 99,3 & $<0,1$ & 0,5 & $<0,1$ & - \\
\hline T3 & 99,1 & $<0,1$ & 0,6 & 0,1 & - \\
\hline \multirow[t]{2}{*}{$\mathrm{T} 4$} & 99,6 & $<0,1$ & 0,2 & $<0,1$ & - \\
\hline & \multicolumn{5}{|c|}{$0,1-0,2 \mathrm{~m}$} \\
\hline $\mathrm{T} 1$ & 99,4 & $<0,1$ & 0,4 & $<0,1$ & $<0,1$ \\
\hline $\mathrm{T} 2$ & 99,3 & $<0,1$ & 0,5 & $<0,1$ & $<0,1$ \\
\hline T3 & 99,3 & $<0,1$ & 0,5 & $<0,1$ & $<0,1$ \\
\hline \multirow[t]{2}{*}{$\mathrm{T} 4$} & 99,4 & $<0,1$ & 0,4 & $<0,1$ & - \\
\hline & \multicolumn{5}{|c|}{$0,2-0,4 \mathrm{~m}$} \\
\hline $\mathrm{T} 1$ & 99,1 & $<0,1$ & 0,7 & $<0,1$ & $<0,1$ \\
\hline $\mathrm{T} 2$ & 98,1 & $<0,1$ & 1,6 & $<0,1$ & 0,1 \\
\hline $\mathrm{T} 3$ & 98,5 & $<0,1$ & 1,2 & $<0,1$ & 0,1 \\
\hline \multirow[t]{2}{*}{$\mathrm{T} 4$} & 98,9 & $<0,1$ & 0,9 & $<0,1$ & $<0,1$ \\
\hline & \multicolumn{5}{|c|}{$0,4-0,6 \mathrm{~m}$} \\
\hline $\mathrm{T} 1$ & 98,1 & $<0,1$ & 0,8 & $<0,1$ & $<0,1$ \\
\hline $\mathrm{T} 2$ & 98,8 & $<0,1$ & 1,0 & $<0,1$ & $<0,1$ \\
\hline $\mathrm{T} 3$ & 98,7 & $<0,1$ & 1,1 & $<0,1$ & $<0,1$ \\
\hline \multirow[t]{2}{*}{$\mathrm{T} 4$} & 98,9 & $<0,1$ & 0,9 & $<0,1$ & $<0,1$ \\
\hline & \multicolumn{5}{|c|}{$0,6-0,8 \mathrm{~m}$} \\
\hline $\mathrm{T} 1$ & 99,2 & $<0,1$ & 0,6 & $<0,1$ & $<0,1$ \\
\hline $\mathrm{T} 2$ & 98,9 & $<0,1$ & 1,0 & $<0,1$ & $<0,1$ \\
\hline $\mathrm{T} 3$ & 98,5 & $<0,1$ & 1,3 & $<0,1$ & $<0,1$ \\
\hline $\mathrm{T} 4$ & 99,1 & $<0,1$ & 0,8 & $<0,1$ & $<0,1$ \\
\hline
\end{tabular}


Tabela 25. Porcentagem das espécies de manganês na solução do solo, em função da dose de gesso

\begin{tabular}{|c|c|c|c|c|c|}
\hline Dose de gesso & $\mathrm{Mn}^{+2}$ & $\mathrm{MnCl}^{+}$ & $\mathrm{MnSO}_{4}$ & $\mathrm{MnNO}_{3}^{+}$ & $\mathrm{MnF}^{+}$ \\
\hline \multirow[t]{2}{*}{ tha $^{-1}$} & \multicolumn{5}{|c|}{$\%$} \\
\hline & \multicolumn{5}{|c|}{$0-0,05 \mathrm{~m}$} \\
\hline 0 & 99,1 & $<0,1$ & 0,6 & 0,1 & - \\
\hline 3 & 99,2 & $<0,1$ & 0,5 & 0,1 & - \\
\hline 6 & 99,0 & $<0,1$ & 0,7 & 0,1 & - \\
\hline \multirow[t]{2}{*}{9} & 99,1 & $<0,1$ & 0,7 & 0,1 & - \\
\hline & \multicolumn{5}{|c|}{$0,05-0,1 \mathrm{~m}$} \\
\hline 0 & 99,5 & $<0,1$ & 0,3 & $<0,1$ & - \\
\hline 3 & 99,4 & $<0,1$ & 0,4 & $<0,1$ & - \\
\hline 6 & 99,3 & $<0,1$ & 0,5 & $<0,1$ & - \\
\hline \multirow[t]{2}{*}{9} & 99,1 & $<0,1$ & 0,7 & $<0,1$ & - \\
\hline & \multicolumn{5}{|c|}{$0,1-0,2 \mathrm{~m}$} \\
\hline 0 & 99,4 & $<0,1$ & 0,4 & $<0,1$ & $<0,1$ \\
\hline 3 & 99,6 & $<0,1$ & 0,2 & $<0,1$ & $<0,1$ \\
\hline 6 & 99,2 & $<0,1$ & 0,6 & $<0,1$ & $<0,1$ \\
\hline \multirow[t]{2}{*}{9} & 99,1 & $<0,1$ & 0,7 & $<0,1$ & $<0,1$ \\
\hline & \multicolumn{5}{|c|}{$0,2-0,4 \mathrm{~m}$} \\
\hline 0 & 99,6 & $<0,1$ & 0,2 & $<0,1$ & $<0,1$ \\
\hline 3 & 99,2 & $<0,1$ & 0,6 & $<0,1$ & $<0,1$ \\
\hline 6 & 99,1 & $<0,1$ & 0,6 & $<0,1$ & $<0,1$ \\
\hline \multirow[t]{2}{*}{9} & 98,4 & $<0,1$ & 1,3 & $<0,1$ & $<0,1$ \\
\hline & \multicolumn{5}{|c|}{$0,4-0,6 \mathrm{~m}$} \\
\hline 0 & 99,1 & $<0,1$ & 0,7 & $<0,1$ & $<0,1$ \\
\hline 3 & 99,3 & $<0,1$ & 0,5 & $<0,1$ & $<0,1$ \\
\hline 6 & 99,0 & $<0,1$ & 0,8 & $<0,1$ & $<0,1$ \\
\hline \multirow[t]{2}{*}{9} & 98,7 & $<0,1$ & 1,1 & $<0,1$ & $<0,1$ \\
\hline & \multicolumn{5}{|c|}{$0,6-0,8 \mathrm{~m}$} \\
\hline 0 & 99,2 & $<0,1$ & 0,6 & $<0,1$ & $<0,1$ \\
\hline 3 & 99,8 & $<0,1$ & - & $<0,1$ & $<0,1$ \\
\hline 6 & 99,7 & $<0,1$ & 0,6 & $<0,1$ & $<0,1$ \\
\hline 9 & 98,9 & $<0,1$ & 0,8 & $<0,1$ & $<0,1$ \\
\hline
\end{tabular}


Tabela 26. Porcentagem das espécies de manganês na solução do solo, em função da dose de gesso no tratamento $4,5 \mathrm{t} \mathrm{ha}^{-1}$ de calcário em superfície (aplicação única)

\begin{tabular}{|c|c|c|c|c|c|}
\hline Dose de gesso & $\mathrm{Mn}^{+2}$ & $\mathrm{MnCl}^{+}$ & $\mathrm{MnSO}_{4}$ & $\mathrm{MnNO}_{3}^{+}$ & $\mathrm{MnF}^{+}$ \\
\hline \multirow[t]{2}{*}{$\mathrm{tha}^{-1}$} & & & $\%$ & & \\
\hline & & & $0-0,05 \mathrm{~m}$ & & \\
\hline 0 & 99,2 & $<0,1$ & 0,6 & 0,1 & $<0,1$ \\
\hline 3 & 99,2 & $<0,1$ & 0,5 & 0,1 & $<0,1$ \\
\hline 6 & 99,1 & $<0,1$ & 0,6 & 0,1 & $<0,1$ \\
\hline \multirow[t]{2}{*}{9} & 98,9 & $<0,1$ & 0,7 & 0,2 & $<0,1$ \\
\hline & & & $0,05-0,1 \mathrm{~m}$ & & \\
\hline 0 & 99,1 & $<0,1$ & 0,6 & 0,1 & - \\
\hline 3 & 99,4 & $<0,1$ & 0,4 & $<0,1$ & - \\
\hline 6 & 99,3 & $<0,1$ & 0,5 & $<0,1$ & - \\
\hline \multirow[t]{2}{*}{9} & 99,1 & $<0,1$ & 0,7 & $<0,1$ & - \\
\hline & & & $0,1-0,2 \mathrm{~m}$ & & \\
\hline 0 & 99,3 & $<0,1$ & 0,5 & $<0,1$ & $<0,1$ \\
\hline 3 & 99,3 & $<0,1$ & 0,5 & $<0,1$ & $<0,1$ \\
\hline 6 & 99,3 & $<0,1$ & 0,5 & $<0,1$ & $<0,1$ \\
\hline \multirow[t]{2}{*}{9} & 98,7 & $<0,1$ & 1,1 & $<0,1$ & $<0,1$ \\
\hline & & & $0,2-0,4 \mathrm{~m}$ & & \\
\hline 0 & 98,5 & $<0,1$ & 1,2 & $<0,1$ & $<0,1$ \\
\hline 3 & 98,7 & $<0,1$ & 1,0 & $<0,1$ & $<0,1$ \\
\hline 6 & 98,0 & $<0,1$ & 1,7 & $<0,1$ & $<0,1$ \\
\hline \multirow[t]{2}{*}{9} & 97,8 & $<0,1$ & 2,0 & $<0,1$ & $<0,1$ \\
\hline & & & $0,4-0,6 \mathrm{~m}$ & & \\
\hline 0 & 98,7 & $<0,1$ & 1,1 & $<0,1$ & $<0,1$ \\
\hline 3 & 99,5 & $<0,1$ & 0,3 & $<0,1$ & $<0,1$ \\
\hline 6 & 98,5 & $<0,1$ & 1,3 & $<0,1$ & $<0,1$ \\
\hline \multirow[t]{2}{*}{9} & 97,8 & $<0,1$ & 1,9 & $<0,1$ & $<0,1$ \\
\hline & & & $0,6-0,8 \mathrm{~m}$ & & \\
\hline 0 & 98,5 & $<0,1$ & 1,3 & $<0,1$ & $<0,1$ \\
\hline 3 & 99,5 & $<0,1$ & 0,3 & $<0,1$ & $<0,1$ \\
\hline 6 & 99,4 & $<0,1$ & 0,3 & $<0,1$ & $<0,1$ \\
\hline 9 & 98.3 & $<0,1$ & 1,4 & $<0,1$ & $<0,1$ \\
\hline
\end{tabular}




\subsubsection{Distribuição das espécies de fósforo}

Observou-se grande interação do $\mathrm{P}$ com os outros constituintes da solução do solo (Tabelas 27, 28 e 29). A quantidade $\mathrm{HPO}_{4}^{-} \mathrm{e}_{2} \mathrm{PO}^{-2}$ presente na solução do solo depende do pH (Havilin et al., 1999). Em pH igual a 7,2 há aproximadamente quantidades iguais dessas duas formas de fósforo em solução. Como os valores de $\mathrm{pH}$ da solução do solo encontrados estão bem abaixo de 7,2, a forma $\mathrm{H}_{2} \mathrm{PO}_{4}^{-}$foi a espécie dominante encontrada.

A espécie $\mathrm{H}_{2} \mathrm{PO}_{4}^{-}$, que pelas condições de $\mathrm{pH}$ normalmente encontrado nos solos agrícolas, é a forma mais absorvida pelas plantas, apresentou redução em sua concentração com os tratamentos empregados. O efeito da calagem pode ser atribuído tanto ao aumento do pH, quanto à elevação da concentração dos cátions em solução, aumentando a formação de pares iônicos. Esse último efeito também deve ser atribuído à aplicação de gesso. De maneira geral, a proporção dos pares iônicos formados entre fósforo e os cátions em solução seguiu a seguinte ordem para os tratamentos com calagem: $\mathrm{Al}>\mathrm{Mg}>\mathrm{Fe}$ ou $\mathrm{Ca}>\mathrm{K}$. No tratamento exclusivo com gesso agrícola, houve apenas a alteração das posições de $\mathrm{Mg}$ e $\mathrm{Fe}$, devido ao não fornecimento de $\mathrm{Mg}$. No entanto, esta seqüência não pode ser aplicada em todos os tratamentos e profundidades, indicando apenas uma tendência de combinação do P com os demais elementos, estando, contudo, sujeita a muitas interferências e variações.

Como o teor de fósforo em solução é baixo em relação aos outros elementos (cátions de maneira geral), o impacto da redução da atividade do fosfato em solução pelos cátions é muito maior do que a redução da atividade destes pelo fosfato. Com o aumento da profundidade do solo, as espécies livres de fósforo, ou seja, que não formam par iônico com os cátions, passaram a representar maior concentração na solução do solo, devido à redução dos teores de cátions. 
Tabela 27. Porcentagem das espécies de fósforo na solução do solo, em função das formas de aplicação do calcário

\begin{tabular}{|c|c|c|c|c|c|c|c|c|c|}
\hline Tratamento & $\mathrm{HPO}_{4}^{-2}$ & $\mathrm{H}_{2} \mathrm{PO}_{4}^{-}$ & $\mathrm{H}_{3} \mathrm{PO}_{4}$ & $\mathrm{Al}-\mathrm{HPO}_{4}$ & $\mathrm{Al}_{2} \mathrm{PO}_{4}^{-3}$ & $\mathrm{Ca}-\mathrm{H}_{2} \mathrm{PO}_{4}$ & $\mathrm{Mg}-\mathrm{H}_{2} \mathrm{PO}_{4}$ & $\mathrm{Fe}-\mathrm{HPO}_{4}$ & $\mathrm{~K}-\mathrm{H}_{2} \mathrm{PO}_{4}$ \\
\hline & \multicolumn{9}{|c|}{$\%$} \\
\hline & \multicolumn{9}{|c|}{$0-0,05 \mathrm{~m}$} \\
\hline $\mathrm{T} 1$ & 0,6 & 82,9 & 0,1 & 12,0 & 0,1 & 0,2 & 1,0 & 2,1 & $<0,1$ \\
\hline $\mathrm{T} 2$ & 4,6 & 56,7 & $<0,1$ & 34,0 & 1,6 & 0,2 & 2,1 & $<0,1$ & $<0,1$ \\
\hline $\mathrm{T} 3$ & 3,5 & 54,6 & $<0,1$ & 36,8 & 1,4 & 0,6 & 2,2 & $<0,1$ & $<0,1$ \\
\hline \multirow[t]{2}{*}{$\mathrm{T} 4$} & 0,1 & 38,3 & $<0,1$ & 54,1 & 7,0 & 0,5 & 0,1 & $<0,1$ & - \\
\hline & \multicolumn{9}{|c|}{$0,05-0,1 \mathrm{~m}$} \\
\hline $\mathrm{T} 1$ & 0,3 & 75,8 & 0,2 & 21,9 & 0,4 & 0,1 & 0,5 & 0,5 & $<0,1$ \\
\hline $\mathrm{T} 2$ & 1,1 & 51,3 & $<0,1$ & 43,6 & 2,7 & 0,1 & 0,8 & 0,0 & $<0,1$ \\
\hline $\mathrm{T} 3$ & 0,6 & 65,6 & $<0,1$ & 31,0 & 1,1 & 0,1 & 0,9 & 0,3 & $<0,1$ \\
\hline \multirow[t]{2}{*}{$\mathrm{T} 4$} & 0,3 & 22,8 & $<0,1$ & 62,1 & 13,8 & 0,1 & 0,4 & 0,3 & $<0,1$ \\
\hline & \multicolumn{9}{|c|}{$0,1-0,2 \mathrm{~m}$} \\
\hline $\mathrm{T} 1$ & $<0,1$ & 97,6 & 0,5 & 0,1 & 0,1 & 0,5 & 0,0 & 0,9 & 0,04 \\
\hline $\mathrm{T} 2$ & 0,6 & 94,9 & 0,1 & 2,9 & - & 0,1 & 0,8 & 0,1 & $<0,1$ \\
\hline $\mathrm{T} 3$ & 0,5 & 96,9 & 0,2 & 1,3 & - & 0,1 & 0,7 & 0,1 & $<0,1$ \\
\hline \multirow[t]{2}{*}{$\mathrm{T} 4$} & 0,5 & 48,0 & $<0,1$ & 46,9 & 3,4 & 0,1 & 0,6 & 0,1 & $<0,1$ \\
\hline & \multicolumn{9}{|c|}{$0,2-0,4 \mathrm{~m}$} \\
\hline $\mathrm{T} 1$ & 0,4 & 96,7 & 0,2 & 1,7 & - & 0,10 & 0,5 & 0,1 & $<0,1$ \\
\hline $\mathrm{T} 2$ & 0,6 & 98,2 & 0,1 & $<0,1$ & - & $<0,1$ & 0,7 & - & $<0,1$ \\
\hline T3 & 0,4 & 98,4 & 0,2 & $<0,1$ & - & 0,10 & 0,7 & - & $<0,1$ \\
\hline \multirow[t]{2}{*}{$\mathrm{T} 4$} & 0,5 & 95,8 & 0,1 & 2,3 & - & 0,11 & 0,9 & - & $<0,1$ \\
\hline & \multicolumn{9}{|c|}{$0,4-0,6 \mathrm{~m}-$} \\
\hline $\mathrm{T} 1$ & 0,4 & 98,8 & 0,2 & $<0,1$ & - & $<0,1$ & 0,4 & - & - \\
\hline $\mathrm{T} 2$ & 0,6 & 98,2 & 0,1 & $<0,1$ & - & $<0,1$ & 0,5 & - & - \\
\hline $\mathrm{T} 3$ & 0,3 & 98,7 & 0,2 & $<0,1$ & - & $<0,1$ & 0,4 & - & - \\
\hline \multirow[t]{2}{*}{$\mathrm{T} 4$} & 0,3 & 98,7 & 0,2 & $<0,1$ & - & $<0,1$ & 0,5 & - & - \\
\hline & \multicolumn{9}{|c|}{$0,6-0,8 \mathrm{~m}$} \\
\hline $\mathrm{T} 1$ & 0,4 & 98,8 & 0,2 & $<0,1$ & - & $<0,1$ & 0,3 & - & - \\
\hline $\mathrm{T} 2$ & 0,5 & 98,6 & 0,1 & 0,1 & - & $<0,1$ & 0,4 & - & - \\
\hline T3 & 0,4 & 96,4 & 0,1 & 1,8 & - & $<0,1$ & 0,5 & - & - \\
\hline $\mathrm{T} 4$ & 0,3 & 98,6 & 0,2 & 0,2 & - & $<0,1$ & 0,4 & - & - \\
\hline
\end{tabular}


Tabela 28. Porcentagem das espécies de fósforo na solução do solo, em função da dose de gesso

\begin{tabular}{|c|c|c|c|c|c|c|c|c|}
\hline Dose de gesso & $\mathrm{HPO}_{4}^{-2}$ & $\mathrm{H}_{2} \mathrm{PO}_{4}^{-}$ & $\mathrm{H}_{3} \mathrm{PO} 4$ & $\mathrm{Al}-\mathrm{HPO}_{4}$ & $\mathrm{Ca}-\mathrm{H}_{2} \mathrm{PO}_{4}$ & $\mathrm{Mg}-\mathrm{H}_{2} \mathrm{PO}_{4}$ & $\mathrm{Fe}-\mathrm{HPO}_{4}$ & $\mathrm{~K}-\mathrm{H}_{2} \mathrm{PO}_{4}$ \\
\hline $\mathrm{tha}^{-1}$ & \multicolumn{8}{|c|}{$\%$} \\
\hline & \multicolumn{8}{|c|}{$0-0,05 \mathrm{~m}$} \\
\hline 0 & 0,6 & 83,1 & 0,1 & 12,1 & 0,3 & 1,0 & 2,4 & 0,12 \\
\hline 3 & 0,1 & 27,0 & $<0,1$ & 71,5 & 0,2 & 0,2 & 0,7 & $<0,1$ \\
\hline 6 & 0,3 & 54,9 & 0,1 & 42,9 & 0,4 & 0,4 & 0,8 & $<0,1$ \\
\hline \multirow[t]{2}{*}{9} & 0,8 & 49,6 & $<0,1$ & 47,9 & 0,4 & 0,8 & 0,2 & $<0,1$ \\
\hline & \multicolumn{8}{|c|}{$0,05-0,1 \mathrm{~m}$} \\
\hline 0 & 0,3 & 75,8 & 0,1 & 22,3 & 0,2 & 0,5 & 0,5 & $<0,1$ \\
\hline 3 & 0,3 & 87,2 & 0,2 & 11,0 & 0,2 & 0,3 & 0,5 & $<0,1$ \\
\hline 6 & 0,3 & 72,3 & 0,1 & 25,4 & 0,2 & 0,2 & 1,2 & $<0,1$ \\
\hline \multirow[t]{2}{*}{9} & 0,4 & 81,0 & 0,1 & 16,5 & 0,3 & 0,2 & 1,1 & $<0,1$ \\
\hline & \multicolumn{8}{|c|}{$0,1-0,2 \mathrm{~m}$} \\
\hline 0 & 0,4 & 96,7 & 0,2 & 1,7 & 0,1 & 0,5 & 0,1 & $<0,1$ \\
\hline 3 & 0,2 & 92,6 & 0,3 & 5,6 & 0,2 & 0,4 & 0,5 & $<0,1$ \\
\hline 6 & 0,3 & 97,6 & 0,3 & 1,0 & 0,2 & 0,2 & 0,1 & $<0,1$ \\
\hline \multirow[t]{2}{*}{9} & 0,4 & 96,8 & 0,2 & 1,7 & 0,2 & 0,2 & 0,2 & $<0,1$ \\
\hline & \multicolumn{8}{|c|}{$0,2-0,4 \mathrm{~m}$} \\
\hline 0 & 0,3 & 97,7 & 0,2 & 0,2 & 0,2 & 0,4 & 0,4 & $<0,1$ \\
\hline 3 & 0,3 & 98,5 & 0,2 & 0,2 & 0,3 & 0,4 & 0,3 & $<0,1$ \\
\hline 6 & 0,3 & 98,7 & 0,3 & $<0,1$ & 0,3 & 0,2 & 0,3 & $<0,1$ \\
\hline \multirow[t]{2}{*}{9} & 0,3 & 98,8 & 0,2 & $<0,1$ & 0,2 & 0,2 & 0,3 & $<0,1$ \\
\hline & \multicolumn{8}{|c|}{$0,4-0,6 \mathrm{~m}$} \\
\hline 0 & 0,4 & 98,8 & 0,2 & $<0,1$ & $<0,1$ & 0,4 & - & $<0,1$ \\
\hline 3 & 0,2 & 98,7 & 0,3 & $<0,1$ & 0,1 & 0,4 & - & $<0,1$ \\
\hline 6 & 0,3 & 98,6 & 0,2 & $<0,1$ & 0,2 & 0,4 & - & $<0,1$ \\
\hline \multirow[t]{2}{*}{9} & 0,4 & 98,8 & 0,2 & $<0,1$ & 0,2 & 0,2 & - & $<0,1$ \\
\hline & \multicolumn{8}{|c|}{$0,6-0,8 \mathrm{~m}$} \\
\hline 0 & 0,4 & 98,8 & 0,2 & $<0,1$ & $<0,1$ & 0,3 & - & - \\
\hline 3 & 0,3 & 98,7 & 0,2 & $<0,1$ & $<0,1$ & 0,4 & - & - \\
\hline 6 & 0,4 & 98,6 & 0,2 & $<0,1$ & $<0,1$ & 0,5 & - & - \\
\hline 9 & 0,8 & 98,3 & 0,1 & $<0,1$ & 0,2 & 0,4 & - & - \\
\hline
\end{tabular}


Tabela 29. Porcentagem das espécies de fósforo na solução do solo, em função da dose de gesso no tratamento $4,5 \mathrm{t} \mathrm{ha}^{-1}$ de calcário em superfície (aplicação única)

\begin{tabular}{|c|c|c|c|c|c|c|c|c|}
\hline Dose de gesso & $\mathrm{HPO}_{4}^{-2}$ & $\mathrm{H}_{2} \mathrm{PO}_{4}^{-}$ & $\mathrm{H}_{3} \mathrm{PO} 4$ & $\mathrm{AlHPO}_{4}^{+}$ & $\mathrm{CaH}_{2} \mathrm{PO}_{4}^{+}$ & $\mathrm{MgH}_{2} \mathrm{PO}_{4}^{+}$ & $\mathrm{FeHPO}_{4}{ }^{+}$ & $\mathrm{KH}_{2} \mathrm{PO}_{4}$ \\
\hline $\mathrm{t} \mathrm{ha}^{-1}$ & \multicolumn{8}{|c|}{$\%$} \\
\hline & \multicolumn{8}{|c|}{$0-0,05 \mathrm{~m}$} \\
\hline 0 & 3,5 & 54,6 & - & 38,8 & 0,5 & 2,2 & $<0,1$ & $<0,1$ \\
\hline 3 & 2,0 & 65,5 & $<0,1$ & 29,5 & 0,5 & 1,9 & 0,2 & $<0,1$ \\
\hline 6 & 2,1 & 25,9 & - & 70,4 & 0,4 & 0,9 & $<0,1$ & $<0,1$ \\
\hline \multirow[t]{2}{*}{9} & 3,8 & 51,9 & $<0,1$ & 41,4 & 0,7 & 1,8 & $<0,1$ & $<0,1$ \\
\hline & \multicolumn{8}{|c|}{$00,5-0,1 \mathrm{~m}$} \\
\hline 0 & 0,6 & 65,6 & $<0,1$ & 32,1 & 0,1 & 0,9 & 0,3 & $<0,1$ \\
\hline 3 & 0,5 & 77,0 & 0,1 & 20,1 & 0,3 & 1,0 & 0,5 & $<0,1$ \\
\hline 6 & 0,5 & 55,9 & $<0,1$ & 41,7 & 0,2 & 0,5 & 0,8 & $<0,1$ \\
\hline \multirow[t]{2}{*}{9} & 0,0 & 58,1 & 1,0 & 39,4 & 0,2 & 0,6 & $<0,1$ & $<0,1$ \\
\hline & \multicolumn{8}{|c|}{$0,1-0,2 \mathrm{~m}$} \\
\hline 0 & 0,5 & 96,9 & 0,1 & 1,3 & 0,1 & 0,7 & 0,1 & $<0,1$ \\
\hline 3 & 0,4 & 96,3 & 0,2 & 0,7 & 0,1 & 1,0 & 1,0 & $<0,1$ \\
\hline 6 & 0,3 & 95,3 & 0,2 & 2,9 & 0,2 & 0,6 & 0,2 & $<0,1$ \\
\hline \multirow[t]{2}{*}{9} & 0,6 & 96,0 & 0,1 & 2,1 & 0,2 & 0,5 & 0,2 & $<0,1$ \\
\hline & \multicolumn{8}{|c|}{$0,2-0,4 \mathrm{~m}$} \\
\hline 0 & 0,4 & 98,4 & 0,2 & - & 0,1 & 0,7 & $<0,1$ & $<0,1$ \\
\hline 3 & 0,4 & 97,0 & 0,2 & $<0,1$ & 0,2 & 0,8 & $<0,1$ & $<0,1$ \\
\hline 6 & 0,4 & 98,4 & 0,2 & - & 0,2 & 0,6 & $<0,1$ & $<0,1$ \\
\hline \multirow[t]{2}{*}{9} & 0,5 & 98,1 & 0,1 & $<0,1$ & 0,2 & 0,8 & $<0,1$ & $<0,1$ \\
\hline & \multicolumn{8}{|c|}{$0,4-0,6 \mathrm{~m}$} \\
\hline 0 & 0,3 & 98,7 & 0,2 & $<0,1$ & - & 0,4 & - & - \\
\hline 3 & 0,4 & 98,4 & 0,2 & $<0,1$ & 0,1 & 0,6 & - & - \\
\hline 6 & 0,6 & 98,3 & 0,1 & $<0,1$ & 0,1 & 0,6 & - & - \\
\hline \multirow[t]{2}{*}{9} & 0,5 & 98,2 & 0,1 & $<0,1$ & 0,3 & 0,6 & - & - \\
\hline & \multicolumn{8}{|c|}{$0,6-0,8 \mathrm{~m}$} \\
\hline 0 & 0,4 & 96,4 & 0,1 & 0,47 & $<0,1$ & 0,5 & - & - \\
\hline 3 & 0,4 & 98,5 & 0,2 & 0,43 & $<0,1$ & 0,6 & - & - \\
\hline 6 & 0,6 & 98,4 & 0,1 & 0,61 & 0,1 & 0,6 & - & - \\
\hline 9 & 0,6 & 98,2 & 0,1 & 0,61 & 0,2 & 0,7 & - & - \\
\hline
\end{tabular}




\subsubsection{Distribuição das espécies de S-sulfato}

Como esperado, $\mathrm{o} \mathrm{SO}_{4}^{-2}$ foi a forma predominante de enxofre na solução do solo, independentemente do tratamento e da profundidade de amostragem (Tabelas 30, 31 e 32). As principais alterações nas formas de enxofre podem ser esperadas somente em ambientes reduzidos, com a formação de várias espécies de sulfetos, o que não foi a condição do ambiente de estudo.

$\mathrm{Na}$ solução do solo, $\mathrm{o} \mathrm{SO}_{4}^{-2}$ apresentou a maior porcentagem ligação com o Mg principalmente, seguido pelo $\mathrm{Ca}, \mathrm{Al}$ ou $\mathrm{K}$. Mesmo com a predominância da forma livre de $\mathrm{S}$ na solução do solo, a solubilidade do $\mathrm{SO}_{4}^{-2}$ no solo é limitada pela solubilidade do $\mathrm{CaSO}_{4} \cdot 2 \mathrm{H}_{2} \mathrm{O}$ (gesso), sendo que na concentração de $\mathrm{Ca}^{+2}$ de $10^{-2,5} \mathrm{~mol} \mathrm{~L}^{-1}$, a de $\mathrm{SO}_{4}^{-2}$ deve ser limitada em $10^{-2,14} \mathrm{~mol} \mathrm{~L}^{-1}$ (Lindsay, 1979). Portanto, em aplicações de doses elevadas de calcário em superfície no SPD, é possível que em um primeiro momento a disponibilidade de $\mathrm{SO}_{4}^{-2}$ seja reduzida na solução do solo das camadas mais superficiais do solo.

\subsubsection{Distribuição das espécies de $\mathrm{N}$-nitrato}

Na solução do solo, o nitrato ocorreu predominantemente na forma livre (Tabelas 33, 34 e 35), independentemente do tratamento e da profundidade, indicando baixa combinação com demais elemento em solução e, formando par iônico somente com o Ca e K. Amaral et al. (1998), realizando especiação iônica de solução percolada, observaram que o íon nitrato encontrava-se $100 \%$ na forma livre.

\subsubsection{Distribuição das espécies de cloreto}

Assim como o nitrato, o cloreto também ocorreu na solução do solo predominantemente como íon livre (Tabelas 36, 37 e 38), sem variação entre tratamentos e profundidade de amostragem. Quando formou par iônico, foi somente com $\mathrm{Ca}$ e $\mathrm{Mg}$, contribuindo, portanto para a lixiviação desses cátions, mesmo que em baixíssima escala. 
Tabela 30. Porcentagem das espécies de S-sulfato na solução do solo, em função das formas de aplicação do calcário

\begin{tabular}{|c|c|c|c|c|c|}
\hline Tratamento* & $\mathrm{SO}_{4}^{-2}$ & $\mathrm{AlSO}_{4}^{+}$ & $\mathrm{MgSO}_{4}^{0}$ & $\mathrm{CaSO}_{4}{ }_{4}$ & $\mathrm{KSO}_{4}$ \\
\hline & & & $\%$ & & \\
\hline & & & $0-0,05 \mathrm{~m}$ & & \\
\hline $\mathrm{T} 1$ & 93,5 & 0,5 & 3,1 & 2,2 & 0,4 \\
\hline $\mathrm{T} 2$ & 91,0 & 0,1 & 5,1 & 3,2 & 0,3 \\
\hline $\mathrm{T} 3$ & 89,8 & 0,2 & 6,3 & 3,2 & 0,3 \\
\hline \multirow[t]{2}{*}{$\mathrm{T} 4$} & 86,0 & 6,5 & 3,9 & 3,1 & 0,2 \\
\hline & & & $0,05-0,1 \mathrm{~m}$ & & \\
\hline $\mathrm{T} 1$ & 93,0 & 1,4 & 1,8 & 1,5 & 0,2 \\
\hline $\mathrm{T} 2$ & 93,7 & 0,9 & 3,4 & 1,6 & 0,1 \\
\hline $\mathrm{T} 3$ & 93,4 & 1,1 & 3,3 & 1,7 & 0,1 \\
\hline \multirow[t]{2}{*}{$\mathrm{T} 4$} & 89,0 & 4,2 & 3,7 & 2,6 & 0,1 \\
\hline & & & $0,1-0,2 \mathrm{~m}$ & & \\
\hline $\mathrm{T} 1$ & 97,0 & 0,1 & 1,6 & 0,8 & 0,2 \\
\hline $\mathrm{T} 2$ & 96,1 & 0,1 & 2,6 & 0,9 & 0,1 \\
\hline $\mathrm{T} 3$ & 96,4 & $<0,1$ & 2,3 & 0,8 & 0,1 \\
\hline \multirow[t]{2}{*}{$\mathrm{T} 4$} & 92,4 & 2,2 & 3,3 & 1,7 & 0,1 \\
\hline & & & $0,2-0,4 \mathrm{~m}$ & & \\
\hline $\mathrm{T} 1$ & 97,3 & 0,1 & 1,6 & 0,2 & $<0,1$ \\
\hline $\mathrm{T} 2$ & 96,7 & - & 2,2 & 0,7 & $<0,1$ \\
\hline $\mathrm{T} 3$ & 96,5 & - & 2,3 & 0,8 & $<0,1$ \\
\hline \multirow[t]{2}{*}{$\mathrm{T} 4$} & 96,0 & 0,1 & 2,7 & 0,8 & $<0,1$ \\
\hline & & & $0,4-0,6 \mathrm{~m}$ & & \\
\hline $\mathrm{T} 1$ & 97,9 & - & 1,3 & 0,4 & $<0,1$ \\
\hline $\mathrm{T} 2$ & 97,6 & - & 1,5 & 0,5 & $<0,1$ \\
\hline $\mathrm{T} 3$ & 97,7 & - & 1,4 & 0,5 & $<0,1$ \\
\hline \multirow[t]{2}{*}{$\mathrm{T} 4$} & 97,6 & - & 1,6 & 0,5 & $<0,1$ \\
\hline & & & $0,6-0,8 \mathrm{~m}$ & & \\
\hline $\mathrm{T} 1$ & 98,0 & - & 1,1 & 0,5 & $<0,1$ \\
\hline $\mathrm{T} 2$ & 98,0 & - & 1,3 & 0,4 & $<0,1$ \\
\hline $\mathrm{T} 3$ & 97,2 & - & 1,5 & 0,6 & - \\
\hline $\mathrm{T} 4$ & 98,0 & - & 1,3 & $<0,1$ & $<0,1$ \\
\hline
\end{tabular}


Tabela 31. Porcentagem das espécies de S-sulfato na solução do solo, em função da dose de gesso

\begin{tabular}{|c|c|c|c|c|c|c|}
\hline Dose de gesso & $\mathrm{SO}_{4}^{-2}$ & $\mathrm{HSO}_{4}^{-}$ & $\mathrm{AlSO}_{4}^{+}$ & $\mathrm{MgSO}_{4}^{0}$ & $\mathrm{CaSO}_{4}^{0}$ & $\mathrm{KSO}_{4}$ \\
\hline $\mathrm{th}^{-1}$ & \multicolumn{6}{|c|}{$\%$} \\
\hline \multicolumn{7}{|c|}{$0-0,05 \mathrm{~m}$} \\
\hline 0 & 93,5 & $<0,1$ & 0,5 & 3,1 & 2,2 & 0,4 \\
\hline 3 & 84,6 & $<0,1$ & 9,1 & 2,1 & 3,6 & 0,2 \\
\hline 6 & 90,0 & $<0,1$ & 3,3 & 2,0 & 4,0 & 0,3 \\
\hline 9 & 90,3 & $<0,1$ & 1,3 & 3,7 & 4,3 & 0,3 \\
\hline \multicolumn{7}{|c|}{$0,05-0,1 \mathrm{~m}$} \\
\hline 0 & 94,8 & 0,1 & 1,4 & 1,7 & 1,5 & 0,2 \\
\hline 3 & 95,6 & 0,1 & 0,8 & 1,1 & 1,9 & 0,1 \\
\hline 6 & 94,3 & 0,1 & 2,0 & 0,8 & 2,4 & 0,1 \\
\hline 9 & 95,3 & 0,1 & 0,9 & 0,7 & 2,6 & 0,2 \\
\hline \multicolumn{7}{|c|}{$0,1-0,2 \mathrm{~m}$} \\
\hline 0 & 97,0 & 0,1 & 0,1 & 1,6 & 0,8 & 0,2 \\
\hline 3 & 96,1 & 0,2 & 0,5 & 1,2 & 1,6 & 0,1 \\
\hline 6 & 97,0 & 0,2 & $<0,1$ & 0,7 & 1,7 & 0,1 \\
\hline 9 & 96,9 & 0,1 & 0,1 & 0,6 & 1,9 & 0,2 \\
\hline \multicolumn{7}{|c|}{$0,2-0,4 \mathrm{~m}$} \\
\hline 0 & 97,0 & 0,1 & 0,1 & 1,6 & 0,8 & 0,1 \\
\hline 3 & 97,1 & 0,1 & $<0,1$ & 1,2 & 1,2 & 0,1 \\
\hline 6 & 96,9 & 0,1 & - & 1,0 & 1,6 & 0,1 \\
\hline 9 & 96,9 & 0,1 & - & 0,6 & 2,1 & 0,1 \\
\hline \multicolumn{7}{|c|}{$0,4-0,6 \mathrm{~m}$} \\
\hline 0 & 97,9 & 0,1 & - & 1,3 & 0,4 & $<0,1$ \\
\hline 3 & 97,3 & 0,2 & - & 1,5 & 0,8 & $<0,1$ \\
\hline 6 & 97,0 & 0,1 & - & 1,4 & 1,2 & $<0,1$ \\
\hline 9 & 97,2 & 0,1 & - & 0,6 & 1,8 & $<0,1$ \\
\hline \multicolumn{7}{|c|}{$0,6-0,8 \mathrm{~m}$} \\
\hline 0 & 97,9 & 0,1 & - & 1,1 & 0,5 & $<0,1$ \\
\hline 3 & 97,7 & 0,1 & - & 1,4 & 0,5 & $<0,1$ \\
\hline 6 & 97,3 & 0,1 & - & 1,7 & 0,7 & $<0,1$ \\
\hline 9 & 97,1 & - & - & 1,1 & 1,5 & $<0,1$ \\
\hline
\end{tabular}


Tabela 32. Porcentagem das espécies de S-sulfato na solução do solo, em função da dose de gesso no tratamento $4,5 \mathrm{t} \mathrm{ha}^{-1}$ de calcário em superfície (aplicação única)

\begin{tabular}{|c|c|c|c|c|c|c|}
\hline Dose de gesso & $\mathrm{SO}_{4}^{-2}$ & $\mathrm{HSO}_{4}^{-}$ & $\mathrm{AlSO}_{4}^{+}$ & $\mathrm{MgSO}_{4}^{0}$ & $\mathrm{CaSO}_{4}^{0}$ & $\mathrm{KSO}_{4}$ \\
\hline $\mathrm{t} \mathrm{ha}^{-1}$ & \multicolumn{6}{|c|}{$\%$} \\
\hline \multicolumn{7}{|c|}{$0-0,05 \mathrm{~m}$} \\
\hline 0 & 89,8 & - & 0,2 & 6,3 & 3,2 & 0,3 \\
\hline 3 & 89,9 & $<0,1$ & 0,3 & 5,6 & 3,7 & 0,3 \\
\hline 6 & 89,1 & - & 0,6 & 5,0 & 4,7 & 0,3 \\
\hline 9 & 89,4 & - & 0,2 & 5,2 & 4,7 & 0,2 \\
\hline \multicolumn{7}{|c|}{$0,05-0,1 \mathrm{~m}$} \\
\hline 0 & 93,4 & $<0,1$ & 1,1 & 3,3 & 1,7 & 0,2 \\
\hline 3 & 92,2 & $<0,1$ & 0,8 & 3,4 & 3,1 & 0,2 \\
\hline 6 & 92,9 & $<0,1$ & 1,7 & 2,7 & 2,3 & 0,2 \\
\hline 9 & 93,4 & $<0,1$ & 0,9 & 2,8 & 2,5 & 0,2 \\
\hline \multicolumn{7}{|c|}{$0,1-0,2 \mathrm{~m}$} \\
\hline 0 & 96,4 & 0,1 & $<0,1$ & 2,3 & 0,8 & 0,1 \\
\hline 3 & 94,7 & 0,1 & $<0,1$ & 2,9 & 1,4 & 0,1 \\
\hline 6 & 95,8 & 0,1 & 0,2 & 1,9 & 1,7 & $<0,1$ \\
\hline 9 & 96,1 & $<0,1$ & 0,1 & 1,4 & 2,1 & 0,1 \\
\hline \multicolumn{7}{|c|}{$0,2-0,4 \mathrm{~m}$} \\
\hline 0 & 96,5 & 0,1 & - & 2,3 & 0,8 & $<0,1$ \\
\hline 3 & 95,7 & 0,1 & - & 2,4 & 1,5 & 0,1 \\
\hline 6 & 96,1 & 0,1 & - & 1,9 & 1,6 & $<0,1$ \\
\hline 9 & 95,2 & 0,1 & - & 2,3 & 2,2 & $<0,1$ \\
\hline \multicolumn{7}{|c|}{$0,4-0,6 \mathrm{~m}$} \\
\hline 0 & 97,7 & 0,1 & - & 1,4 & 0,5 & $<0,1$ \\
\hline 3 & 96,7 & 0,1 & - & 2,0 & 0,9 & $<0,1$ \\
\hline 6 & 96,9 & $<0,1$ & - & 1,7 & 1,1 & $<0,1$ \\
\hline 9 & 95,7 & 0,1 & - & 1,8 & 2,2 & $<0,1$ \\
\hline \multicolumn{7}{|c|}{$0,6-0,8 \mathrm{~m}$} \\
\hline 0 & 97,2 & 0,1 & 0,1 & 1,5 & 0,6 & $<0,1$ \\
\hline 3 & 97,1 & 0,1 & - & 1,9 & 0,7 & $<0,1$ \\
\hline 6 & 97,1 & 0,1 & - & 1,8 & 0,8 & $<0,1$ \\
\hline 9 & 95,8 & 0,1 & - & 2,1 & 1,8 & $<0,1$ \\
\hline
\end{tabular}


Tabela 33. Porcentagem das espécies de N-nitrato na solução do solo, em função das formas de aplicação do calcário

\begin{tabular}{|c|c|c|c|}
\hline Tratamento* & $\mathrm{NO}_{3}^{-}$ & $\mathrm{CaNO}_{3}{ }^{+}$ & $\mathrm{KNO}_{3}$ \\
\hline \multicolumn{4}{|c|}{$\%$} \\
\hline \multicolumn{4}{|c|}{$0-0,05 \mathrm{~m}$} \\
\hline $\mathrm{T} 1$ & 99,9 & $<0,1$ & $<0,1$ \\
\hline $\mathrm{T} 2$ & 99,9 & $<0,1$ & $<0,1$ \\
\hline $\mathrm{T} 3$ & 99,9 & $<0,1$ & $<0,1$ \\
\hline $\mathrm{T} 4$ & 99,9 & $<0,1$ & $<0,1$ \\
\hline \multicolumn{4}{|c|}{$0,5-0,1 \mathrm{~m}$} \\
\hline $\mathrm{T} 1$ & 99,9 & $<0,1$ & $<0,1$ \\
\hline $\mathrm{T} 2$ & 99,9 & $<0,1$ & $<0,1$ \\
\hline $\mathrm{T} 3$ & 99,9 & $<0,1$ & $<0,1$ \\
\hline $\mathrm{T} 4$ & 99,9 & $<0,1$ & $<0,1$ \\
\hline \multicolumn{4}{|c|}{$0,1-0,2 \mathrm{~m}$} \\
\hline $\mathrm{T} 1$ & 99,9 & $<0,1$ & $<0,1$ \\
\hline $\mathrm{T} 2$ & 99,9 & $<0,1$ & $<0,1$ \\
\hline $\mathrm{T} 3$ & 99,9 & $<0,1$ & $<0,1$ \\
\hline $\mathrm{T} 4$ & 99,9 & $<0,1$ & $<0,1$ \\
\hline \multicolumn{4}{|c|}{$0,2-0,4 \mathrm{~m}$} \\
\hline $\mathrm{T} 1$ & 99,9 & $<0,1$ & $<0,1$ \\
\hline $\mathrm{T} 2$ & 99,9 & $<0,1$ & $<0,1$ \\
\hline $\mathrm{T} 3$ & 99,9 & $<0,1$ & $<0,1$ \\
\hline $\mathrm{T} 4$ & 99,9 & $<0,1$ & $<0,1$ \\
\hline \multicolumn{4}{|c|}{$0,4-0,6 \mathrm{~m}$} \\
\hline $\mathrm{T} 1$ & 99,9 & $<0,1$ & $<0,1$ \\
\hline $\mathrm{T} 2$ & 99,9 & $<0,1$ & $<0,1$ \\
\hline $\mathrm{T} 3$ & 99,9 & $<0,1$ & $<0,1$ \\
\hline $\mathrm{T} 4$ & 99,9 & $<0,1$ & $<0,1$ \\
\hline \multicolumn{4}{|c|}{$0,6-0,8 \mathrm{~m}$} \\
\hline $\mathrm{T} 1$ & 99,9 & $<0,1$ & $<0,1$ \\
\hline $\mathrm{T} 2$ & 99,9 & $<0,1$ & $<0,1$ \\
\hline $\mathrm{T} 3$ & 99,9 & $<0,1$ & $<0,1$ \\
\hline $\mathrm{T} 4$ & 99,9 & $<0,1$ & $<0,1$ \\
\hline
\end{tabular}

*T1=testemunha; T2= 4,5 $\mathrm{t} \mathrm{ha}^{-1}\left(3\right.$ aplicações de 1,5 $\mathrm{t} \mathrm{ha}^{-1}$ ano $\left.^{-1}\right)$; T3=4,5 $\mathrm{t} \mathrm{ha}^{-1}$ aplicado em superfície; $\mathrm{T} 4=4,5 \mathrm{t} \mathrm{ha}^{-1}$ incorporado ao solo. 
Tabela 34. Porcentagem das espécies de N-nitrato na solução do solo, em função da dose de gesso

\begin{tabular}{|c|c|c|c|}
\hline Dose de gesso & $\mathrm{NO}_{3}^{-}$ & $\mathrm{CaNO}_{3}{ }^{+}$ & $\mathrm{KNO}_{3}$ \\
\hline \multirow[t]{2}{*}{$\mathrm{tha}^{-1}$} & \multicolumn{3}{|c|}{$\%$} \\
\hline & \multicolumn{3}{|c|}{$0-0,05 \mathrm{~m}$} \\
\hline 0 & 99,9 & $<0,1$ & $<0,1$ \\
\hline 3 & 99,8 & $<0,1$ & $<0,1$ \\
\hline 6 & 99,8 & $<0,1$ & $<0,1$ \\
\hline \multirow[t]{2}{*}{9} & 99,8 & $<0,1$ & $<0,1$ \\
\hline & \multicolumn{3}{|c|}{$0,5-0,1 \mathrm{~m}$} \\
\hline 0 & 99,9 & $<0,1$ & $<0,1$ \\
\hline 3 & 99,9 & $<0,1$ & $<0,1$ \\
\hline 6 & 99,9 & $<0,1$ & $<0,1$ \\
\hline \multirow[t]{2}{*}{9} & 99,9 & $<0,1$ & $<0,1$ \\
\hline & \multicolumn{3}{|c|}{$0,1-0,2 \mathrm{~m}$} \\
\hline 0 & 99,9 & $<0,1$ & $<0,1$ \\
\hline 3 & 99,9 & $<0,1$ & $<0,1$ \\
\hline 6 & 99,9 & $<0,1$ & $<0,1$ \\
\hline \multirow[t]{2}{*}{9} & 99,9 & $<0,1$ & $<0,1$ \\
\hline & \multicolumn{3}{|c|}{$0,2-0,4 \mathrm{~m}$} \\
\hline 0 & 99,9 & $<0,1$ & $<0,1$ \\
\hline 3 & 99,9 & $<0,1$ & $<0,1$ \\
\hline 6 & 99,9 & $<0,1$ & $<0,1$ \\
\hline \multirow[t]{2}{*}{9} & 99,9 & $<0,1$ & $<0,1$ \\
\hline & \multicolumn{3}{|c|}{$0,4-0,6 \mathrm{~m}$} \\
\hline 0 & 99,9 & $<0,1$ & - \\
\hline 3 & 99,9 & $<0,1$ & - \\
\hline 6 & 99,9 & $<0,1$ & - \\
\hline \multirow[t]{2}{*}{9} & 99,9 & $<0,1$ & - \\
\hline & \multicolumn{3}{|c|}{$0,6-0,8 \mathrm{~m}$} \\
\hline 0 & 99,9 & $<0,1$ & - \\
\hline 3 & 99,9 & $<0,1$ & - \\
\hline 6 & 99,9 & $<0,1$ & - \\
\hline 9 & 99,9 & $<0,1$ & - \\
\hline
\end{tabular}


Tabela 35. Porcentagem das espécies de N-nitrato na solução do solo, em função da dose de gesso no tratamento $4,5 \mathrm{t} \mathrm{ha}^{-1}$ de calcário em superfície (aplicação única)

\begin{tabular}{|c|c|c|c|}
\hline Dose de gesso & $\mathrm{NO}_{3}^{-}$ & $\mathrm{CaNO}_{3}{ }^{+}$ & $\mathrm{KNO}_{3}$ \\
\hline \multirow{2}{*}{$\mathrm{tha}^{-1}$} & \multicolumn{3}{|c|}{$\%$} \\
\hline & \multicolumn{3}{|c|}{$0-0,05 \mathrm{~m}$} \\
\hline 0 & 99,8 & - & $<0,1$ \\
\hline 3 & 99,8 & - & $<0,1$ \\
\hline 6 & 99,8 & - & $<0,1$ \\
\hline \multirow[t]{2}{*}{9} & 99,8 & - & $<0,1$ \\
\hline & \multicolumn{3}{|c|}{$0,5-0,1 \mathrm{~m}$} \\
\hline 0 & 99,9 & $<0,1$ & $<0,1$ \\
\hline 3 & 99,9 & $<0,1$ & $<0,1$ \\
\hline 6 & 99,9 & $<0,1$ & $<0,1$ \\
\hline \multirow[t]{2}{*}{9} & 99,9 & $<0,1$ & $<0,1$ \\
\hline & \multicolumn{3}{|c|}{$0,1-0,2 \mathrm{~m}$} \\
\hline 0 & 99,9 & $<0,1$ & $<0,1$ \\
\hline 3 & 99,9 & $<0,1$ & $<0,1$ \\
\hline 6 & 99,9 & $<0,1$ & $<0,1$ \\
\hline \multirow[t]{2}{*}{9} & 99,9 & $<0,1$ & $<0,1$ \\
\hline & \multicolumn{3}{|c|}{$0,2-0,4 \mathrm{~m}$} \\
\hline 0 & 99,9 & $<0,1$ & - \\
\hline 3 & 99,9 & $<0,1$ & - \\
\hline 6 & 99,9 & $<0,1$ & - \\
\hline \multirow[t]{2}{*}{9} & 99,9 & $<0,1$ & - \\
\hline & \multicolumn{3}{|c|}{$0,4-0,6 \mathrm{~m}$} \\
\hline 0 & 99,9 & $<0,1$ & - \\
\hline 3 & 99,9 & $<0,1$ & - \\
\hline 6 & 99,9 & $<0,1$ & - \\
\hline \multirow[t]{2}{*}{9} & 99,9 & $<0,1$ & - \\
\hline & \multicolumn{3}{|c|}{$0,6-0,8 \mathrm{~m}$} \\
\hline 0 & 99,9 & $<0,1$ & - \\
\hline 3 & 99,9 & $<0,1$ & - \\
\hline 6 & 99,9 & $<0,1$ & - \\
\hline 9 & 99,9 & $<0,1$ & - \\
\hline
\end{tabular}


Tabela 36. Porcentagem das espécies de cloreto na solução do solo, em função das formas de aplicação do calcário

\begin{tabular}{|c|c|c|c|}
\hline Tratamento & $\mathrm{Cl}^{-}$ & $\mathrm{CaCl}^{+}$ & $\mathrm{MgCl}^{+}$ \\
\hline \multicolumn{4}{|c|}{$\%$} \\
\hline \multicolumn{4}{|c|}{$0-0,05 \mathrm{~m}$} \\
\hline $\mathrm{T} 1$ & 99,8 & $<0,1$ & 0,1 \\
\hline $\mathrm{T} 2$ & 99,7 & $<0,1$ & 0,1 \\
\hline T3 & 99,6 & $<0,1$ & 0,2 \\
\hline $\mathrm{T} 4$ & 99,7 & $<0,1$ & 0,1 \\
\hline \multicolumn{4}{|c|}{$0,5-0,1 \mathrm{~m}$} \\
\hline $\mathrm{T} 1$ & 99,8 & $<0,1$ & $<0,1$ \\
\hline $\mathrm{T} 2$ & 99,8 & $<0,1$ & 0,1 \\
\hline T3 & 99,8 & $<0,1$ & 0,1 \\
\hline $\mathrm{T} 4$ & 99,7 & $<0,1$ & 0,1 \\
\hline \multicolumn{4}{|c|}{$0,1-0,2 \mathrm{~m}$} \\
\hline $\mathrm{T} 1$ & 99,9 & $<0,1$ & $<0,1$ \\
\hline $\mathrm{T} 2$ & 99,9 & $<0,1$ & $<0,1$ \\
\hline T3 & 99,9 & $<0,1$ & $<0,1$ \\
\hline $\mathrm{T} 4$ & 99,8 & $<0,1$ & $<0,1$ \\
\hline \multicolumn{4}{|c|}{$0,2-0,4 \mathrm{~m}$} \\
\hline $\mathrm{T} 1$ & 99,9 & $<0,1$ & $<0,1$ \\
\hline $\mathrm{T} 2$ & 99,9 & $<0,1$ & $<0,1$ \\
\hline $\mathrm{T} 3$ & 99,9 & $<0,1$ & $<0,1$ \\
\hline $\mathrm{T} 4$ & 99,9 & $<0,1$ & $<0,1$ \\
\hline \multicolumn{4}{|c|}{$0,4-0,6 \mathrm{~m}$} \\
\hline $\mathrm{T} 1$ & 99,9 & $<0,1$ & $<0,1$ \\
\hline $\mathrm{T} 2$ & 99,9 & $<0,1$ & $<0,1$ \\
\hline $\mathrm{T} 3$ & 99,9 & $<0,1$ & $<0,1$ \\
\hline $\mathrm{T} 4$ & 99,9 & $<0,1$ & $<0,1$ \\
\hline \multicolumn{4}{|c|}{$0,6-0,8 \mathrm{~m}$} \\
\hline $\mathrm{T} 1$ & 99,9 & $<0,1$ & $<0,1$ \\
\hline $\mathrm{T} 2$ & 99,9 & $<0,1$ & $<0,1$ \\
\hline T3 & 99,9 & $<0,1$ & $<0,1$ \\
\hline $\mathrm{T} 4$ & 99,9 & $<0,1$ & $<0,1$ \\
\hline
\end{tabular}

*T1=testemunha; T2= 4,5 $\mathrm{t} \mathrm{ha}^{-1}\left(3\right.$ aplicações de 1,5 $\mathrm{t} \mathrm{ha}^{-1}$ ano $\left.^{-1}\right)$; T3=4,5 $\mathrm{t} \mathrm{ha}^{-1}$ aplicado em superfície; $\mathrm{T} 4=4,5 \mathrm{t} \mathrm{ha}^{-1}$ incorporado ao solo. 
Tabela 37. Porcentagem das espécies de cloreto na solução do solo, em função da dose de gesso

\begin{tabular}{|c|c|c|c|}
\hline Dose de gesso & $\mathrm{Cl}^{-}$ & $\mathrm{CaCl}^{+}$ & $\mathrm{MgCl}^{+}$ \\
\hline \multirow[t]{2}{*}{$\mathrm{t} \mathrm{ha}^{-1}$} & \multicolumn{3}{|c|}{$\%$} \\
\hline & \multicolumn{3}{|c|}{$0-0,05 \mathrm{~m}$} \\
\hline 0 & 99,8 & $<0,1$ & $<0,1$ \\
\hline 3 & 99,7 & $<0,1$ & $<0,1$ \\
\hline 6 & 99,7 & $<0,1$ & $<0,1$ \\
\hline \multirow[t]{2}{*}{9} & 99,7 & $<0,1$ & 0,1 \\
\hline & \multicolumn{3}{|c|}{$0,5-0,1 \mathrm{~m}$} \\
\hline 0 & 99,8 & $<0,1$ & $<0,1$ \\
\hline 3 & 99,9 & $<0,1$ & $<0,1$ \\
\hline 6 & 99,9 & $<0,1$ & $<0,1$ \\
\hline \multirow[t]{2}{*}{9} & 99,9 & $<0,1$ & $<0,1$ \\
\hline & \multicolumn{3}{|c|}{$0,1-0,2 \mathrm{~m}$} \\
\hline 0 & 99,9 & $<0,1$ & $<0,1$ \\
\hline 3 & 99,9 & $<0,1$ & $<0,1$ \\
\hline 6 & 99,9 & $<0,1$ & $<0,1$ \\
\hline \multirow[t]{2}{*}{9} & 99,9 & $<0,1$ & $<0,1$ \\
\hline & \multicolumn{3}{|c|}{$0,2-0,4 \mathrm{~m}$} \\
\hline 0 & 99,9 & $<0,1$ & $<0,1$ \\
\hline 3 & 99,9 & $<0,1$ & $<0,1$ \\
\hline 6 & 99,9 & $<0,1$ & $<0,1$ \\
\hline \multirow[t]{2}{*}{9} & 99,9 & $<0,1$ & $<0,1$ \\
\hline & \multicolumn{3}{|c|}{$0,4-0,6 \mathrm{~m}$} \\
\hline 0 & 99,9 & $<0,1$ & $<0,1$ \\
\hline 3 & 99,9 & $<0,1$ & $<0,1$ \\
\hline 6 & 99,9 & $<0,1$ & $<0,1$ \\
\hline \multirow[t]{2}{*}{9} & 99,9 & $<0,1$ & $<0,1$ \\
\hline & \multicolumn{3}{|c|}{$0,6-0,8 \mathrm{~m}$} \\
\hline 0 & 99,9 & $<0,1$ & $<0,1$ \\
\hline 3 & 99,9 & $<0,1$ & $<0,1$ \\
\hline 6 & 99,9 & $<0,1$ & $<0,1$ \\
\hline 9 & 99,9 & $<0,1$ & $<0,1$ \\
\hline
\end{tabular}


Tabela 38. Porcentagem das espécies de cloreto na solução do solo, em função da dose de gesso no tratamento $4,5 \mathrm{t} \mathrm{ha}^{-1}$ de calcário em superfície (aplicação única)

\begin{tabular}{|c|c|c|c|}
\hline Dose de gesso & $\mathrm{Cl}^{-}$ & $\mathrm{CaCl}^{+}$ & $\mathrm{MgCl}^{+}$ \\
\hline \multirow[t]{2}{*}{$\mathrm{t} \mathrm{ha}^{-1}$} & \multicolumn{3}{|c|}{$\%$} \\
\hline & \multicolumn{3}{|c|}{$0-0,05 \mathrm{~m}$} \\
\hline 0 & 99,6 & $<0,1$ & 0,2 \\
\hline 3 & 99,6 & 0,1 & 0,2 \\
\hline 6 & 99,6 & 0,1 & 0,2 \\
\hline \multirow[t]{2}{*}{9} & 99,6 & 0,1 & 0,2 \\
\hline & \multicolumn{3}{|c|}{$0,5-0,1 \mathrm{~m}$} \\
\hline 0 & 99,8 & $<0,1$ & 0,1 \\
\hline 3 & 99,8 & $<0,1$ & 0,1 \\
\hline 6 & 99,8 & $<0,1$ & $<0,1$ \\
\hline \multirow[t]{2}{*}{9} & 99,8 & $<0,1$ & $<0,1$ \\
\hline & \multicolumn{3}{|c|}{$0,1-0,2 \mathrm{~m}$} \\
\hline 0 & 99,9 & $<0,1$ & $<0,1$ \\
\hline 3 & 99,8 & $<0,1$ & $<0,1$ \\
\hline 6 & 99,9 & $<0,1$ & $<0,1$ \\
\hline \multirow[t]{2}{*}{9} & 99,9 & $<0,1$ & $<0,1$ \\
\hline & \multicolumn{3}{|c|}{$0,2-0,4 \mathrm{~m}$} \\
\hline 0 & 99,9 & $<0,1$ & $<0,1$ \\
\hline 3 & 99,8 & $<0,1$ & $<0,1$ \\
\hline 6 & 99,9 & $<0,1$ & $<0,1$ \\
\hline \multirow[t]{2}{*}{9} & 99,8 & $<0,1$ & $<0,1$ \\
\hline & \multicolumn{3}{|c|}{$0,4-0,6 \mathrm{~m}$} \\
\hline 0 & 99,9 & $<0,1$ & $<0,1$ \\
\hline 3 & 99,9 & $<0,1$ & $<0,1$ \\
\hline 6 & 99,9 & $<0,1$ & $<0,1$ \\
\hline \multirow[t]{2}{*}{9} & 99,9 & $<0,1$ & $<0,1$ \\
\hline & \multicolumn{3}{|c|}{$0,6-0,8 \mathrm{~m}$} \\
\hline 0 & 99,9 & $<0,1$ & $<0,1$ \\
\hline 3 & 99,9 & $<0,1$ & $<0,1$ \\
\hline 6 & 99,9 & $<0,1$ & $<0,1$ \\
\hline 9 & 99,9 & $<0,1$ & $<0,1$ \\
\hline
\end{tabular}




\subsection{Fracionamento do Al na fase sólida do solo e efeito dos tratamentos}

Não houve interação significativa entre calagem e gessagem na redução do Al trocável do solo. A calagem promoveu redução do $\mathrm{Al}^{+3}$ até $0,4 \mathrm{~m}$ (Tabela 39). Nas profundidades de 0,05-0,1 e 0,1-0,2 $\mathrm{m}$ a calagem incorporada diferiu da calagem em superfície, conferindo maior redução do $\mathrm{Al}^{+3}$. Oliveira \& Pavan (1996) também observaram a redução do $\mathrm{Al}$ trocável até $0,4 \mathrm{~m}$ de profundidade aos 32 meses após a calagem em superfície. Caires et al. (1998) encontraram diminuição do Al trocável até $0,2 \mathrm{~m}$ aos 28 meses da realização da calagem. Nos tratamentos que receberam calagem os teores de $\mathrm{Al}$, na camada de 0-0,05 m, ficaram abaixo do limite de detecção da metodologia utilizada para determinação do $\mathrm{Al}$ (extração com $\mathrm{KCl}$ e titulação com $\mathrm{NaOH}$ ), devido aos elevados teores de $\mathrm{MO}$ e $\mathrm{pH}$ mais elevado.

O efeito da aplicação superficial do gesso na redução do Al trocável após 55 meses ocorreu somente na última profundidade (Figura 15). Possivelmente, os efeitos nas demais camadas deixaram de existir, devido ao longo período transcorrido da instalação do experimento até as determinações. Num tempo bem menor após a gessagem (14 meses), Caires et al. (1999) encontraram que aplicação superficial do gesso provocou redução do Al trocável nas camadas de 0,05-0,1, 0,2-0,4, 0,4-0,6 e 0,6-0,8 m num Latossolo Vermelho distrófico.

Muitos mecanismos são atribuídos como responsáveis pela redução desta forma de $\mathrm{Al}$ no solo, tais como o aumento do $\mathrm{pH}$ da solução do solo, complexação do Al pelo fluoreto presente como impureza no gesso e também a formação do par iônico $\mathrm{AlSO}_{4}{ }^{+}$(Shaimberg et al., 1989). Além da redução da saturação com Al do complexo de troca, também são observados acréscimos significativos dos teores de $\mathrm{Ca}^{+2}$, elevando a V\% em profundidade. 
Tabela 39. Teores de $\mathrm{Al}$ extraído com $\mathrm{KCl}$ em função das formas de aplicação do calcário

\begin{tabular}{|c|c|c|}
\hline Profundidade & Tratamento & Média* \\
\hline $\mathrm{m}$ & $\mathrm{t} \mathrm{ha}^{-1}$ & $\mathrm{mmol}_{\mathrm{c}} \mathrm{kg}^{-1}$ \\
\hline $0-0,05$ & $\begin{array}{c}\text { Sem calcário } \\
4,5 \text { em superfície parcelado }\left(1,5 \mathrm{ano}^{-1}\right) \\
4,5 \text { em superfície } \\
4,5 \text { incorporado }\end{array}$ & $\begin{array}{l}1,40 \\
\text { nd }^{* *} \\
\text { nd } \\
\text { nd }\end{array}$ \\
\hline $0,05-0,1$ & $\begin{array}{c}\text { Sem calcário } \\
4,5 \text { em superfície parcelado }\left(1,5 \mathrm{ano}^{-1}\right) \\
4,5 \text { em superfície } \\
4,5 \text { incorporado }\end{array}$ & $\begin{array}{l}4,7 \mathrm{a} \\
1,1 \mathrm{~b} \\
1,0 \mathrm{~b} \\
0,4 \mathrm{c}\end{array}$ \\
\hline $0,1-0,2$ & $\begin{array}{c}\text { Sem calcário } \\
4,5 \text { em superfície parcelado }\left(1,5 \mathrm{ano}^{-1}\right) \\
4,5 \text { em superfície } \\
4,5 \text { incorporado }\end{array}$ & $\begin{array}{l}6,6 \mathrm{a} \\
4,8 \mathrm{~b} \\
4,2 \mathrm{~b} \\
1,1 \mathrm{c}\end{array}$ \\
\hline $0,2-0,4$ & $\begin{array}{c}\text { Sem calcário } \\
4,5 \text { em superfície parcelado }\left(1,5 \mathrm{ano}^{-1}\right) \\
4,5 \text { em superfície } \\
4,5 \text { incorporado }\end{array}$ & $\begin{array}{l}6,0 \mathrm{a} \\
3,8 \mathrm{~b} \\
3,6 \mathrm{~b} \\
3,0 \mathrm{~b}\end{array}$ \\
\hline $0,4-0,6$ & $\begin{array}{c}\text { Sem calcário } \\
4,5 \text { em superfície parcelado }\left(1,5 \mathrm{ano}^{-1}\right) \\
4,5 \text { em superfície } \\
4,5 \text { incorporado }\end{array}$ & $\begin{array}{l}3,9 \mathrm{a} \\
2,6 \mathrm{a} \\
2,8 \mathrm{a} \\
2,5 \mathrm{a}\end{array}$ \\
\hline $0,6-0,8$ & $\begin{array}{c}\text { Sem calcário } \\
4,5 \text { em superfície parcelado }\left(1,5 \mathrm{ano}^{-1}\right) \\
4,5 \text { em superfície } \\
4,5 \text { incorporado }\end{array}$ & $\begin{array}{l}2,0 \mathrm{a} \\
1,8 \mathrm{a} \\
1,5 \mathrm{a} \\
1,4 \mathrm{a}\end{array}$ \\
\hline
\end{tabular}

*Significativo pelo teste Tukey a 5\%. Médias seguidas pela mesma letra não diferem dentro de cada profundidade. ** não detectado. 


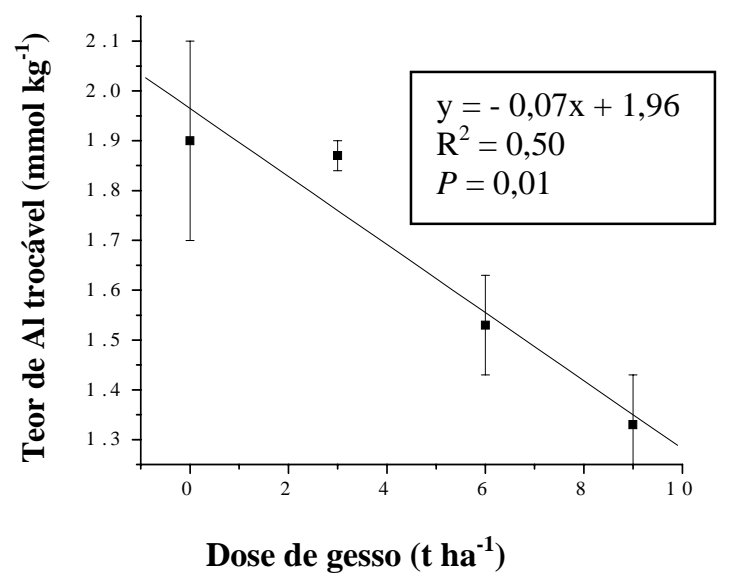

Figura 15 - Variação do teor de Al trocável, em função da gessagem, na profundidade de $0,6-0,8 \mathrm{~m}$

A calagem também promoveu a redução do $\mathrm{Al}-\mathrm{CuCl}_{2}$, mas somente nas profundidades de 0-0,05 e 0,1-0,2 m (Tabela 40). Não foi observado efeito da gesssagem nos teores de $\mathrm{Al}$ extraídos em $\mathrm{CuCl}_{2}$ em nenhuma profundidade. $\mathrm{Na}$ primeira camada não houve efeito das formas de aplicação do calcário na redução do $\mathrm{Al}-\mathrm{CuCl}_{2}$. $\mathrm{Na}$ profundidade de 0,1-0,2 $\mathrm{m}$ a calagem incorporada diferiu da calagem superficial, conferindo maior redução aos teores de Al extraído. Figueiredo \& Almeida (1991), trabalhando com 26 amostras de solos ácidos de Santa Catarina, observaram que os teores de $\mathrm{Al}$ extraído com $\mathrm{CuCl}_{2}$ reduziram com o aumento da dose de calcário. Contudo, o uso da solução de $\mathrm{CuCl}_{2}$ não constitui um método adequado para avaliar o Al precipitado pela calagem, porque o $\mathrm{pH}$ baixo dessa solução tamponada $(3,3)$ diminui o pH da mistura solo/solução, podendo redissolver o alumínio já precipitado. Figueiredo \& Almeida (1991) concluíram em seu trabalho que o emprego de $\mathrm{CuCl}_{2}$ para quantificar as formas não trocáveis de $\mathrm{Al}$ em solos calcareados não foram adequados, por ocasionarem a redissolução do Al (Oates \& Kamprath, 1983).

Kamprath (1970) encontrou que foi requerido o dobro da doses de calcário para neutralizar todo o Al trocável em Ultissolos ácidos, sugerindo que há outras formas de $\mathrm{Al}$ reativo no solo que não são trocáveis com o $\mathrm{KCl}$, mas reagem com o calcário, e 
que as formas reativas não trocáveis de Al devem tornar-se significantes fontes fitotóxicas de $\mathrm{Al}$ com o tempo. Em solos sob SPD, como foi observado, grande parte do Al do solo encontrou-se numa forma não trocável, portanto estas formas devem apresentar importante contribuição na dinâmica do Al.

Tabela 40. Teores de $\mathrm{Al}$ extraído com $\mathrm{CuCl}_{2}$ em função das formas de aplicação do calcário

\begin{tabular}{|c|c|c|}
\hline Profundidade & Tratamento & Média* \\
\hline $\mathrm{m}$ & $\mathrm{t} \mathrm{ha}^{-1}$ & $\mathrm{mmol}_{\mathrm{c}} \mathrm{kg}^{-1}$ \\
\hline $0-0,05$ & $\begin{array}{c}\text { Sem calcário } \\
4,5 \text { em superfície parcelado }\left(1,5 \mathrm{ano}^{-1}\right) \\
4,5 \text { em superfície } \\
4,5 \text { incorporado }\end{array}$ & $\begin{array}{l}39,6 \mathrm{a} \\
21,7 \mathrm{~b} \\
19,9 \mathrm{~b} \\
19,7 \mathrm{~b}\end{array}$ \\
\hline $0,05-0,1$ & $\begin{array}{c}\text { Sem calcário } \\
4,5 \text { em superfície parcelado }\left(1,5 \mathrm{ano}^{-1}\right) \\
4,5 \text { em superfície } \\
4,5 \text { incorporado }\end{array}$ & $\begin{array}{l}41,6 \mathrm{a} \\
35,4 \mathrm{a} \\
32,9 \mathrm{a} \\
26,3 \mathrm{a}\end{array}$ \\
\hline $0,1-0,2$ & $\begin{array}{c}\text { Sem calcário } \\
4,5 \text { em superfície parcelado }\left(1,5 \mathrm{ano}^{-1}\right) \\
4,5 \text { em superfície } \\
4,5 \text { incorporado }\end{array}$ & $\begin{array}{l}49,11 \mathrm{a} \\
42,06 \mathrm{~b} \\
37,33 \mathrm{~b} \\
30,08 \mathrm{c}\end{array}$ \\
\hline $0,2-0,4$ & $\begin{array}{c}\text { Sem calcário } \\
4,5 \text { em superfície parcelado }\left(1,5 \mathrm{ano}^{-1}\right) \\
4,5 \text { em superfície } \\
4,5 \text { incorporado }\end{array}$ & $\begin{array}{l}43,61 \mathrm{a} \\
41,22 \mathrm{a} \\
39,74 \mathrm{a} \\
32,38 \mathrm{a}\end{array}$ \\
\hline $0,4-0,6$ & $\begin{array}{c}\text { Sem calcário } \\
4,5 \text { em superfície parcelado }\left(1,5 \mathrm{ano}^{-1}\right) \\
4,5 \text { em superfície } \\
4,5 \text { incorporado }\end{array}$ & $\begin{array}{l}37,38 \text { a } \\
32,49 \text { a } \\
32,93 \text { a } \\
29,97 \text { a }\end{array}$ \\
\hline $0,6-0,8$ & $\begin{array}{c}\text { Sem calcário } \\
4,5 \text { em superfície parcelado }\left(1,5 \mathrm{ano}^{-1}\right) \\
4,5 \text { em superfície } \\
4,5 \text { incorporado }\end{array}$ & $\begin{array}{l}34,88 \mathrm{a} \\
29,49 \mathrm{a} \\
31,24 \mathrm{a} \\
25,60 \mathrm{a}\end{array}$ \\
\hline
\end{tabular}

*Significativo pelo teste Tukey a 5\% . Médias seguidas pela mesma letra não diferem dentro de cada profundidade.

A calagem afetou significativamente o Al complexado pela matéria orgânica apenas na camada de 0-0,05 m, mas não houve diferença entre as formas de aplicação (Tabela 41). O efeito do calcário em reduzir o Al ligado à MO é dado tanto 
pelo aumento do pH do solo, quanto pelo aumento da concentração de $\mathrm{Ca}$ e $\mathrm{Mg}$ oriundos da calagem, que provocam o deslocamento deste alumínio que estava nos complexos orgânicos. Mendonça \& Rowell (1994) observaram redução do Al complexado pela MO na camada superficial do solo $(0-0,08 \mathrm{~m})$ com aplicação de calcário, devido à remoção do $\mathrm{Al}$ pelo Ca oriundo do calcário, mas, no entanto, esse $\mathrm{Al}$ foi precipitado, pois não foi detectado aumento dos teores trocáveis.

Tabela 41. Teores de Al complexado com MO do solo em função das formas de aplicação do calcário

\begin{tabular}{|c|c|c|}
\hline Profundidade & Tratamento & Média* \\
\hline $\mathrm{m}$ & t ha $^{-1}$ & $\mathrm{mmol}_{\mathrm{c}} \mathrm{kg}^{-1}$ \\
\hline $0-0,05$ & $\begin{array}{c}\text { Sem calcário } \\
4,5 \text { em superfície parcelado }\left(1,5 \mathrm{ano}^{-1}\right) \\
4,5 \text { em superfície } \\
4,5 \text { incorporado }\end{array}$ & $\begin{array}{l}36,70 \mathrm{a} \\
19,56 \mathrm{~b} \\
18,63 \mathrm{~b} \\
21,51 \mathrm{~b}\end{array}$ \\
\hline $0,05-0,1$ & $\begin{array}{c}\text { Sem calcário } \\
4,5 \text { em superfície parcelado }\left(1,5 \mathrm{ano}^{-1}\right) \\
4,5 \text { em superfície } \\
4,5 \text { incorporado }\end{array}$ & $\begin{array}{l}36,93 \mathrm{a} \\
34,35 \mathrm{a} \\
31,87 \mathrm{a} \\
25,94 \mathrm{a}\end{array}$ \\
\hline $0,1-0,2$ & $\begin{array}{c}\text { Sem calcário } \\
4,5 \text { em superfície parcelado }\left(1,5 \mathrm{ano}^{-1}\right) \\
4,5 \text { em superfície } \\
4,5 \text { incorporado }\end{array}$ & $\begin{array}{l}42,55 \mathrm{a} \\
33,16 \mathrm{a} \\
37,31 \mathrm{a} \\
30,00 \mathrm{a}\end{array}$ \\
\hline $0,2-0,4$ & $\begin{array}{c}\text { Sem calcário } \\
4,5 \text { em superfície parcelado }\left(1,5 \mathrm{ano}^{-1}\right) \\
4,5 \text { em superfície } \\
4,5 \text { incorporado }\end{array}$ & $\begin{array}{l}37,63 \mathrm{a} \\
37,43 \mathrm{a} \\
35,21 \mathrm{a} \\
29,54 \mathrm{a}\end{array}$ \\
\hline $0,4-0,6$ & $\begin{array}{c}\text { Sem calcário } \\
4,5 \text { em superfície parcelado }\left(1,5 \mathrm{ano}^{-1}\right) \\
4,5 \text { em superfície } \\
4,5 \text { incorporado }\end{array}$ & $\begin{array}{l}33,45 \mathrm{a} \\
30,16 \mathrm{a} \\
29,09 \mathrm{a} \\
26,50 \mathrm{a}\end{array}$ \\
\hline $0,6-0,8$ & $\begin{array}{c}\text { Sem calcário } \\
4,5 \text { em superfície parcelado }\left(1,5 \mathrm{ano}^{-1}\right) \\
4,5 \text { em superfície } \\
4,5 \text { incorporado }\end{array}$ & $\begin{array}{l}32,88 \mathrm{a} \\
27,72 \mathrm{a} \\
29,77 \mathrm{a} \\
26,42 \mathrm{a}\end{array}$ \\
\hline
\end{tabular}

*Significativo pelo teste Tukey a 5\% . Médias seguidas pela mesma letra não diferem dentro de cada profundidade. 
Em todos os tratamentos e profundidades de amostragem, a quantidade de $\mathrm{Al}$ extraído com o $\mathrm{CuCl}_{2}$ foi muito maior do a de extraído com $\mathrm{KCl}$ em. $\mathrm{O} \mathrm{Al}$ extraído em $\mathrm{CuCl}_{2}$ foi na média dos tratamentos, 70,$2 ; 35,6 ; 13,8 ; 10,4 ; 11,4 ; 19,0$ vezes maior do que o $\mathrm{Al}$ extraído em $\mathrm{KCl}$ nas profundidades de 0-0,05, 0,05-0,1, 0,1-0,2, 0,2-0,4, 0,4-0,6 e 0,6-0,8 m, respectivamente. A elevada diferença existente entre do Al extraído e $\mathrm{CuCl}_{2}$ e $\mathrm{Al} \mathrm{KCl}$, principalmente nas duas primeiras camadas é devido aos altos teores de MO, que atua na complexação do Al. Juo \& Kamprath (1979) também obtiveram maiores valores de $\mathrm{Al}$ extraídos com $\mathrm{CuCl}_{2}$. Com exceção das duas primeiras profundidades, os valores de $\mathrm{Al}$ extraídos com $\mathrm{CuCl}_{2}$ em relação aos extraídos com $\mathrm{KCl}$ estão bem próximos dos encontrados pelos referidos autores, em trabalho realizado em horizontes superficiais de vários solos, entre eles Oxisolos.

Os teores de $\mathrm{Al}$ extraídos com $\mathrm{KCl}$ ou $\mathrm{CuCl}_{2}$, além dos próprios teores absolutos de $\mathrm{Al}$ e de $\mathrm{MO}$, dependem também da constituição mineralógica do solo. A diferença entre o $\mathrm{Al}$ extraído em $\mathrm{CuCl}_{2}$ e $\mathrm{KCl}$ nos horizontes superficiais pode ser atribuída principalmente aos complexos Al-MO, enquanto que no subsolo, a quantidade muito maior de $\mathrm{Al}$ extraído pelo $\mathrm{CuCl}_{2}$ deve ser atribuída aos polímeros $\mathrm{Al}-\mathrm{OH}$, bem como as formas meta estáveis de hidróxidos e oxi hidróxidos de $\mathrm{Al}$, devido ao baixo $\mathrm{pH}$ da solução de cobre (Juo \& Kamprath, 1979). Este fato foi comprovado pelos autores mediante a acidificação da solução de $\mathrm{KCl}$ com ácido clorídrico a pH 3,0, obtendo extração semelhante de $\mathrm{Al}$ em subsuperfície em relação ao $\mathrm{CuCl}_{2}$; no entanto, na camada superficial, o $\mathrm{CuCl}_{2}$ continuou a extrair 20 vezes mais Al. Desta maneira, no presente trabalho, como foi observada redução dos teores de MO com o aumento da profundidade, possivelmente houve uma redução relativa dos complexos Al-MO e aumento dos polímeros de $\mathrm{Al}-\mathrm{OH}$, nos teores de Al extraídos com o cloreto de cobre.

Em todas as profundidades o $\mathrm{Al}-\mathrm{KCl}$ e o $\mathrm{Al}-\mathrm{CuCl}_{2}$ apresentaram correlação positiva e significativa $(\mathrm{r}=0,87, P<0,0001 ; \mathrm{r}=0,72, P=0,02 ; \mathrm{r}=0,80$, $P=0,02 ; \mathrm{r}=0,53, P=0,03 ; \mathrm{r}=0,75, P=0,0008 ; \mathrm{r}=0,6, P=0,01$ para as profundidades de $0-0,05, \quad 0,05-0,1, \quad 0,1-0,2, \quad 0,2-0,4, \quad 0,4-0,6$ e $\quad 0,6-0,8$ m, respectivamente) indicando que estas duas formas de $\mathrm{Al}$ estão em equilíbrio. Possivelmente, o $\mathrm{Al}$ extraído pelo $\mathrm{CuCl}_{2}$ é responsável pela reposição do $\mathrm{Al}$ trocável, 
quando este é neutralizado pela calagem e/ou gessagem, atuando desta maneira como forma tamponante de $\mathrm{Al}$ no solo. Estas duas formas de $\mathrm{Al}$ apresentaram uma correlação negativa com $\mathrm{pH}$ do solo em todas as profundidades. Estas correlações negativas indicam, que à medida que há elevação do $\mathrm{pH}$ do solo, ocorre aumento das formas precipitadas de $\mathrm{Al}$, mesmo estando a ligado à $\mathrm{MO}$.

A porcentagem de complexação de Al pela MO foi 98,5; 95,4; 91,3; 89,4; 91,0 e 90,6 para as profundidades de $0-0,05 ; 0,05-0,1 ; 0,1-0,2 ; 0,2-0,4 ; 0,4-0,6$ e 0,6-0,8 m, respectivamente. O Al complexado pela MO não apresentou correlação com os teores de $\mathrm{C}$ orgânico do solo em nenhuma das profundidades, indicando que a complexação não depende exclusivamente dos teores de $\mathrm{C}$ orgânico do solo, mas também do grau do humificação desta matéria orgânica (atividade de seus radicais).

As formas não trocáveis do alumínio, embora não exerçam efeitos fitotóxicos diretos, atuam no tamponamento do $\mathrm{pH}$ do solo e afetam tanto a atividade do $\mathrm{Al}^{+3}$ na solução do solo (Juo \& Kamprath, 1979), como a necessidade de calcário (Figueiredo \& Almeida, 1979). No SPD, a maior parte do Al extraído está complexado pela MO; portanto, esta deve ser a forma de alumínio predominantemente em controlar a atividade do $\mathrm{Al}$ na solução do solo. No entanto, o $\mathrm{Al}-\mathrm{CuCl}_{2}$ parece não esta atuando diretamente no controle da atividade dos íons $\mathrm{Al}^{+3}$ em solução, pois em nenhuma profundidade foi observada correlação entre os teores de $\mathrm{Al}-\mathrm{CuCl}_{2}$ e atividade. A atividade do íon $\mathrm{Al}^{+3}$ se correlacionou somente com o $\mathrm{Al}$ trocável $(\mathrm{r}=0,48, P=0,05$; $\mathrm{r}=0,56, P=0,02$ nas profundidades de 0-0,05 e 0,05-0,1 m, respectivamente). Mas, como nestas duas profundidades também foi encontrada correlação positiva entre $\mathrm{Al}-\mathrm{KCl}$ e $\mathrm{Al}-\mathrm{CuCl}_{2}$, pode-se dizer que o $\mathrm{Al}$ extraído com $\mathrm{CuCl}_{2}$ atua de maneira indireta no controle da atividade do $\mathrm{Al}$ em solução.

Apesar da fase líquida e sólida do solo encontrarem-se em equilíbrio, os teores de Al em solução não se correlacionaram de forma significativa com nenhuma das formas de $\mathrm{Al}$ da fase sólida do solo. A concentração e a atividade do Al em solução depende não só dos mecanismos que controlam sua distribuição entre a fase sólida e líquida, mas também do seu comportamento físico-químico na solução (Kaminsk \& Rheinheimer, 2000), devido ao comportamento do Al em solução de estar sempre 
combinado com outros elementos constituintes do meio, daí a importância do fracionamento do $\mathrm{Al}$, tanto na fase líquida quanto na sólida do solo. 


\section{CONCLUSÕES}

- A calagem realizada em superfície ou incorporada elevou o pH da solução do solo até 0,2 m. Com exceção da camada 0-0,05 m, quando o calcário foi incorporado, os teores de $\mathrm{Ca}$ e $\mathrm{Mg}$ em solução foram incrementados até 0,2 e 0,6 $\mathrm{m}$, respectivamente;

- Os ânions orgânicos e o fluoreto foram os principais responsáveis pela complexação do Al na solução do solo, e a forma predominante de Al ligado à fase sólida do solo no SPD foi a complexada pela MO;

- O aumento da concentração dos cátions básicos na solução do solo foi acompanhado pelo aumento das correspondentes atividades;

- Os tratamentos não afetaram a concentração e a atividade do Al na solução do solo. A calagem elevou os teores solúveis de $\mathrm{Ca}$ e $\mathrm{Mg}$, mas somente o $\mathrm{Mg}$ teve, ao mesmo tempo, o aumento de sua atividade;

- A aplicação de gesso agiu negativamente sobre o $\mathrm{Mg}$, tanto pela indução de lixiviação, quanto pela redução da atividade deste cátion. Ao mesmo tempo, elevou a concentração e atividade de Ca na solução do solo;

- A especiação de alguns elementos em maior ou menor intensidade variou com os tratamentos e com as profundidades. Para $\mathrm{Ca}$ e $\mathrm{Mg}$, os principais ligantes em solução foram os ânions orgânicos. Para o P, o principal par iônico formado foi 
com o $\mathrm{Al}$, enquanto o $\mathrm{SO}_{4}{ }^{-2}$ formou par iônico com $\mathrm{Ca}$ e $\mathrm{Mg}$ principalmente. $\mathrm{A}$ especiação do $\mathrm{Fe}$ ocorreu entre espécies hidroxiladas ou ligado ao COD. Os elementos $\mathrm{Mn}, \mathrm{K}, \mathrm{N}_{-} \mathrm{NO}_{3}^{-}$e $\mathrm{Cl}$ não formaram pares iônicos com outros elementos em proporções significativas, ao longo de todas as profundidades. 


\section{REFERÊNCIAS BIBLIOGRÁFICAS}

ADAMS, F.; LUND, Z.F. Effect of chemical activity of soil solution aluminum on cotton root penetration of acid subsoils. Soil Science, v. 121, p. 193-198, 1966.

ADAMS, M.L.; MCINTOSH, P.D.; PATTERSON, R.D.; POWELL, K.J. Aluminium speciation in seasonally dry high country soils, South Island, New Zeland. Australian Journal of Soil Research, v. 37, p. 1005-1015, 1999.

ADRIANO, D.C. Trace elements in the terrestrial envairoment. New York: SpringerVerlag, 1986. 533p.

ALLEONI， L.R.F.; ZAMBROSI， F.C.B.; MOREIRA， S.G. PROCHNOW， L.I.; PAULETTI, V. Liming and electrochemical attributes of an oxisol under no tillage. Scientia Agrícola, v. 60, p. 119-123, 2003.

ALVA, A.K.; SUMNER, M.E. Effects of phosphosypsum or calcium sulfate on alumion reactive aluminium in solutions at varying $\mathrm{pH}$. Communications in Soil Science and Plant Analysis, v. 19, p. 1715-1730, 1988.

AMARAL, F.C.S. Efeito do flúor sobre o alumínio e o fósforo em um Podzólico Vermelho-Amarelo e sua acumulação em algumas espécies vegetais. Piracicaba, 1997. 140 p. Tese (Doutorado) - Escola Superior de Agricultura "Luiz de Queiroz", Universidade de São Paulo. 
AMARAL, F.C.S.; VETTORAZZO, S.C.; CHITOLINA, J.C. Efeito do fluoreto de cálcio e do carbonato de cálcio na composição química da solução percolada de um solo ácido. Revista Brasileira de Ciência do Solo, v. 22, p. 379-385, 1998.

ANGHINONI, I.; SALET, R.L. Reaplicação de calcário no sistema de plantio direto. In: KAMINSK, J. Uso de corretivos da acidez do solo no plantio direto. Pelotas: SBCS - Núcleo Regional Sul, 2000. p.41-60.

BAYER, C.; MIELNICZUK, J. Características químicas do solo afetados por métodos de preparo e sistema de cultura. Revista Brasileira de Ciência do Solo, v. 21, p. 105-112, 1997.

BERTON, R.S. Especiação iônica da solução do solo - metodologias e aplicações. In: SIMPÓSIO AVANÇADO DE SOLOS E NUTRIÇÃO DE PLANTAS, 2., Piracicaba, 1989. Piracicaba:ESALQ, 1989. p.16-40.

BESSO, T.; BELL, C. Soil and solution phase changes and mung bean response during ameliration of aluminum toxicity with organic matter. Pant and Soil, v. 140, p. 183$192,1992$.

BOEKERT, C.M.. Micronutrientes no solo - manganês. In: FERREIRA, N.E.; CRUZ, M.C. P. da. Micronutrientes na Agricultura. Piracicaba: Potafos, 1991. cap. 5, p. 113-266.

BRENES, E.; PEARSON, R.W. Root responses of graminae species to soil acidity in on Oxisol and on Ultisol. Soil Science, v. 116, p. 295-302, 1973.

BRUCE, R.C.; WARREL, L.A.; EDWARDS, D.G.; BELL, L.C. Effects of aluminum and calcium in the solution of soil acids on root elongation of Glycine max cv. Forest. Australian Journal of Soil Research, v. 38, p. 319-338, 1988. 
CAIRES, E.F.; BANZATO, D.A.; FONSECA, A.F. Calagem na superfície em sistema de plantio direto. Revista Brasileira de Ciência do Solo, v. 24, p. 161-169, 2000.

CAIRES, E.F.; CHUERI, W.A.; MADRUGA. E.F.; FIGUEIREDO, A. Alterações de características químicas do solo e resposta da soja ao calcário e gesso aplicados na superfície em sistema de cultivo sem preparo do solo. Revista Brasileira de Ciência do Solo, v. 22, p. 27-34, 1998.

CAIRES, E.F.; FONSECA, A.F.; MENDES, J.; CHUEIRI, W.A.; MADRUGA, E.F. Produção de milho, trigo e soja em função das alterações das características químicas do solo pela aplicação de calcário e gesso na superfície, em sistema de plantio direto. Revista Brasileira de Ciência do Solo, v. 23, p. 315-327, 1999.

CAIRES, E.F.; KUSMAN, M.T.; BARTH, G.; GARBUIO, F.J. PADILHA, J.M. Alterações químicas do solo e resposta do milho à calagem e aplicação de gesso. Revista Brasileira de Ciência do Solo, v. 28, p. 125-136, 2004.

CAMARGO, O.A. Micronutrientes no solo. In: FERREIRA, N.E.; CRUZ, M.C. P. da. Micronutrientes na agricultura. Piracicaba: Potafos, 1991. cap. 5, p. 113-266.

CAMBRI, M.A. Calagem e formas de alumínio em três localidades sob sistema de plantio direto. Piracicaba, 2004. 83p. Tese (Doutorado) - Escola Superior de Agricultura “Luiz de Queiroz”, Universidade de São Paulo.

CAMBRI, M.A.; ALLEONI, L.R.F. Complexação do alumínio pela matéria orgânica em solos sob sistema de plantio direto (compact disc). In: CONGRESSO BRASILEIRO DE CIÊNCIA DO SOLO, 29., Ribeirão Preto, 2003. Solo: alicerce dos sistemas de produção: resumos. Ribeirão Preto: UNESP, 2003. 
CAMERON, R.S.; RITCHIE, G.S.P.; ROBSON, A.D. Relative toxicities of inorganic aluminum complexes to barley. Soil Science Society of America Journal, v. 50, p. 1231-1236, 1986.

CANCÈS, B.; PONTHIEU, M.; CASTREC-ROUEllE, M.; AUBRY, E.; BENEDETTI, M.F. Metal íons speciations in a soil and its solution: experimental data and model resulsts. Geoderma, v.113, p. 641-355, 2003.

CHANTIGNY, M.H. Dissolved and water-extractable organic matter in soils: a review on the influence of land use management practices. Geoderma, v. 113, p. 357-380, 2003.

CHAVES, J.C.D.; PAVAN, M.A.; MIYAZAWA, M. Especiação química da solução do solo para interpretação da absorção de cálcio e alumínio por raízes de cafeeiro. Pesquisa Agropecuária Brasileira, v.26, p. 447-453, 1991.

CIOTTA, M.N.; BAYER, C.; ERNANI, P.R.; FONTOURA, S.M.V.; WOBETO, C. ALBUQUERQUE, J.A. Manejo da calagem e os componentes da acidez de Latossolo Bruno em plantio direto. Revista Brasileira de Ciência do Solo, v.28, p. 317-326, 2004.

CURTIN, D.; SMILLIE, G.W. Soil solution composition as affected by limming and incubation. Soil Science Society of America Journal, v. 47, p. 701-707, 1983.

DAHLGREN, R.A. Comparision of soil solution extraction producers: effect on solute chemistry. Communications in Soil Science and Plant Analysis, v. 24, p. 17831794, 1993. 
DAL BÓ, M.A.; RIBEIRO, A.C.; COSTA, L.M.; THIÉBAUT, J.T.L.; NOVAIS, R.F. Efeito da aplicação de diferentes fontes de cálcio em colunas de solo cultivadas com cana de açúcar. I Movimentação de bases no solo. Revista Brasileira de Ciência do Solo, v.10, p. 195-198, 1986.

DIARLOF, E. HARPER, S.M.; ASHER, C.; SMITH, F.W. Effects of humic and fúlvico acids on the rhizotoxicity og lamthanum and aluminum to corn. Australian Journal of Soil Research, v. 36, p. 913-919, 1998.

DYNIA, J.F.; CAMARGO, O.A. Adsorção e movimento de sulfato em latossolo de cerrado submetido a calagem e adubação fosfatada. Revista Brasileira de Ciência do Solo, v.19, p. 249-253, 1995.

EDMEADES, D.C.; WHEELER, D.M.; CLINTON, O.E. The chemical composition and ionic strength of soil solution from New Zealand topsoils. Australian Journal of Soil Research, v. 23, p. 151-165, 1985.

ELTZ, F.L.F.; PEIXOTO, R.T.G.; JASTER, F. Efeito de sistemas de preparo do solo nas propriedades físicas e químicas de um Latossolo Bruno álico. Revista Brasileira de Ciência do solo, v.13, p. 259-267, 1989.

EMPRESA BRASILEIRA DE PESQUISA AGROPECUÁRIA. Centro Nacional de Pesquisa de Solos. Manual de análises químicas de solos, plantas e fertilizantes. 2 ed. Rio de Janeiro, 1997. 212p.

ERNANI, P.R.; BARBER, S.A. Composição da solução do solo e lixiviação de cátions afetadas pela aplicação de cloreto e sulfato de cálcio em um solo ácido. Revista Brasileira de Ciência do Solo, v. 17, p. 41-46, 1993. 
ERNANI, P.R.; RIBEIRO, M.S.; BAYER, C. Modificações químicas em solos ácidos ocasionados pelos método de aplicação de corretivo da acidez e d gesso agrícola. Scientia Agricola, v.58, p. 825-831, 2001.

FIGUEIREDO. O.A.R.; ALMEIDA, J.A. Q uantificação das formas trocáveis e não trocáveis de alumínio em solos ácidos do estado de Santa Catarina. Revista Brasileira de Ciência do Solo, v. 15, p. 151-156, 1991.

FRANCHINI, J.C.; MIYAZAWA, M.; PAVAN, M.A.; MALAVOLTA, E. Dinâmica de íons em solos ácidos lixiviado com extratos de resíduos de adubos verdes e soluções puras de ácidos orgânicos. Pesquisa Agropecuária Brasileira, v. 34, p. 2267-2276, 1999.

FRANCHINI, J.C.; MEDA, A.R.; CASSIOLATO, M.E.; MIYAZAWA, M.; PAVAN, M.A. Potencial de extratos de resíduos vegetais na mobilização de calcário no solo por método biológico. Scientia Agricola, v. 58, p. 357-360, 2001.

GILLMAN. G.P.; BELL. L.C. Soil solution studies on weathered soils from tropical north queensland. Australian Journal of Soil Research, v. 16, p. 67-77, 1977.

GONZALEZ-ERICO, E.; KAMPRATH, E.J.; NADERMAN, G.C.; SOARES W.V. Effect of depth of lime incorporation on the growth of corn on an oxisol of central Brazil. Soil Science Society of America Journal. v. 43, p. 1155-1158, 1979.

GRIMM, D.M.; AZARRAGA, L.V.; CARREIRA, L.A.; SUSETYO, W. Continuous multiligand distribution model used to predict the stability constant of copper (II) metal complexation with humic material from fluorescence quenching data. Environmental Science \& Technology, v. 25, p. 1427-1431, 1991. 
GUGGERBERGER, G.; ZECH, W. Retention of dissolved organic carbonand sulfate in aggrecated acid forest soils. Journal of Enviroment Quality, v. 21, p. 643-653, 1992.

GUSTAFSSON, J.P. Visual MINTEQ. http://www.lwr.kth.se/English/OurSoftware/ Vminteq (26 out. 2004.).

HARGROVE, W.L.; THOMAS, G.W. Extraction of aluminum from aluminum-organic matter in relation to titratable acidity. Soil Science Society American Journal, v. 48 , p. $1458-1460,1984$.

HAVLIN, J.L.; BEATON, J.D.; TISDALE, S.L.; NELSON, W.L. Soil fertility and fertilizers: an introduction to nutrient management. New Jersey: Prentice Hall, 1999. cap. 5, p. 154-195: Phosphorus.

HEES, P.A.W. van; LUNDSTÖM, U.S. Equilibrium models of aluminum and iron complexation with different organic acids in soil. Geoderma, v. 94, p. 201-221, 2000.

HUE, N.V.; CRADDOCK, G.K.; ADAMS, F. Effect of organic acids on aluminum toxicity in subsoils. Soil Science Society of America Journal, v. 50, p. 28-34, 1986.

ISMAIL, I.; BLEVINS, R.L., FRYE, W.W. Long-term no tillage effects on soil properties and continuous corn yelds. Soil Science Society of America Journal, v. 58, p. 193-198, 1994.

JUO. A.S.R., JUO; KAMPRATH, E.J. Copper chloride as na extractant for estimating the potencially reactive aluminum pool in acid soils. Soil Science Society of America Journal, v. 43, p. 35-38, 1979. 
KAMINSK, J.; RHEINHEIMER. Acidez do solo e nutrição de plantas. In: KAMINSK,

J. Uso de corretivos da acidez do solo no plantio direto. Pelotas: SBCS - Núcleo Regional Sul, 2000, p. 21-40

KAMPRATH, E.J. Exchangeable Al as a criteria for liming leached mineral soils. Soil Science Society of America Proceedings, v. 34, p. 252-254, 1970.

LINDSAY, W.L. Chemical equilibria in soils. New York: Wiley, 1979. 450p.

LINDSAY, W.L.; WALTHALL, P.M. The solubility of aluminum in soils. In: SPOSITO, G. (Ed.). The environmental chemistry of aluminum. Boca Raton: Lewis, 1995. p. 333-361.

LOPES, A.S..; WIETHOLTER, S.; GUILHERME, L.R.G.; SILVA, C.A. Sistema plantio direto: bases para manejo da fertilidade do solo. São Paulo: ANDA, 2004. $110 \mathrm{p}$.

MENDONÇA, E.S.; ROWELL, D.L. Dinâmica do alumínio e de diferentes frações orgânicas de um latossolo argiloso sob cerrado e soja. Revista Brasileira de Ciência do Solo, v. 18, p. 295-303, 1994.

MIYAZAWA, M.; PAVAN, M.A. SANTOS, J.C.F. Effects of addition of crop residues on the leaching of $\mathrm{Ca}$ and $\mathrm{Mg}$ in Oxisols. In: INTERNATIONAL SYMPOSIUM ON PLANT-SOIL INTERACTIONS AT LOW pH, Belo Horizonte, 1996. Resumos. Belo Horizonte, SBCS;EMBRAPA-CPAC, 1996. p.8.

MOKOLOBATE, M.S.; HAYNES, R.J. Increases in pH and soluble salts influence the that additions of organic residues have on concentrations of exchangeable and soils solution aluminium. European Journal of Soil Science, v. 53, p. 481-489, 2002. 
MUZILLI, O. Influência do sistema de plantio direto, comparado ao convencional, sobre a fertilidade da camada arável do solo. Revista Brasileira de Ciência do Solo, v.7, p. $75-102,1983$.

MUZILLI, O. O plantio direto no Brasil. In: FANCELLI, L.A.; TORRADO, P.V.; MACHADO, J. Atualização em plantio direto. Campinas: Fundação Cargil, 1985. cap. 1, p. 3-16.

NEMETH, K.; MENGEL, K.; GRIMME, H. The concentration of K, Ca and Mg in the saturation extract in relation to exchangeable $\mathrm{K}, \mathrm{Ca}, \mathrm{Mg}$. Soil Science, v. 109, p. $179-185,1970$.

NOEMMIK, H. Fluorine in Swedsh agricultural products, soil and drinking water. Acta Polytechinica, v. 127, p. 1-121, 1953.

OATES, K.M.; KAMPRATH, E.J. Soil acidity and limming: II. Evaluation of using aluminium extracted by various chloride salts for determining lime requeriments. Soil Science Society of America Journal, v. 47, p. 690-692, 1983.

OLIVEIRA, E.L., de; PAVAN, M.A. Control of acidity in no tillage system soybean production. Soil \& Tillage Reseatch, v. 38, p. 47-57, 1996.

OLIVEIRA, E.L. de; PAVAN, M.A. Redução da acidez do solo pelo uso de calcário e gesso e resposta da soja cultivada em plantio direto. In: REUNIÃO BRASILEIRA DE FERTILIDADE DO SOLO E NUTRIÇÃO DE PLANTAS, 21, Petrolina, 1994. Anais. Petrolina: SBCS; EMBRAPA-CPSTSA, 1994. p. 178.

PAVAN, M.A.; BINGHAM, F.T.; PERYEA, F.J. Influence of calcium and magnesium salts on acid soil chemistry and calcium nutrition of apple. Soil Science of America Journal, v. 51 p. 1526-1530, 1987. 
PAVAN, M.A., BINGHAM, F.T., PRATT, P.F. Toxicity of Al to coffee in ultisols and oxisols amended with $\mathrm{CaCO}_{3}, \mathrm{MgCO}_{3}$, and $\mathrm{CaSO}_{4} \cdot 2 \mathrm{H}_{2} \mathrm{O}$. Soil Science of America Journal, v. 46 p. 1201-1207, 1982.

PIONKE, H.B.; COREY, R.B. Relations between acidic aluminum and soil pH, clay, and organic matter. Soil Science Society of America Proceedings, v. 34, p. 749$752,1967$.

POTTKER, D. Correção da acidez do solo em lavouras sob plantio direto e campo nativo. In: KAMINSK, J. Uso de corretivos da acidez do solo no plantio direto. Pelotas: SBCS - Núcleo Regional Sul, 2000. p. 77-94.

PREZOTTI, L.C.; DEFILIPO, B.V. Formas de potássio em solos do estado de Minas Gerais. Revista Brasileira de Ciência do Solo, v. 11, p. 109-114, 1987.

QIAN, P.; WOLT, J.D. Effects of drying and time of incubation on the composition of displaced soil solution. Soil Science, v. 149, p. 367-374, 1990.

QUAGGIO, J.A.; RAIJ, B. van; GALLO, P.B.; MASCARENHAS, H.A.A. Respostas da soja à aplicação de calcário e gesso e lixiviação de íons no perfil do solo. Pesquisa Agropecuária Brasileira, v. 28, p. 375-383, 1993.

RAIJ, B. van; ANDRADE, J.C.; CANTARELlA, H.; QUAGGIO, J.A. Análise química para avaliação da fertilidade de solos tropicais. Campinas: Instituto Agronômico Campinas, 2001. 284p.

RAIJ, B. van; CANTARELLA, H.; FURLANI, P.R. Efeito na reação do solo, da absorção de amônio e nitrato pelo sorgo, na presença e ausência de gesso. Revista Brasileira de Ciência do Solo, v.12, p. 131-136, 1988. 
REICHARDT, K.; LIBARDI, P.L.; MEIRELLES, N.M.F.; FERREYRA, F.F.; ZAGATTO, E.A.G.; MATSUI, E. Extração e análise de nitrato em solução de solo. Revista Brasileira de Ciência do Solo, v. 1, p. 130-132, 1977.

RITCHEY, K.D.; SOUZA, K.M.G.; LOBATO,E.; CORREA, O. Calcium leaching to increase rooting depth in a Brazilian Savannah Oxisol. Agronomy Journal, v. 72, p. 40-44, 1980.

SALET. R.L. Dinâmica de ions na solução de um solo submetido ao sistema de plantio direto. Porto Alegre, 1994. 110 p. Dissertação (Mestrado) - Faculdade de Agronomia, Universidade Federal do Rio Grande do Sul.

SALET, R.L. Toxidez de alumínio no sistema de plantio direto. Porto alegre, 1998. 109 p. Tese (Doutorado) - Faculdade de Agronomia, Universidade Federal do Rio Grande do Sul.

SANTOS, H.P. dos; TOMM, G.O. LHAMBY, J.C.B. Plantio direto versus convencional: efeito na fertilidade do solo e no rendimento de grãos de culturas em rotação com cevada. Revista Brasileira de Ciência do Solo, v. 19, p. 449-454, 1995.

SCHREFFLER, A.M.; SHARPE, W.E. Effects of lime, fertilizer, and herbicide on Forest and soil solution chemistry, hardwood regeneration, and hardwood growth following shelter wood harvest. Forest Ecology and Management, v. 177, p. 471484, 2003.

SHAIMBERG. I.; SUMNER, M.E.; MILLER. W.P.; FARINA, M.P.W.; PAVAN, M.A. Use of gypsum on soils: a review. Advances in Soil Science, v. 9, p. 1-101, 1989. 
SHAMSHUDDIN, J.; MUHRIZAL, I.; FAUZIAH, M.H.A.; HUSNI, M.H.A. Effects of additing organic materials to an acid sulfate soil on the growth of cocoa (Theobroma cacoa L.) seedlings. Science of the Total Enviroment, v. 323, p. 33-45, 2004.

SHIGEMITSU, A. Extraction of active aluminum from acid soils in Japan with different reagents. Geoderma, v. 14, p. 63-74, 1975.

SOON, Y.K. Fractionation of extractable aluminium in acid soil; A review and a proposed procedure. Communications in Soil Science and Plant Analysis, v. 24, p. 1683-1708, 1993.

SPOSITO, G. The thermodynamics of soil solutions. New York: Oxford University Press, 1981. 223 p.

SPOSITO, G. The chemistry of soils. New York: Oxford Univesity Press, 1989. 277 p.

SPOSITO, G. Chemical equilibrium and kinetics in soils. New York: Oxford Univesity Press, 1994. 288 p.

STARK, N.; JORDAN, C.F. Nutrient retention in the root mat of an Amazonian rain. Forest Ecology, v. 59, p.404-432, 1978.

URRUTIA, M.; MACÍAS, F.; GARCÍA-RODEJA, E. Evaluación del CuCl2 y del $\mathrm{LaCl} 3$ como extractantes de aluminio en suelos ácidos de Galicia. Nova Acta Científica Compostelana (Bioloxía), v. 5, p. 173-182, 1995.

VENCE, G.F.; STEVENSON, F.J. SIKORA, F.J. Enviromental chemistry of aluminumorganic complexes. In: SPOSITO, F.J.; SIKORA, F.J. The enviromental chemistry of aluminum. Boca Raton: Lewis, 1995. p. 169-220. 
WADT, P.G.S.; WADT, L.H.O. Movimentação de cátions em amostras de um Latossolo Vermelho Amarelo incubadas com duas fontes de cálcio. Scientia Agricola, v.56, p. 1157-1164, 1999.

WOLT, J.D. Obtaining soil solution: laboratory methods. In: WOLT, J.D. Soil solution chemistry: applications to environmental science and agriculture. New York: John Wiley, 1994. p. 95-120.

ZIGLIO, C.M.; MIYAZAWA, M.; PAVAN. M.A. Formas orgânicas e inorgânicas de mobilização do cálcio no solo. Brazilian Archives of Biology and Technology, v. 42, p. 257-262, 1999. 